Citation: Ho, A. K., Sidanius, J., Kteily, N., Sheehy-Skeffington, J, Pratto, F., Henkel, K. E., Foels, R., \& Stewart, A. L. (in press). The nature of social dominance orientation: Theorizing and measuring preferences for intergroup inequality using the new $\mathrm{SDO}_{7}$ scale. Journal of Personality and Social Psychology.

Please note: This version of the manuscript has not undergone copy-editing (i.e., it has not yet been published). This article may not exactly replicate the final version published in the APA journal. It is not the copy of record.

The Nature of Social Dominance Orientation:

Theorizing and Measuring Preferences for Intergroup Inequality Using the New $\mathrm{SDO}_{7} \mathrm{Scale}$

$\begin{array}{cc}\text { Arnold K. Ho* } & \text { Jim Sidanius* }^{*} \\ \text { University of Michigan } & \text { Harvard University } \\ \text { Nour Kteily } & \\ \begin{array}{c}\text { Kellogg School of Management } \\ \text { Northwestern University }\end{array} & \text { Jennifer Sheehy-Skeffington } \\ & \text { Brunel University } \\ \text { Felicia Pratto } & \\ \text { University of Connecticut } & \text { Kristin E. Henkel } \\ \text { Rob Foels } & \text { University of Saint Joseph } \\ \text { Richard Stockton College } & \text { Andrew L. Stewart } \\ \end{array}$

Arnold K. Ho, Department of Psychology and Interdisciplinary Program in Organizational Studies, University of Michigan; Jim Sidanius, Department of Psychology and Department of African and African American Studies, Harvard University; Nour Kteily, Department of Management and Organizations, Kellogg School of Management, Northwestern University; Jennifer Sheehy-Skeffington, Division of Psychology, Brunel University; Felicia Pratto, Department of Psychology, University of Connecticut; Kristin E. Henkel, Department of Psychology, University of Saint Joseph; Rob Foels, Department of Psychology, Richard Stockton College; Andrew L. Stewart, Department of Psychology, Clark University.

*The first two authors contributed to this manuscript equally as first authors, and the second two authors contributed to this manuscript equally as second authors.

We thank Suzanne Freedberg and Yuching Lin for research assistance.

Correspondence concerning this article should be addressed to Arnold K. Ho, Department of Psychology, University of Michigan, 530 Church Street, Ann Arbor, MI 48109. E-mail: arnoldho@umich.edu 


\begin{abstract}
A new conceptualization and measurement of social dominance orientation-individual differences in the preference for group based hierarchy and inequality—is introduced. In contrast to previous measures of social dominance orientation that were designed to be unidimensional, the new measure $\left(\mathrm{SDO}_{7}\right)$ embeds two theoretically-grounded subdimensions of SDO - SDO-Dominance (SDO-D) and SDO-Egalitarianism (SDO-E). SDO-D constitutes a preference for systems of group-based dominance in which high status groups forcefully oppress lower status groups. SDO-E constitutes a preference for systems of group-based inequality that are maintained by an interrelated network of subtle hierarchy-enhancing ideologies and social policies. Confirmatory factor and criterion validity analyses confirmed that SDO-D and SDO-E are theoretically distinct and dissociate in terms of the intergroup outcomes they best predict. For the first time, distinct personality and individual difference bases of SDO-D and SDO-E are outlined. We clarify the construct validity of SDO by strictly assessing a preference for dominance hierarchies in general, removing a possible confound relating to support for hierarchy benefitting the ingroup. Consistent with this, results show that among members of a disadvantaged ethnic minority group (African Americans), endorsement of $\mathrm{SDO}_{7}$ is inversely related to ingroup identity. We further demonstrate these effects using nationally representative samples of U.S. Blacks and Whites, documenting the generalizability of these findings. Finally, we introduce and validate a brief four-item measure of each dimension. This paper importantly extends our theoretical understanding of one of the most generative constructs in social psychology, and introduces powerful new tools for its measurement.
\end{abstract}

Keywords: social dominance orientation, $\mathrm{SDO}_{7}$ scale, SDO-Dominance, SDOEgalitarianism, group-based hierarchy, inequality, prejudice 


\section{The Nature of Social Dominance Orientation: Theorizing and Measuring Preferences for Intergroup Inequality Using the $\mathrm{New}^{\mathrm{SDO}}{ }_{7}$ Scale}

Group-based inequality and conflict is as varied as it is ubiquitous. Inequality in power and resources between groups is a feature of all societies with an economic surplus (Sidanius \& Pratto, 1999). Furthermore, inequality takes on many forms, as evident in simultaneous controversies over the use of drones in warfare, responses to immigration, sectarian violence in the Middle East, and the merits of affirmative action, to list only a few issues currently prominent in American domestic and international affairs. What accounts for the complex and pervasive nature of intergroup conflict? As part of a multilevel theory of intergroup relations, social dominance theory posits that individuals' attitudes about inequality between social groups in general, or their social dominance orientation, interacts with societal and institutional forces to produce and reproduce systems of social inequality (Pratto, Sidanius, Stallworth, \& Malle, 1994). Individual levels of social dominance orientation have been found to predict such an array of intergroup attitudes and behaviorsover time and across cultures - that the construct occupies a role solidly at the heart of social and political psychology (Lee, Pratto, \& Johnson, 2011).

Recently, we found that this over-arching orientation breaks down into two specific subdimensions — support for intergroup dominance, and intergroup anti-egalitarianism— enabling us to predict intergroup attitudes and behaviors with even more precision (Ho et al., 2012). The dominance dimension is characterized by support for overt oppression and aggressive intergroup behaviors designed to maintain the subordination of one or more groups, whereas the anti-egalitarianism dimension entails a preference for intergroup inequalities that are maintained by an interrelated network of subtle hierarchy-enhancing ideologies and social policies. Notwithstanding the advances made in uncovering the subdimensions of SDO, they remain heavily understudied. For one, little is known about the 
different personality bases that undergird each of the subdimensions. Moreover, the nature of previous SDO scales has meant that the conceptual differences between the subdimensions have been confounded with the way in which they were measured, reducing confidence that these dimensions reflect substantive and not methodological differences. In the current paper, we unlock the predictive potential of this new bi-dimensional structure by presenting an empirically validated and reliable scale, with both short and long forms, designed to tap into each dimension separately. This enables us to investigate the unique personality antecedents and downstream attitudinal consequences of each subdimension, while maintaining the overall predictive power of SDO. Furthermore, and critically, the new measure introduced here addresses a longstanding concern over whether SDO constitutes support for ingroup dominance or whether it assesses support for intergroup hierarchy and inequality irrespective of which group is on top (Jost \& Thompson, 2000; Kteily, Ho, \& Sidanius, 2012; Pratto, Sidanius, \& Levin, 2006). In sum, our work improves on previous SDO research by broadening our theoretical understanding of (and confidence in) its distinct components and personality bases, addressing alternative interpretations of its effects, and providing superior tools with which to assess it.

\section{Social Dominance Orientation}

Social dominance orientation (SDO), as a measure of support for inequality between social groups, has been shown to play a central role in a range of intergroup attitudes, behaviors, and policy preferences (for a review, see Sidanius, Cotterill, Sheehy-Skeffington, Kteily, \& Carvacho, 2015). It is a potent predictor of generalized prejudice against, and persecution of, a wide array of denigrated groups, such as poor people, ethnic minorities, foreigners, gay people, women, immigrants, and refugees (e.g., Altemeyer, 1996; Asbrock, Sibley, \& Duckitt, 2010; Costello \& Hodson, 2011; Kteily, Bruneau, Waytz, \& Cotterill, in press; Sidanius \& Pratto, 1999; Thomsen, Green \& Sidanius, 2008). In addition, SDO is 
related to the endorsement of a range of group-relevant social ideologies, including political conservatism, noblesse oblige, just world beliefs, nationalism, patriotism, militarism, internal attributions for poverty, sexism, rape myths, endorsement of karma, the Protestant Work Ethic, and other consequential hierarchy-enhancing legitimizing beliefs, across a variety of cultures (e.g., Cotterill, Sidanius, Badwardj \& Kumar, 2014; Hodson, Rush, \& MacInnis, 2010; Pratto et al., 1994; Sidanius \& Pratto, 1999). SDO also predicts support for grouprelevant social policies that uphold the hierarchical status quo, such as support for wars of aggression, punitive criminal justice policies, the death penalty and torture, and opposition to humanitarian practices, social welfare, and affirmative action (e.g., Federico \& Sidanius, 2002; Gutierrez \& Unzueta, 2013; Pratto \& Glasford, 2008; Kteily, Cotterill, Sidanius, Sheehy-Skeffington, \& Bergh, 2014; Sidanius \& Pratto, 1999; Sidanius, Mitchell, Haley, \& Navarrete, 2006). Beyond influencing group-relevant attitudes, SDO can even yield accurate predictions about individuals' life choices - for instance, the kinds of jobs they seek and obtain (i.e., whether such jobs promote intergroup hierarchy or equality), the kinds of subjects they choose to study in college, and how well they perform in these areas (for a review, see Haley \& Sidanius, 2005).

As shown by studies in which SDO predicts intergroup attitudes in novel situations, SDO is a generalized orientation not reducible to an individual's socialized attitudes toward specific social groups. Thus, in addition to driving prejudice toward familiar and actual social groups, SDO predicts affective responses to minimal groups, novel social categories, and new social policies (e.g., Amiot \& Bourhis, 2005; Ho et al., 2012; Ho, Sidanius, Cuddy, \& Banaji, 2013; Krosch, Berntsen, Amodio, Jost, \& Van Bavel, 2013; Pratto et al., 1994; Reynolds, Turner, Haslam, Ryan, Bizumic, \& Subasic, 2007; Sidanius et al., 1994; see Kteily, Ho, \& Sidanius, 2012). Strengthening the case for its causal role, SDO has been shown to exhibit a cross-lagged impact on future personality facets, intergroup attitudes, and 
behavior across periods of time as great as four years (Kteily, Sidanius, \& Levin, 2011; Sidanius et al., 2013; Thomsen et al., 2010).

\section{Subdimensions of Social Dominance Orientation}

Although SDO has clearly been useful for understanding intergroup attitudes and behaviors when treated as a unidimensional construct, recent research has taken seriously the possibility that it is composed of different facets (Ho et al., 2012; Jost \& Thompson, 2000, Kugler, Cooper, \& Nosek, 2010). Ho et al. (2012) presented evidence that one subdimension of SDO — the dominance subdimension (SDO-D) — represents a preference for group-based dominance hierarchies in which dominant groups actively oppress subordinate groups. In this work, SDO-D better predicted support for aggressive behaviors directed toward subordinate groups (e.g., immigrant persecution), endorsement of beliefs that would justify oppression (e.g., "old-fashioned" racism), and a strong focus on group competition and threat. Thus, SDO-D constitutes support for the active, even violent, maintenance of oppressive hierarchies in which high status groups dominate and control the prerogatives of low status groups. The second major subdimension of SDO-SDO-Egalitarianism (SDOE) —was shown to represent opposition to equality between groups, as supported by an interrelated network of subtle hierarchy-enhancing beliefs and social policies. SDO-E better predicted political conservatism in the United States, support for ideologies that would subtly justify inequality (e.g., the Protestant Work Ethic), and opposition to policies that would bring about more intergroup equality (e.g., affirmative action); in short, it manifested itself in an affinity for ideologies and policies that maintain inequality, especially those that have ostensibly different purposes (such as economic efficiency and meritocracy). In contrast to SDO-D, the types of hierarchy-enhancing attitudes and policies predicted by SDO-E typically do not involve violent or overt confrontation; SDO-E is thus more subtle in nature and 
represents support for differential intergroup access to power and resources that need not involve outright domination and oppression.

This conclusion is consistent with previous findings with respect to what SDO-D and SDO-E best predict (Jost \& Thompson, 2000; Kugler et al., 2010). Recent work by Kteily et al. (in press) has further shown that SDO-D is more strongly correlated than SDO-E with blatant forms of dehumanization, involving the overt and conscious denial of outgroup humanity, whereas the two subdimensions are equally correlated with more subtle forms of dehumanization (e.g., infrahumanization; Leyens et al., 2000). Other work has found that SDO-D is related to a desire for muscularity among men (Swami, Neofytou, Jablonska, Thirlwell, Taylor, \& McCreary, 2013), torture (Larsson, Björklund, \& Bäckström, 2012), and hierarchy-enhancing beliefs about citizenship and assimilation (Hindriks, Verkuyten, \& Coenders, 2014), whereas SDO-E is related to negative affect toward migrants (Martinovic \& Verkuyten, 2013), hierarchy-attenuating beliefs about citizenship and multiculturalism (Hindriks et al, 2014), and the belief that less democratic forms of government are fair (Ellenbroek, Verkuyten, Thijs, \& Poppe, 2014). Thus, there is now ample evidence for the existence of two theoretically meaningful subdimensions of SDO that are related to predictably different types of intergroup phenomena.

Notably, the proposed distinction between SDO-D and SDO-E parallels theorizing in the intergroup relations literature that has differentiated forceful from subtle means of hierarchy maintenance (e.g., Jackman, 1994). That literature suggests that subtle approaches to hierarchy maintenance may be more effective at gaining the compliance of subordinate group members and thus may be generally preferred as a (less costly) means of maintaining inequality than physical coercion. The present work, in contrast, argues that whereas some individuals (those high on SDO-E) prioritize subtle means of hierarchy maintenance, other 
individuals (those high on SDO-D) may be specifically oriented toward the overt domination of some groups by others.

Confound between substantive theoretical dimensions and item wording. Before the full potential of this new distinction can be realized, however, a key limitation in the most widely used measure of SDO (the 16-item ' $\mathrm{SDO}_{6}$ scale': Pratto at al., 1994), on which the studies cited above are based, must be addressed. In the existing scale, the same items that are used to tap into the dominance dimension are also those worded in a pro-trait direction (such that high scores on these items index high SDO); conversely, all of the items used to tap into anti-egalitarianism are worded in the con-trait direction (with high scores indexing low SDO; these items are reverse-scored in computing composite SDO and SDO-E subdimension scores). If we are to take evidence for SDO's bi-dimensional structure seriously, this would represent a confounding of the scale's 'method' dimensions (i.e., pro-trait and con-trait item wordings) with its substantive dimensions (i.e., dominance and anti-egalitarianism).

Preference for ingroup dominance? The above issue compounds another shortcoming of the $\mathrm{SDO}_{6}$ scale, which has led to confusion over whether SDO taps into desire for dominance of one's own group, versus support for hierarchical intergroup organization in general (e.g., Jost \& Thompson, 2000, Sibley \& Liu, 2010, Kteily, Ho, \& Sidanius, 2012). Although early definitions of SDO did in fact refer to a preference for ingroup dominance (e.g., Pratto et al., 1994), social dominance theorists later clarified SDO's definition as a general orientation toward hierarchy as opposed to a preference for ingroupdominance, and provided empirical support for this conceptualization (see Kteily et al., 2012; Pratto et al., 2006; Sidanius, Levin, Federico \& Pratto, 2001). In contrast to this more recent conceptualization, Jost and Thompson (2000) presented SDO-D as "group justification"i.e., constituting support for one's in-group irrespective of one's group position. These authors found empirical support for this distinction in evidence that ingroup identification 
was positively correlated with SDO-D across several large samples of African Americans, a group with low political and socio-economic status in the U.S. In aiming to improve the construct validity of SDO, the current work addresses this theoretical debate by reexamining its relationship, when measured with our new scale, with ingroup identification among members of the same low status group in the United States.

Personality bases of the SDO subdimensions. Finally, we advance theorizing on SDO's bidimensional structure by presenting the first evidence of dissociable personality antecedents of each subdimension. This new direction in research on the SDO subdimensions has the potential to yield insights into individual differences that characterize those who desire oppressive dominance hierarchies, versus those that prefer more nuanced efforts toward the promotion and maintenance of group-based inequality, a distinction that has important intergroup consequences (see Jackman, 1994). Researchers have long been interested in personality antecedents of SDO (see Table 1), and thus, in addition to examining how the subdimensions are differentially associated with these antecedents, it is also important to establish that the new measure of SDO, as a whole, relates to personality and individual differences in a similar fashion as previous measures of SDO.

\section{The Present Research}

In embarking on this project, we had seven major goals, from which our hypotheses follow. Our first goal was to develop a new measure of social dominance orientation that taps into each subdimension in a balanced manner, with the same number of pro-trait items as con-trait items. As SDO was previously assumed to be unidimensional, previous versions of the SDO scale (e.g., 14-item $\mathrm{SDO}_{5}$ Scale; see Pratto et al., 1994) did not address this issue. Since both differences in substance and wording direction should influence how participants respond (Bishop, Oldendick, \& Tuchfarber, 1978), we expected to find support for a fourfactor model representing SDO-D, SDO-E, pro-trait items, and con-trait items, with each item 
loading on one substantive (SDO-D or SDO-E) and one method (pro-trait or con-trait) dimension (see Figure 1). In particular, we predicted this four-factor model would fit the data well in a confirmatory factor analysis, and exhibit better fit than a two-factor model that did not take into account substantive (dominance and anti-egalitarianism) dimensions, a twofactor model that did not take into account wording direction, and a one-factor model that ignored both wording direction and substantive dimensions (H1).

Our second goal was to test the predictive validity of our new measures of SDO-D and SDO-E. Consistent with previous examinations of the different substantive dimensions of SDO (Ho et al., 2012), we hypothesized that SDO-D would be a stronger predictor (than SDO-E) of intergroup attitudes and behaviors contributing to the overt domination and subjugation of low status groups, such as support for aggression against subordinate groups (e.g., immigrant persecution), support for beliefs legitimizing group dominance and oppression (e.g., old fashioned racism), and heightened attention to group competition (e.g., beliefs about the zero-sum nature of intergroup conflict; H2A). To complement and extend previous findings with respect to $\mathrm{H} 2 \mathrm{~A}$, we also predicted SDO-D would strongly relate to support for torture and military intervention in the Middle East (e.g., Iran and Syria). Compared to SDO-D, SDO-E was hypothesized to be more related to beliefs that would justify inequality without necessarily entailing the forceful domination of some groups over others: for example, political conservatism in the U.S., opposition to an equal distribution of resources, and opposition to government policies (e.g., social welfare) that promote greater equality (H2B). Again, we extended previous examinations of SDO-E's predictive validity by also adding attitudes toward wealth redistribution and societal (as opposed to governmental) obligations to ensure equality as key outcomes of theoretical interest.

Third, since the new measure for each subdimension is modeled on the dimensions discovered using the $\mathrm{SDO}_{6}$ scale, we aimed to test whether this new measure is strongly 
related to the $\mathrm{SDO}_{6}$ scale, and exhibits similar relationships with criterion variables when compared with the $\mathrm{SDO}_{6}$ measure's relationship with the same criteria (H3). Given the well documented predictive power of the $\mathrm{SDO}_{6}$ scale, we wanted to ensure that the $\mathrm{SDO}_{7}$ scale, taken as a whole, would be equally predictive of theoretically relevant outcome variables. Moreover, documenting that the $\mathrm{SDO}_{6}$ and $\mathrm{SDO}_{7}$ scales behave similarly in spite of the clarifications and improvements embedded into the new scale would mitigate any fears about the validity of conclusions from the large body of research findings using the older version. ${ }^{1}$

Fourth, we aimed to improve the construct validity of the SDO-D subdimension, by eliminating any items that could suggest the desire for ingroup dominance. We hypothesized that the $\mathrm{SDO}_{7}$ dominance subdimension—without the use of "ingroup" items—-should be more negatively related to ingroup identity among ethnic minority respondents than the $\mathrm{SDO}_{6}$ dominance subdimension (H4). If SDO-D indexes support for intergroup hierarchy in general (rather than simply reflecting support for ingroup dominance), then we should in fact find that ingroup identification is negatively correlated with SDO-D in low status groups such as ethnic minorities — as the organization of groups along a dominance hierarchy clearly disadvantages low status groups.

Fifth, we aimed to introduce a short measure for each subdimension, consisting of four items (two pro-trait and two con-trait) per dimension. All else being equal, longer scales tend to be have higher alpha reliabilities than shorter scales, and as such, the reliability of the short measure is expected to be somewhat lower (Ghiselli, Campbell, \& Zedeck, 1981). Nevertheless, we expected this new short measure to exhibit properties similar to the full measure as described in the hypotheses above (H5), and recognize that this shorter scale may be of use to researchers interested in assessing both dimensions of SDO but facing space constraints in their research. 
Our sixth goal was to test the relationship of our new scale, and its constituent subscales, with personality traits and individual differences. We conducted these tests in a large convenience sample as well as in a nationally representative sample of U.S. Blacks and Whites. Firstly, based on past research using previous versions of the SDO scale (see Table 1), we expected the $\mathrm{SDO}_{7}$ scale, as a whole, to be significantly correlated with a number of personality and individual differences (H6).

Secondly, we conducted the first exploration of whether SDO-D and SDO-E might have dissociable personality and individual difference antecedents, as a further way of testing whether their psychological substrates differ.

Based on SDO-D's hypothesized relationship with intergroup aggression, blatant dehumanization, and perceptions of intergroup competition, we hypothesized it would be more strongly related to (lower) HEXACO Honesty-Humility, "Dark Triad" traits (Machiavellianism, narcissism, and psychopathy), and the holding of a competitive jungle worldview than SDO-E (H7). These individual differences have previously been shown to relate to overt hostility and heightened attention to competition (Ashton, Lee, \& de Vries, 2014; Jones \& Paulhus, 2010; Sibley, Harding, Perry, Asbrock, \& Duckitt, 2010; see Table 1). Beyond this prediction, we did not have apriori hypotheses concerning the dissociation of the subdimensions in terms of personality and individual differences, but rather conducted these studies to inform subsequent research.

Our final goal was to examine how the new scale works among a nationally representative sample of U.S. Blacks and Whites. Previous work in political psychology (e.g., Federico \& Sidanius, 2002; Henry, 2011) has shown that correlations between sociopolitical constructs are stronger in educated (e.g., university) samples than in general population samples. As such, the inclusion of a nationally representative sample should provide some assurance that these findings generalize to the broader population. Finally, 
these data allow us to directly compare the levels of SDO among Blacks and Whites, to see if previous findings demonstrating differences in SDO among social groups as a function of group status - with higher status groups exhibiting higher levels of SDO because group-based hierarchy confers an advantage to them (Lee et al., 2011; Sidanius \& Pratto, 1999)—hold here.

We tested the above hypotheses in seven large American samples drawn from different sources. In addition to five White American samples, we also obtained data from two large samples of Black Americans, enabling us to test H4 concerning the relationship between ethnic identity and SDO-D. The African American samples also allow us to examine if the new measures exhibit similar properties within a minority group with lower social status than those groups usually tested (DeNavas-Walt, Proctor, \& Smith, 2011; Kahn, Ho, Sidanius, \& Pratto, 2009). With the exception of Sample 1, designed to select items for the new scale, and Sample 6, focusing on personality, all surveys were omnibus surveys of social and political attitudes including measures used for other research.

\section{Methods}

\section{Participants}

In all seven samples, we only analyzed data from participants native to the U.S. We analyzed responses only of White participants in Samples 1-3 and Sample 6 because we did not have enough ethnic minority respondents from any one group with which to conduct meaningful analyses. Sample 1 was drawn from Amazon MTurk and consisted of 528 White participants $\left(60.6 \%\right.$ female; $\left.M_{\text {age }}=34.4, S D=12.51\right) .11 .6 \%$ of participants had completed high school or less, $34.3 \%$ had completed some college, $28.6 \%$ had completed a bachelor's degree, and $25.6 \%$ had partially completed or completed a graduate or professional degree. Political affiliation for Samples $1-5 b$ is reported in Table 2B and in a supplemental appendix. 
Sample 2 was drawn from participants recruited through SocialSci (www.socialsci.com), an internet-based social science research platform, and included 483 White participants $\left(50.7 \%\right.$ female, $\left.M_{\text {age }}=26.8, S D=9.70\right) .{ }^{2} 15.7 \%$ had completed high school or less, $33.7 \%$ had completed some college, $28.6 \%$ had completed a bachelor's degree, and $21.3 \%$ had partially completed or completed a graduate or professional degree.

Sample 3 was drawn from Amazon MTurk, and consisted of 458 White participants $\left(57.9 \%\right.$ female; $\left.M_{\text {age }}=35.4, S D=11.86\right) .12 .1 \%$ had completed high school or less, $37.6 \%$ had completed some college, $27.5 \%$ had completed a bachelor's degree, and $22.1 \%$ had partially completed or completed a graduate or professional degree. Due to the length of the survey completed by this sample, it was split into two parts. There was some attrition between parts 1 and 2, and thus for some criterion variables, the sample size was 355 (see supplemental appendix).

Sample 4 consisted of 762 African American participants recruited through Qualtrics Panels, a survey service that enables the targeting of specific demographic groups. The sample was $40.8 \%$ female and the average age was $43.4(S D=14.28)$. Degree of education was unavailable for this sample.

Samples $5 \mathrm{a}$ and $5 \mathrm{~b}$ consisted of a stratified random sample of 214 White Americans $\left(50 \%\right.$ female, $\left.M_{\text {age }}=51.79, S D=16.47\right)$ and 210 African Americans $\left(54.3 \%\right.$ female, $M_{\text {age }}=$ $47.85, S D=16.09)$, respectively, and were drawn from a nationally representative panel operated by GFK Knowledge Panel (formerly Knowledge Networks). Among the White sample, $4.7 \%$ had completed less than high school, $26.6 \%$ had completed high school, $31.8 \%$ had completed some college, and 36.9\% had completed a bachelor's degree or higher. Among the Black sample, $14.3 \%$ had completed less than high school, 30.0\% had completed high school, $31.0 \%$ had completed some college, and $24.8 \%$ had completed a bachelor's degree or higher. 
Sample 6, recruited exclusively to examine SDO's relationship with personality traits, consisted of 452 White Americans (64.7\% female, $\left.M_{\text {age }}=37.82, S D=13.05\right)$ recruited through Amazon MTurk. 14.0\% had completed high school or less, 35.2\% had completed some college, $30.1 \%$ had completed a bachelor's degree, and $20.6 \%$ had partially completed or completed a graduate or professional degree.

\section{Measures}

Social dominance orientation. We included the 16 item $\mathrm{SDO}_{6}$ scale (Samples 1-4; Pratto et al., 1994) to test whether the new $\mathrm{SDO}_{7}$ scale matched the $\mathrm{SDO}_{6}$ scale in the direction and magnitude of its relationship with our criterion variables.

To create the $\mathrm{SDO}_{7}$ scale, we wrote 70 new items representing the dominance and anti-egalitarianism subdimensions, balancing each of these dimensions with pro-trait and con-trait items. We combined these items with items from the $\mathrm{SDO}_{6}$ scale and other new items assessing inclusiveness in group relations and the belief that group inequality is "natural." We subjected 99 potential SDO items to a principle axis factor analysis (tested on Sample 1$)^{3}$. The scree plot from this analysis revealed a four dimensional solution. A second principle axis factor analysis was conducted with restriction to four factors, and this yielded two substantive factors representing dominance and anti-egalitarianism. The eight highest loading items were selected from each of these two factors to create the new scale, taking into account wording direction (pro-trait and con-trait) and redundancy (see Appendix 1). As can be seen in Appendix 1, this scale has an equal number of pro-trait and con-trait items in the dominance and anti-egalitarianism subdimensions. One of the items that loaded highly on the dominance subdimension was from the $\mathrm{SDO}_{6}$ scale, and suggests the desire for ingroup dominance ("Sometimes other groups must be kept in their place" - italics added for emphasis), which is not consistent with the current conceptualization of SDO as a general orientation toward group inequality irrespective of one's ingroup position (Ho et al., 2012; 
Kteily et al., 2012; Pratto et al., 2006; Sidanius et al., 2001). Thus, in Samples 2-6 we replaced the first part of this item ("Sometimes other groups") with "Some groups of people" to form the item used in the final $\mathrm{SDO}_{7}$ scale ("Some groups of people must be kept in their place").

Intergroup attitudes hypothesized to be more strongly related to SDO-D. To measure variables predicted to be more related to SDO-D than to SDO-E, we included scales covering "old-fashioned racism", perceptions of zero-sum competition, and support for various forms of aggression. Table $2 \mathrm{a}$ lists all of the measures predicted to be more related to SDO-D, provides descriptive statistics and scale reliabilities (Cronbach's $\alpha$ ), and indicates the samples in which they appear. The supplemental appendix contains the items and information about the scales used. ${ }^{4}$

\section{Intergroup attitudes hypothesized to be more strongly related to SDO-E. To} measure variables expected to be more related to SDO-E than SDO-D, we assessed attitudes towards policies and legitimizing ideologies and practices that have the result of maintaining inequality, even if they have another ostensible agenda. Thus, our measures included political conservatism and system legitimacy beliefs in the U.S., as well as support for the unequal distribution of resources, opposition to social policies that would increase intergroup equality, and symbolic racism (see Table 2b and Supplemental Appendix; see Supplemental Tables 1-5 for bivariate correlations between all criterion variables and SDO).

Ethnic identity. This was assessed using four items in Samples 4 and $5 b(\alpha=.86 ; 7$ point scale; $M=5.55, S D=1.32$ in Sample 4; $\alpha=.81, M=5.29, S D=1.36$ in Sample 5b; Sidanius, Levin, van Laar, \& Sears, 2008). The items were: 1) How strongly do you identify with other members of your ethnic group? 2) How important is your ethnicity to your identity? 3) How often do you think of yourself as a member of your ethnic group? 4) How close do you feel to other members of your ethnic group? 
Personality and individual differences. In Sample 6, we assessed a number of personality traits that have been previously shown to relate to the overall SDO construct, but have not yet been examined with respect to their differential associations with SDO-D and SDO-E (see Table 1 for references to previous studies examining the relationship between SDO and personality and individual differences, Table 9 for descriptive statistics and Supplemental Table 6 for bivariate correlations between all personality and individual difference variables and SDO). This included the Big 5 dimensions of personality (DeYoung, Quilty, \& Peterson, 2007), the HEXACO Personality Inventory (Lee \& Ashton, 2004), the "Dark Triad" (Machiavellianism, narcissism, and psychopathy; Paulhus \& Williams, 2002), empathic concern (Davis, 1983), need for closure (Webster \& Kruglanski, 1994), and traits and "worldviews" from Duckitt and Sibley's dual-process model (i.e., social conformity, tough-mindedness, dangerous world view, and competitive jungle world view; Duckitt, Wagner, du Plessis, \& Birum, 2002). Machiavellianism and empathic concern were also measured in Samples 5a and 5b. In Sample 6, for exploratory purposes, we also assessed participant concern with key areas of morality as discussed by the Moral Foundations framework (Harm/care, Fairness/reciprocity, Ingroup/loyalty, Authority/respect, and Purity/sanctity; Graham, Haidt, \& Nosek, 2009; See Table 9 and Supplemental Appendix). The Moral Foundations Questionnaire (MFQ, Graham et al., 2009) measures the extent to which one thinks that a transgression that occurs in a particular realm constitutes a moral violation (e.g., from the fairness dimension, "Whether or not some people were treated differently than others"; 0 = "not at all relevant (This consideration has nothing to do with my judgments of right and wrong)" to $5=$ "extremely relevant (This is one of the most important factors when I judge right and wrong)". The MFQ also assesses agreement with a set of moral values (e.g., from the authority dimension, "Respect for authority is something all children need to learn."; 0 = "Strongly disagree" to 5 = "Strongly agree"). Thus, scores on 
any one moral foundation are computed as an average of one's agreement with the moral values in that domain, and a high rating of the moral relevance of transgressions falling within it (Graham et al., 2009).

\section{Results}

\section{Factor Structure of $\mathrm{SDO}_{7}$}

Our first goal was to establish that a four-factor model, taking into account both substantive differences between the SDO-D and SDO-E dimensions as well as differences in wording direction (i.e., pro-trait or con-trait; see Figure 1) would fit the data well, and indeed better than a one-factor model, or two factor models that account for substantive dimensions or wording direction alone. As revealed in Table 3, and consistent with H1, in each of the seven samples, we found that a four-factor model fit the data well, and indeed better than any of the two- and one-factor models. For example, in Sample 1, the four-factor model yielded a good fit $\left(\chi^{2} / \mathrm{df}\right.$ ratio $\left.=2.43, \mathrm{RMSEA}=.06, \mathrm{CFI}=.97\right)$ and fit better than the two-factor wording-direction (method) model $\left(\chi^{2} / \mathrm{df}\right.$ ratio $\left.=5.32, \mathrm{RMSEA}=.10, \mathrm{CFI}=.90\right)$, the twofactor substantive $(\mathrm{D}, \mathrm{E})$ model $\left(\chi^{2} / \mathrm{df}\right.$ ratio $\left.=4.08, \mathrm{RMSEA}=.08, \mathrm{CFI}=.98\right)$, and the singlefactor model $\left(\chi^{2} / \mathrm{df}\right.$ ratio $=6.46, \mathrm{RMSEA}=.11, \mathrm{CFI}=.97$; see Table 3 for fit statistics for all seven samples). Furthermore, in all seven samples, a chi-square difference test between the four-factor model and each of the other three models revealed that the four-factor model was a significantly better fit in every comparison (see Table 3).

\section{Predictive Validity of SDO-D and SDO-E}

Having established that the factor structure of our new measure consists of SDO-D and SDO-E subdimensions as well as pro- and con-trait (semantic) categories, we proceeded to test the predictive validity of the SDO-D and SDO-E subdimensions. To do so, we regressed a number of criterion variables on SDO-D and SDO-E in a series of simultaneous regression analyses, and then compared the magnitude of the semi-partial (part) correlations 
between SDO-D and a given criterion variable and SDO-E and the same criterion variable. ${ }^{5}$ This allowed us to test whether the relationship between SDO-D and a given criterion variable is stronger than the relationship between SDO-E and the same criterion variable, after the overlap between SDO-D and SDO-E has been taken into account. We performed this analysis using Malgady's test for comparing two dependent semi-partial correlations (Hittner, Finger, Mancuso, \& Silver, 1995; Ho et al., 2012). For Sample 5a and 5b, we used SPSS Complex Samples, which allowed us to use statistical weights to adjust for the sample design (i.e., unequal probability of selection due to stratified sampling) and survey nonresponse. ${ }^{6}$ Taylor series linearization, implemented in SPSS Complex Samples, was used to calculate variance estimates. Given the large number of analyses, we refer readers to Tables 4 and 5 for semi-partial correlation and difference statistics, and summarize the results in the text.

SDO-D Criterion Variables. We hypothesized (H2A) that SDO-D would be a better predictor of old fashioned racism, perceptions of zero-sum competition, and support for aggression against subordinate groups, than SDO-E. Indeed, we found that across the six samples in which this was analyzed, SDO-D was a stronger predictor of variables corresponding to these criteria in 28 cases, predicted equally strongly with SDO-E in 11 cases, and was a weaker predictor in just one case. ${ }^{7}$ To more directly assess the relative strength of SDO-D and -E in predicting these criteria across all 40 criterion variables, we ran a mixed-effects model that tested whether the average contrast in the standardized coefficients for SDO-D and - E- taken from the regression analyses across all criterion variables in all studies - was significantly different from zero in the predicted direction (for example, for old fashioned racism, the $\beta$ for SDO-D was .57 and $\beta$ for SDO-E was -.06. Thus, the contrast was .63.). The standard error for each contrast was estimated from the data (i.e., assumed to be known; e.g., $S E=.11$ for old-fashioned racism). This procedure took 
into account dependence between contrasts within study by estimating random effects between studies. ${ }^{8}$ The analysis for the 40 SDO-D criteria revealed that on average, SDO-D was a significantly stronger predictor of these criteria than SDO-E (Contrast estimate $=.24$, $S E=.07, t=3.60, p=.02)$.

Additionally, for 39 out of 40 SDO-D criterion variables, SDO-D was significantly related, after accounting for SDO-E. This finding held when we applied the BenjaminiHochberg method to control for the false discovery rate (i.e., to account for the possibility of Type 1 errors due to multiple comparisons in each study; Benjamini \& Hochberg, 1995; Benjamini \& Yekutieli, 2001). Taken together, these results were strongly supportive of the theoretical expectations presented in $\mathrm{H} 2 \mathrm{~A}$.

For example, for old-fashioned racism, SDO-D was a significant predictor in all six samples in which it was measured and a significantly stronger predictor than SDO-E in four out of six samples (see Table 4). For perceptions of zero-sum competition, SDO-D was a significant predictor in all samples, and was a significantly or marginally stronger predictor than SDO-E in five samples. With respect to support for immigrant persecution, SDO-D was a significant predictor in all four samples, and a stronger predictor than SDO-E in Samples 13. Interestingly, in Sample 4, SDO-D significantly predicted this criterion, but marginally more weakly than SDO-E. Overall, results for death penalty support, nationalism, punitiveness, militarism, support for war, belief in war's legitimacy, support for military action in Iran and intervention in Syria, torture, and attractiveness of hierarchy-enhancing careers (particularly in law enforcement) revealed a pattern in line with our hypothesis (see Table 4).

SDO-E Criterion Variables. The data were also highly consistent with Hypothesis 2B. Compared to SDO-D, SDO-E was a better predictor of the ideologies and beliefs that are hierarchy-enhancing but ostensibly have other legitimate rationales. Specifically, it was a 
better predictor than SDO-D of system legitimacy beliefs, political conservatism in the U.S., as well as support for the unequal intergroup distribution of resources and opposition to hierarchy attenuating social policies (see Table 5). We found that SDO-E was a stronger predictor than SDO-D of relevant criteria in 24 cases, had the same predictive strength as SDO-D in 12 cases, and was a weaker predictor in just one case. Following the same procedure as above, we tested the overall strength of SDO-E relative to SDO-D in predicting SDO-E criteria, and found that across all 37 SDO-E criterion variables, SDO-E was a significantly stronger predictor than SDO-D (Contrast estimate $=.24, S E=.03, t=8.91, p<$ $.001)$. Furthermore, 33 out of 37 SDO-E criterion variables were significantly related to SDO-E, after controlling for SDO-D. As with SDO-D criterion variables, controlling for the false discovery rate using the Benjamini-Hochberg procedure referenced above did not change this result. These results were strongly consistent with Hypothesis 3.

For example, for political conservatism, which was assessed in Samples 1-5b, SDO-E was a significant predictor in five out of six cases and a significantly better predictor in each of those five cases. System legitimacy beliefs were predicted significantly by SDO-E in Samples 3-5a, and were predicted significantly or marginally significantly more strongly by SDO-E in two samples. Unexpectedly, system legitimacy was predicted by SDO-D but not by SDO-E in Sample 1.

With respect to equality in the distribution of resources between groups in a novel setting (an imaginary new campus of the University of Massachusetts), SDO-E was a significant predictor in all four samples in which it was measured and a significantly stronger predictor in three samples. Support for redistribution of wealth in society, opposition to affirmative action and other policies aimed at racial equality, opposition to social welfare, and an aversion to hierarchy-attenuating careers were similarly more strongly predicted by SDO-E than SDO-D (see Table 5). 


\section{Relationship between $\mathrm{SDO}_{7}$ and $\mathrm{SDO}_{6}$}

Since the new measure was intended to clarify and advance the $\mathrm{SDO}_{6}$ measure, we expected it to be highly correlated with $\mathrm{SDO}_{6}$, and to be correlated with criterion measures with about equal magnitude as for $\mathrm{SDO}_{6}(\mathrm{H} 3)$. Indeed, the SDO-D subdimension of the $\mathrm{SDO}_{7}$ scale shares one item with the $\mathrm{SDO}_{6}$ dominance subdimension (Item 2, Appendix 1), and the SDO-E subdimension of the two scales share two items (Items 10 and 12, Appendix 1). The last two columns in Tables 4 and 5 show that as expected, the correlations between $\mathrm{SDO}_{7}$ and each of the criterion variables were significant, and were almost identical in magnitude to the correlations between $\mathrm{SDO}_{6}$ and these criterion variables. The correlations between $\mathrm{SDO}_{6}$ and $\mathrm{SDO}_{7}$ were $.95, .92, .94$, and .88 , in Samples 1 to 4, respectively. Thus, taking the important step of un-confounding substantive and wording direction differences in order to reveal new theoretical avenues nevertheless maintains the SDO measure's wellestablished validity.

\section{SDO $_{7}$-D: Preference for Ingroup Dominance or Intergroup Hierarchy?}

Next we explored whether the new $\mathrm{SDO}_{7}-\mathrm{D}$ subscale, which lacks items implying a desire for ingroup dominance, would be negatively correlated with ethnic identity among minority group members, as predicted by social dominance theory. Moreover, we examined whether this would be true to a greater extent than the $\mathrm{SDO}_{6}-\mathrm{D}$ 's dominance subscale, which includes the potential ingroup dominance confound. We tested this with Samples 4 and 5b, which consisted only of African American respondents, and found the $\mathrm{SDO}_{7}$ dominance subscale had a correlation of -.21 $(p<.001)$ with ethnic identity in Sample 4. The $\mathrm{SDO}_{6}$ dominance subscale had a correlation of -.12 $(p<.01)$ with ethnic identity in the same sample. ${ }^{9}$ Using Williams' T2 statistic to test the difference between dependent correlations (Steiger, 1980), we found, consistent with H4, that the correlation between ethnic identity and the $\mathrm{SDO}_{7}$ dominance subscale was significantly more negative than the correlation with the 
$\mathrm{SDO}_{6}$ dominance subscale $(t=-3.35, p<.001)$. In Sample 5b, a nationally representative sample of African Americans, the correlation between SDO-D and ethnic identity was -.28 ( $p$ $<.001 ; \mathrm{SDO}_{6}$ was not measured in this case). These results show that the new $\mathrm{SDO}_{7}-\mathrm{D}$ scale is unlikely to be a measure of desire for dominance of one's own group, because the more one identifies with a low status group identity, the lower one is in SDO. Moreover, our analyses suggest that the new $\mathrm{SDO}_{7}-\mathrm{D}$ is even more reflective of group dominance in general (rather than ingroup dominance) than the $\mathrm{SDO}_{6}$ scale, an important advance in its construct validity.

\section{Short Scale}

Having established the factor structure and predictive validity of a new 16-item $\mathrm{SDO}_{7}$ measure assessing both dominance and anti-egalitarianism subdimensions, we moved on to test the factor structure and validity of a shorter version that could be used when space constraints do not allow for the use of the full scale. The eight items for the short scale, which

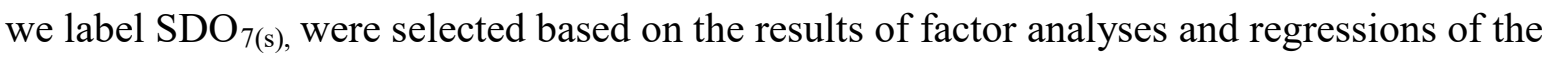
16 items in the $\mathrm{SDO}_{7}$ scale in a separate sample not included in the current paper (see footnote 2). Items were selected that possessed the combined properties of loading highly on their respective substantive dimensions, strongly predicting their respective criteria, and resulting in equal numbers of items representing the substantive and method dimensions (see Appendix 2). We tested the factor structure and predictive validity of the short scale following the same procedures used to test the full scale.

First, we tested whether a four-factor model that takes into account both substantive (dominance and anti-egalitarianism) and wording (pro-trait and con-trait) dimensions (see Figure 2) would fit better than a model that took into account substantive dimensions or wording direction alone or a one-factor model. The fit statistics for each model suggested that this was the case (see Table 6). For example, in Sample 1, the four-factor model 
demonstrated a good fit to the data $\left(\chi^{2} / \mathrm{df}\right.$ ratio $\left.=1.43, \mathrm{RMSEA}=.03, \mathrm{CFI}=1.00\right)$, whereas the models with two method factors $\left(\chi^{2} / \mathrm{df}\right.$ ratio $\left.=5.96, \mathrm{RMSEA}=.10, \mathrm{CFI}=.94\right)$, two substantive factors $\left(\chi^{2} / \mathrm{df}\right.$ ratio $\left.=3.60, \mathrm{RMSEA}=.07, \mathrm{CFI}=.97\right)$, and one-factor $\left(\chi^{2} / \mathrm{df}\right.$ ratio $=6.32, \mathrm{RMSEA}=.11, \mathrm{CFI}=.93)$ fit less well. Indeed, in all seven samples, a chi-square difference test between the four-factor model and each of the other three models revealed that the four-factor model was a significantly better fit in every comparison (see Table 6).

Turning to the predictive validity analyses, we found that for criterion variables that are theoretically aligned with the dominance dimension, SDO- $\mathrm{D}_{(\mathrm{s})}$ predicted more strongly than $\mathrm{SDO}_{\mathrm{E}} \mathrm{E}_{(\mathrm{s})}$ in 25 cases, predicted with equal strength as SDO-E $\mathrm{Es}_{(\mathrm{s})}$ in 14 cases, and predicted less strongly than $\mathrm{SDO}_{(\mathrm{s})}$ in just one case (see Table 7). We ran the same mixed effects model, which revealed that for the 40 SDO-D criteria, SDO-D was a significantly stronger predictor of these criteria than SDO-E (Contrast estimate $=.22, S E=.07, t=3.18, p$ $=.02$ ). Thus, these results of validity analyses with this shorter scale were strongly supportive of theoretical expectations.

For criterion variables theoretically related to SDO-E, SDO-E $\mathrm{E}_{(\mathrm{s})}$ was found to be a better predictor in 22 cases, predicted with equal strength in 14 cases, and was a weaker predictor in one case (see Table 8). On average, across all 37 criteria, SDO-E was a significantly stronger predictor of these criteria than SDO-D (Contrast estimate $=.17, S E=$ $.03, t=5.64, p<.001$ ). Correcting for multiple comparisons (false discoveries) following the Benjamini-Hochberg procedure described above did not change results for semi-partial correlations between the short SDO-D scale and its hypothesized criterion variables, or the short SDO-E scale, and its criterion variables.

Furthermore, just as with the full scale, the short scale was strongly correlated with $\mathrm{SDO}_{6}(r=.92, .90, .92$, and .87 in Samples $1-4$, respectively), and correlated with all of the criterion variables to a similar magnitude to that of the full scale, and of the $\mathrm{SDO}_{6}$ scale (see 
Tables 7 and 8). In sum, and consistent with theoretical expectations, the results with the short scale were highly consistent with what was found with the full scale (H5).

\section{Personality and Individual Differences}

Samples 1-5b represented theoretical advances to our understanding of SDO in that the data clearly revealed how the two dimensions dissociate in terms of the intergroup outcomes they relate to most strongly (with an improved measure), and how SDO-D represents support for group-based dominance in general, irrespective of whether one's ingroup is dominant. In Sample 6 we turned to an examination of the relationships between $\mathrm{SDO}_{7}$ personality and individual differences. These data enabled us to test whether our new $\mathrm{SDO}_{7}$ measure corresponds with various dimensions of personality as did previous SDO measures. Additionally, this allowed us to conduct the first test of the personality and trait bases of SDO-D and SDO-E separately. Due to the large number of findings, we focus here on the personality and individual differences to which we hypothesized SDO-D and -E would differentially relate, and summarize relatively strong semi-partial correlations between SDO-D or $-\mathrm{E}$, on the one hand, and personality and individual differences, on the other.

First, based on previous findings with older versions of the SDO scale (Table 1), we predicted that as a whole, $\mathrm{SDO}_{7}$ should be significantly related to a number of wellestablished personality constructs (H6). Consistent with previous findings using older versions of the $\mathrm{SDO}$ scale, the $\mathrm{SDO}_{7}$ scale was significantly correlated with all of these personality traits and individual differences (see Table 9).

Next, we found in line with H7, that SDO-D was more related to (lower) HEXACO honesty-humility, "Dark Triad" traits, and a "competitive jungle" worldview than was SDOE (see Sample 6, Table 9). For both samples of Whites (5a and 6), SDO-D was significantly or marginally more related to Machiavellianism than SDO-E. Unexpectedly, in the national sample of Blacks (5b), Machiavellianism was marginally more strongly related to SDO-E. 
Psychopathy was also shown to relate significantly more to SDO-D than SDO-E in Sample 6. These results are consistent with previous findings showing that $\mathrm{SDO}_{6}$ is related to the Dark Triad (Hodson et al., 2010), but importantly extend this prior work by showing that it is the SDO-D sub-dimension in particular that may be the primary driver of this relationship. Furthermore, consistent with the finding that SDO-D is strongly related to perceptions of zero-sum competition (see above), having a competitive jungle worldview was significantly more related to SDO-D than SDO-E.

Turning to our exploratory analyses, we observed that there were also several semipartial correlations that either replicated across samples, or were significant and had an absolute values greater than $r=.20$ (i.e., beyond a "small" effect of $r=.10$; Cohen, 1988). These semi-partial correlations, which reflect the relationship between one dimension of SDO and personality and individual differences, while controlling for the other dimension of SDO, allow us to examine the traits that are related to the unique aspect of each dimension of SDO (i.e., not including overlapping variance with the other dimension of SDO). First, we observed that SDO-D was negatively related to empathic concern in both Samples 5a and 6, after controlling for SDO-E. After controlling for SDO-D, the unique portion of SDO-E was significantly negatively related to empathic concern in Samples 5a, 5b, and 6. SDO-E was also significantly negatively related to the harm and fairness dimensions of the moral foundations framework (i.e., increasing levels of SDO-E is associated with less concern about harm and fairness).

\section{Social Dominance Orientation in the U.S. General Population}

Many studies in social and political psychology (including some samples in the current study) make use of convenience samples (e.g., student or crowd-sourcing samples), which differ demographically from general population samples (e.g., in terms of age, education, and socioeconomic-status; Henrich, Heine, \& Norenzayan, 2010). These 
convenience samples, particularly those with college students, may have less crystallized and possibly more liberal sociopolitical attitudes than those from other sociodemographic groups (Henry, 2008; Sears, 1986). Thus, in addition to establishing the consistency of our factor analytic and predictive validity findings in a national sample, and thereby giving us greater confidence in our overall findings, Samples 5a and 5b, representative samples of U.S. Whites and Blacks, provide a rare glimpse into levels of social dominance orientation in the general population (see Table 10a). Notably, the means for the overall scale and each dimension among White respondents (for both full and short versions) appear higher than in each of the other samples (see Table 10a and 10b; see Supplemental Table 7 for SDO skew statistics). Consistent with the other samples, higher status groups (men and Whites) had significantly higher levels of SDO than lower status groups (women and Blacks, respectively; Lee, Pratto, \& Johnson, 2011; Sidanius \& Pratto, 1999; Table 10a and 10b). Furthermore, the relatively larger difference between men and women (.43 point difference) as compared to the race difference (.24 point difference) is also consistent with previous research (Lee et al., 2011).

\section{Discussion}

Since the introduction of the construct two decades ago, social dominance orientation scales have been among the most widely used and generative measures in social and political psychology, providing insight into what drives the myriad forces that contribute to intergroup conflict and inequality. Naturally, questions and debates about the nature of SDO have surfaced during this time, with some researchers arguing that SDO should be conceptualized as having two dimensions (dominance and anti-egalitarianism; Jost \& Thompson, 2000; Ho et al., 2012; Kugler et al., 2010), some questioning the relevance of dominance in contemporary intergroup relations (e.g., Sears, Haley, \& Henry, 2008), and others questioning whether SDO concerns a general orientation toward group-based hierarchy, or merely a preference for one's own group being on top of the hierarchy (e.g., Jost \& 
Thompson, 2000; see Kteily et al., 2012). In the current research, we addressed each of these theoretical issues with the introduction of a new scale - the $\mathrm{SDO}_{7}$ scale-yielding our greatest potential yet to enhance social scientific knowledge on the diverse and persistent nature of intergroup conflict, discrimination and social stratification.

In seven large U.S. adult samples, we tested the factor structure of a new measure, $\mathrm{SDO}_{7}$, consisting of pro- and con-trait indices of SDO-D and SDO-E. In six of these samples, we tested the predictive validity of each dimension, and in a seventh sample, we examined $\mathrm{SDO}_{7}$ 's relationship with personality traits. Consistent with our hypotheses, we found that a four-factor model that takes into account both substantive differences (dominance and anti-egalitarianism) as well as wording differences (pro-trait and con-trait) between items fits the data well, and provides a better fit than two-factor models that only account for substantive differences or wording differences, or a one-factor model.

Furthermore, these balanced measures of SDO-D and SDO-E displayed predictive validity that was similar to what we found with SDO-D and SDO-E scales from the $\mathrm{SDO}_{6}$ measure (Ho et al., 2012). That is, across the six samples, SDO-D was a strong predictor of old-fashioned racism — a belief that legitimizes intergroup dominance-attention to group competition, and support for various forms of aggression and violence toward low status groups. SDO-E, on the other hand, was a stronger predictor of political conservatism and system legitimacy beliefs in the U.S., support for the unequal distribution of resources, opposition to policies that would bring about equality, and relatively subtle prejudice. Our findings thus provide a solid foundation for the emerging field of study on the theoretically important distinction between the SDO-D dimension, that reflects active and aggressive subordination of groups, and the SDO-E dimension, that reflects a more subtle opposition to equality (see also Ellenbroek et al., 2014; Hindriks et al., 2014; Jost \& Thompson, 2000; 
Kteily et al., in press; Kugler et al., 2010; Larsson et al., 2012; Martinovic \& Verkuyten, 2013; Swami et al., 2013).

Importantly, our new measure of SDO, taken as a whole, correlated highly with the $\mathrm{SDO}_{6}$ scale, and had similar correlations with criterion measures and with personality variables as the $\mathrm{SDO}_{6}$ scale. Thus, we can be assured that we have improved upon and theoretically solidified the $\mathrm{SDO}_{6}$ scale while preserving the properties that have made it such a powerful tool for understanding intergroup relations.

\section{Support for Intergroup Dominance Hierarchies or Ingroup Dominance?}

In addition to this substantive and methodologically rigorous contribution, this paper advances theory by allowing us to define the concept of SDO-D in a manner that better taps into SDO as it is currently understood - as an orientation toward group based dominance and inequality, irrespective of the position of one's ingroup in that hierarchy (Kteily et al., 2012; Pratto et al., 2006; Sidanius et al., 2001). Crucially, our finding that regard for or identification with one's ethnic group is inversely related with the new measure of SDO-D among a low-status ethnic group (African Americans in Samples 4 and 5b) demonstrates that we have been successful in developing a measure that reflects a general orientation toward group based inequality, rather than a desire for ingroup dominance or dominance relations of

a particular type (e.g., race-based inequality; see also Kteily et al., 2011, 2012). ${ }^{10}$ Notably, results with our new measure differ from those found by Jost and Thompson (2000) using the $\mathrm{SDO}_{6}$ scale's dominance subdimension, which revealed a positive relationship between ethnic identity and SDO-D among African American college students. ${ }^{11}$ Thus, the present work advances and solidifies, both theoretically and methodologically, what SDO represents.

\section{Personality and Individual Differences}

In addition to the factor structure and predictive power of the new SDO scale, we also began to examine how personality traits and individual differences relate both to the construct 
as a whole, and to SDO-D and -E uniquely. Firstly, $\mathrm{SDO}_{7}$ was found to be related to the personality traits previously associated with SDO. Importantly extending this prior work, we observed that "dark triad" traits such as Machiavellianism and psychopathy were more related to SDO-D than -E. This was also true for honesty/humility and a "competitive jungle" world view, which may explain SDO-D's robust relationship with perceptions of zero-sum competition. The honesty/humility dimension of HEXACO indexes whether one is willing to "get ahead" by dishonest means, which explains why it may resonate with those high on SDO-D, who pay no heed to the social costs of measures used to achieve or maintain groupbased dominance hierarchies; this is also consistent with the relationship between SDO-D and Machiavellianism.

The stronger relationship between social conformity and SDO-E (relative to $-\mathrm{D}$ ) is also consistent with SDO-E's relationship with system justification in societies where the hierarchy is supported more by subtle legitimizing ideologies rather than by the outright oppression of some groups by others. Thus, those high in SDO-E may conform to a norm of inequality, but not one of overt domination. We hasten to add, however, that SDO-E represents more than system justification, status quo bias, or norm conformity alone; this is demonstrated empirically by its relation to preferences for proactively establishing new (albeit subtle) forms of hierarchy (as in the imaginary university context we assessed), and by its relation to advocating decreased social welfare.

Interestingly, although the five dimensions of morality specified by Moral Foundations Theory were all related to $\mathrm{SDO}_{7}$, only the harm/care and fairness/reciprocity dimensions were more related (and negatively so) to one dimension of SDO than the other, with both more related to SDO-E. It is possible that these two moral domains undergird the inclusiveness and equitable treatment demanded by individuals low on SDO-E. By comparison, individuals low on SDO-D may oppose aggressive domination, but may not be 
as demanding of fairness and equality. Future work should continue examining personality and individual difference correlates of SDO-D and SDO-E, or reciprocal effects of these dimensions of SDO with other individual differences or personality factors (see Sidanius et al., 2013).

\section{Understanding the Facets of SDO}

Our research on the powerful and various intergroup effects of the SDO subdimensions, as well as our introductory examination into personality antecedents of these dimensions, begins to offer a clearer picture of what SDO-D and -E entail. People high on SDO-D versus SDO-E prefer different types of inequality and different processes to achieve and maintain inequality: Whereas individuals high on SDO-D prefer dominance hierarchies where high power groups oppress and subjugate low power groups, and are willing to achieve this form of inequality by use of very aggressive measures, individuals high on SDO-E prefer hierarchies where resources are inequitably distributed, and which can be defended by antiegalitarian ideologies. In this sense, SDO-D may appear to be more "severe" than SDO-E.

However, our data suggest that the bidimensional structure is not just a matter of more extreme versus less extreme endorsement of intergroup hierarchy along any dimension. Firstly, social theory has long pointed to the qualitative difference between hierarchyenhancing mechanisms that are aggressive and oppressive and mechanisms that are subtle and ideological (see, e.g., Althusser, 1984). Secondly, on the empirical level, in many cases (e.g., political conservatism and opposition to racial policies in several samples) SDO-D did not have much explanatory power once SDO-E was taken into consideration. Thus, SDO-D and SDO-E uniquely predict different types of intergroup beliefs.

It bears mentioning that although violent forms of conflict and oppression are attention-grabbing, inequality is often more cheaply, sustainably, and thus perhaps more perniciously maintained by more subtle means, involving complex and often consensual 
ideological resources (Jackman, 1994). Indeed, as the role of coercive force in maintaining inequality is arguably decreasing on a global scale (Pinker, 2011), subtle justifications of inequality may rise to take its place, thereby increasing the role to be played by SDO-E in the future, and making the role of hierarchical motivations in society harder to track. However, it warrants noting that evidence presented here and in related work (e.g., Kteily et al., in press) shows that the type of intergroup conflict associated with SDO-D certainly remains a prevalent and consequential feature of contemporary intergroup relations, and thus warrants continued attention.

One interesting direction for future research would be to examine whether individuals high in SDO-E may be more politically sophisticated than those high in SDO-D, and perhaps also more likely to support sophisticated hierarchy-maintenance strategies (e.g., making small concessions to gain the compliance of members of lower status groups; e.g., Chow, Lowery, \& Hogan, 2013). Another interesting possibility is that at least some individuals high on SDO-D also favor relatively subtle methods for hierarchy maintenance, but have different ultimate goals in mind - whereas those relatively high on SDO-E might use sophisticated methods to support the unequal distribution of resources, those high on SDO-D might use sophisticated methods (censorship, propaganda, and the manipulation of information) to maintain dominance hierarchies (e.g., see Guriev \& Triesman, 2015), involving not only inequality but the active oppression of some groups by others. SDO-D's relationship with (relatively low) honesty and Machiavellianism would support this latter possibility.

\section{Using the $\mathrm{SDO}_{7}$ Scale.}

Given the improvements in the measurement of SDO demanded by recent discoveries, and the critical finding that the new measure is related to all of our criterion variables in the same way as the older $\mathrm{SDO}_{6}$ measure is, we recommend that this new $\mathrm{SDO}_{7}$ scale measure be used in place of $\mathrm{SDO}_{6}$. To capture the construct as a whole, and in instances where 
researchers do not have a specific focus on intergroup phenomena that relate more to one dimension of SDO versus the other, it would be desirable to use the whole $\mathrm{SDO}_{7}$ scale.

Additionally, in cases where the intent of a group relevant ideology or policy is ambiguous or otherwise contested (i.e., it is unclear whether it subserves dominance per se, opposition to equality per se, or neither) using the entire scale and then examining the relationship between the ideology or policy on the one hand, and each subdimension of SDO, on the other, may help provide clarity about the underlying motivations. For example, the imprisonment of young Black men in the U.S. has drawn increasing scrutiny in recent years, interpreted by some as the result of fair legal process (e.g., Ferguson, 2015), and by others as comparable to oppressive Jim Crow laws from the first half of the $20^{\text {th }}$ century (e.g., Alexander, 2010). To clarify the intent of support for current incarceration policies, one could examine the relationships of such policy support with each dimension of SDO. If the claim that current rates of incarceration represent efforts at dominance per se is accurate, then not only should support for incarceration policies (e.g., California's "Three Strikes Law") be related to SDO in general, it should be related to SDO-D in particular. Thus, using the whole $\mathrm{SDO}_{7}$ scale, while remaining mindful of its bidimensional structure, can help researchers interpret the precise form of inequality a particular policy or ideology is intended to subserve.

On the other hand, our demonstration of differential predictive validity allows researchers to study solely that aspect of SDO (dominance or anti-egalitarianism) which most closely corresponds to intergroup phenomena in which they are interested. For example, researchers focused on conflicts marked by a high degree of oppression or extreme attitudes can now focus on the SDO-D measure, whereas researchers focused on social policies related to resource redistribution or relatively subtle legitimizing ideologies may focus on SDO-E. Thus, the new scale allows researchers to be more precise in their research involving specific dynamics of intergroup hierarchy (and thereby increase efficiency in situations where 
participant time is costly). One caveat, however, is that if one is interested in examining the unique part of SDO-D or -E that is related to intergroup outcomes, then one would still need to measure both dimensions and include each as a covariate for the other.

In addition, by demonstrating that a shorter form of the new measure- the $\mathrm{SDO}_{7(\mathrm{~s})}$ scale - has similar properties to the full form, we provide researchers with a measure of both dimensions to use in cases where space constraints are a pressing issue. This, too, represents an important contribution of the present research.

\section{Social and Contextual Moderators}

SDO among African Americans. Interestingly, in Samples 5a and 5b, nationally representative samples of White and Black Americans, respectively, we observed that whereas Whites exhibited higher levels of SDO-E than Blacks, the two groups did not differ on SDO-D. One possible explanation is that whereas the American racial hierarchy was previously maintained in overtly oppressive ways (ranging from slavery to Jim Crow laws), it now manifests in terms of vastly different socioeconomic opportunities for Blacks and Whites (Oliver \& Shapiro, 2006). As such, any racial differences in SDO and attitudes towards hierarchy in the U.S. at this point in time might be more reflective of concern for maintaining inequality - SDO-E — than concern for maintaining dominance. This possibility warrants further investigation in future research.

Future research would also do well to identify moderators of the relationship between SDO-D and -E on the one hand, and intergroup beliefs and behaviors, on the other, among African Americans and other ethnic minority groups. Although our data with Black participants was consistent with theoretical expectations for the most part, the dissociation between SDO-D and SDO-E in terms of their relationship with criterion variables was somewhat less consistent among Blacks, suggesting that there may be moderators of the way dominance and anti-egalitarianism relate to intergroup phenomena. This may be attributable 
to the way different groups' particular life experiences influence how they construe various intergroup ideologies and behaviors, and how these then relate to SDO. For example, given Blacks' historical (and contemporary) experiences in the U.S., they may be more likely to construe political liberalism as a form of active opposition to dominance and oppression. If this were the case, it would follow that political liberalism/conservatism would be more related to (low) SDO-D than SDO-E. Future work could examine this by experimentally priming the history of slavery in the U.S., and examining whether that increases the relationship between liberalism/conservatism and SDO-D (vs. -E) among Black Americans. Another possibility for what underlies the greater variability in the dissociation of the subdimensions' predictive power across criterion variables for African Americans is the phenomenon of ideological asymmetry (Levin, Sidanius, Rabinowitz, \& Federico, 1998; Sidanius \& Pratto, 1999). That is, due to the inevitable domination of the ideological realm by high status groups, low status group members have a harder time identifying those attitudes and policy preferences that match their underlying (egalitarian or anti-egalitarian) motivations, resulting in lower apparent structuring of their political attitudes, or 'ideological constraint' (Campbell, Converse, Miller, \& Stoke, 1960).

SDO in other political contexts. Although this paper makes important strides in providing empirical support for the dimensional structure, predictive power, and potential antecedents of SDO in representative samples, future work should examine the workings of this new measure in other national and sociopolitical contexts. Based on the findings of Ho et al. (2012), for example, we would expect political conservatism to be more related to the SDO-D dimension rather than the SDO-E dimension in sociopolitical contexts in which the rhetoric and behavior of political elites support overt group-based dominance in addition to less oppressive forms of inequality.

\section{Additional Considerations}


SDO-E and Ingroup Collective Norms? Another potential consideration worth commenting on surrounds the possibility that SDO-E is more likely than SDO-D to activate collective norms. Indeed, seven out of the eight items in the SDO-E scale use a plural personal pronoun, such as "we" or "our". This was unintentional - these items were derived from a factor analysis we performed on Sample 1, described above. However, one concern is that the plural personal pronoun may make ingroup collective norms more salient, and thereby strengthen the relationship between SDO-E and collective ideologies, such as the Protestant Work Ethic. Alternatively, it is possible that rather than activating collective ingroup norms, "we" may simply represent a generic term referring to all people as opposed to a specific group. Several of our findings would support this latter interpretation. First, SDO-E is strongly related to variables like the distribution of university resources across all of the samples, suggesting that it is related to a preference for inequality in situations not relevant to any specific group identity. Second, some of the SDO-D criteria relate to collective ideologies (e.g., nationalism), whereas some SDO-E criteria, such as interest in hierarchy attenuating jobs or distribution of university resources, do not. Nevertheless, the relative relationship between $\mathrm{SDO}-\mathrm{E}$ and $-\mathrm{D}$, on the one hand, and these criteria, on the other, is consistent with the theoretical distinction we have made between the dimensions of SDO. Third, and importantly, given the American norm of equality (e.g., Katz \& Hass, 1998), one might expect that priming ingroup collective norms would lead to support for equality, rather than inequality, as we find.

Nevertheless, we sought to directly test whether the use of a plural personal pronoun influences the relationship between SDO-E and its criterion variables, and to examine our assumption that "we" generically refers to "people". Thus, we conducted an experiment on Amazon MTurk with American respondents in which we randomly assigned participants to receive either the SDO-E subscale (as presented in Appendix 1), or a modified scale with 
“people” replacing “we” (e.g., "People should not push for group equality.”). This study revealed that the wording did not make a difference (i.e., the version of the SDO-E scale did not moderate its relationships with any criterion variables, and this set of relationships matched those reported in this paper (study reported in full in supplemental materials). As such, it does not seem that the unique relationship we have outlined between SDO-E and outcome measures can be accounted for by the activation of collective norms.

Other aspects of SDO. Finally, it is worth noting that the current findings, as with previous work on subdimensions of SDO, do not preclude the possibility that there are other aspects of social dominance orientation not captured in the current measure or by the $\mathrm{SDO}_{6}$ scale. For example, it may be possible to adapt the concept of communal sharing from relational models theory (Fiske, 1992) to intergroup relations, and to conceptualize opposition to it as an aspect of social dominance orientation (Thomsen, 2009). Indeed, opposition to implementing communal sharing between groups relates to a variety of intergroup variables, from political ideology to support for ethnic persecution in multiple samples across different cultures (Thomsen, Kunst, Sheehy-Skeffington, Fiske, \& Sidanius, 2015). In separate, complementary work, we are currently validating a very short measure of SDO that features inclusiveness as a central element (Pratto et al., 2015). This short measure, underscoring the importance of inclusiveness, has already been shown to relate to attitudes towards women, minorities, and poor people in a variety of countries (Pratto et al., 2013).

\section{Conclusion}

In closing, the current paper continues social dominance theory's tradition of drawing attention to the multitude of forces that underpin social stratification. Specifically, it highlights and empirically undergirds a layer of granularity in the pattern of individual differences in orientation toward intergroup hierarchy, showing that this matters for a range of intergroup processes. In doing so, it provides further evidence for the utility and 
theoretical groundedness of treating social dominance orientation as a two-dimensional construct. This paper presents a validated, psychometrically sound measure of SDO-D and SDO-E, with no compromises to the general predictive validity of SDO. It also further clarifies the current understanding of SDO as a general orientation toward hierarchy rather than a preference for ingroup dominance. We hope that the $\mathrm{SDO}_{7}$ measure is used to advance understanding of the motives undergirding a wide range of intergroup attitudes and behaviors, from opposition to social policies that would promote equality to genocidal violence against minority groups. 


\section{References}

Alexander, M. (2010). The new Jim Crow: mass incarceration in the age of colorblindness. New York: New Press.

Altemeyer, B. (1996). The authoritarian specter. Revue Fran (Vol. 39, p. 374). doi: $10.2307 / 3322995$

Althusser, L. (1984). Essays on Ideology. New York, NY: Verso Books.

Amiot, C. E., \& Bourhis, R. Y. (2005). Discrimination between dominant and subordinate groups: the positive-negative asymmetry effect and normative processes. British Journal of Social Psychology, 44, 289-308. doi:10.1348/014466604X17605

Asbrock, F., Sibley, C. G., \& Duckitt, J. (2010). Right-wing authoritarianism and social dominance orientation and the dimensions of generalized prejudice: A longitudinal test. European Journal of Personality, 24(4), 324-340.

Ashton, M. C., Lee, K., \& de Vries, R. E. (2014). The HEXACO Honesty-Humility, Agreeableness, and Emotionality Factors: A review of research and theory. Personality and Social Psychology Review, 18, 139-152.

Benjamini, Y., \& Hochberg, Y. (1995). Controlling the false discovery rate: a practical and powerful approach to multiple testing. Journal of the Royal Statistical Society. Series B (Methodological), 289-300.

Benjamini, Y., \& Yekutieli, D. (2001). The control of the false discovery rate in multiple testing under dependency. Annals of Statistics, 1165-1188.

Bishop, G. F., Tuchfarber, A. J., \& Oldendick, R. W. (1978). Change in the structure of American political attitudes: The nagging question of question wording. American Journal of Political Science, 250-269.

Campbell, A., Converse, P. E., Miller, W. E., \& Stokes, D. E. (1960). The American Voter. New York and London: John Wiley \& Sons, Inc. 
Chow, R. M., Lowery, B. S., \& Hogan, C. M. (2013). Appeasement: Whites' strategic support for affirmative action. Personality And Social Psychology Bulletin, 39(3), 332-345. doi:10.1177/0146167212475224

Cohen (1988). Statistical Power Analysis for the Behavioral Sciences (2nd ed.), New Jersey: Lawrence Erlbaum Associates.

Costello, K., \& Hodson, G. (2011). Social dominance-based threat reactions to immigrants in need of assistance. European Journal of Social Psychology, 41(2), 220-231. doi:10.1002/ejsp.769

Cotterill, S., Sidanius, J., Bhardwaj, A., \& Kumar, V. (2014). Ideological Support for the Indian Caste System: Social Dominance Orientation, Right-Wing Authoritarianism and Karma. Journal of Social and Political Psychology, 2(1), 98-116.

Davis, M. H. (1983). Measuring individual differences in empathy: Evidence for a multidimensional approach. Journal of Personality and Social Psychology, 44, 113-126.

DeNavas-Walt, C., Proctor, B. D., \& Smith, J. C. (2011). Income, Poverty, and Health Insurance Coverage in the United States: 2010 (Current Population Reports, P60-239). Washington, DC: U.S. Government Printing Office.

DeYoung, C. G., Quilty, L. C., \& Peterson, J. B. (2007). Between facets and domains: 10 aspects of the Big Five. Journal of Personality and Social Psychology, 93(5), 880-896. doi:10.1037/0022-3514.93.5.880.

Duckitt, J., Wagner, C., du Plessis, I., \& Birum, I. (2002). The psychological bases of ideology and prejudice: Testing a dual process model. Journal of Personality And Social Psychology, 83(1), 75-93. doi:10.1037/0022-3514.83.1.75

Ellenbroek, M., Verkuyten, M., Thijs, J., \& Poppe, E. (2014). The Fairness of National Decision-making Procedures: The Views of Adolescents in 18 European Countries. Journal of Community \& Applied Social Psychology, 24(6), 503-517. 
Federico, C. M., \& Sidanius, J. (2002). Sophistication and the antecedents of whites' racial policy attitudes. Public Opinion Quarterly, 66, 145-176. doi:10.1086/339848

Federico, C.M., Weber, C.R., Ergun, D., \& Hunt, C. (2013). Mapping the connections between politics and morality: The multiple sociopolitical orientations involved in moral intuition. Political Psychology, 34, 589-610.

Ferguson, A. (2015). Mitt Romney: Hillary Clinton politicized Baltimore tragedy to get support from the black community. Huffington Post, Retrieved from http://www.huffingtonpost.com/2015/05/04/mitt-romney-hillary-clintonbaltimore_n_7204884.html?ncid=tweetlnkushpmg00000016

Fiske, A. P. (1992). The four elementary forms of sociality: Framework for a unified theory of social relations. Psychological Review, 99(4), 689-723. doi:10.1037/0033295X.99.4.689

Ghiselli, E. E., Campbell, J. P., \& Zedeck, S. (1981). Measurement theory for the behavioral sciences. San Francisco: W. H. Freeman.

Graham, J., Nosek, B. A., Haidt, J., Iyer, R., Koleva, S., \& Ditto, P. H. (2011). Mapping the moral domain. Journal of Personality and Social Psychology, 101, 366-385.

Gramsci, A. (1935/1996). Prison notebooks (Vol. 2). New York: Columbia University Press.

Guriev, S., \& Treisman, D. (2015). The new dictators rule by velvet fist. New York Times, Retrieved from http://www.nytimes.com/2015/05/25/opinion/the-new-dictators-rule-by-velvet-fist.html Gutiérrez, A. S., \& Unzueta, M. M. (2013). Are admissions decisions based on family ties fairer than those that consider race? Social dominance orientation and attitudes toward legacy vs. affirmative action policies. Journal of Experimental Social Psychology, 49(3), 554-558. doi:10.1016/j.jesp.2012.10.011 
Haley, H., \& Sidanius, J. (2005). Person-organization congruence and the maintenance of group-based social hierarchy: A social dominance perspective. Group Processes and Intergroup Relations, 8, 187-203. doi:10.1177/1368430205051067

Henrich, J., Heine, S. J., \& Norenzayan, A. (2010). The weirdest people in the world?. Behavioral and Brain Sciences, 33(2-3), 61-83.

Henry, P. J., \& Sears, D. O. (2002). The symbolic racism 2000 scale. Political Psychology, 23(2), 253-283.

Hindriks, P., Verkuyten, M., \& Coenders, M. (2014). Dimensions of social dominance orientation: The roles of legitimizing myths and national identification. European Journal of Personality, doi:10.1002/per.1955

Hittner, J. B., Finger, M. S., Mancuso, J. P., \& Silver, N. C. (1995). A Microsoft Fortran-77 program for constraining part correlations and related statistics. Educational and Psychological Measurement, 55, 777-784. doi: 10.1016/0098-3004(85)90089-5

Ho, A. K., Sidanius, J., Cuddy, A. C., \& Banaji, M. R. (2013). Status boundary enforcement and the categorization of Black-White biracials. Journal of Experimental Social Psychology, 49(5), 940-943.

Ho, A. K., Sidanius, J., Pratto, F., Levin, S., Thomsen, L., Kteily, N., \& Sheehy-Skeffington, J. (2012). Social dominance orientation: Revisiting the structure and function of a variable predicting social and political attitudes. Personality and Social Psychology Bulletin, 38(5), 583-606. doi:10.1177/0146167211432765

Hodson, G., Hogg, S. M., \& MacInnis, C. C. (2009). The role of 'dark personalities' (narcissism, Machiavellianism, psychopathy), Big Five personality factors, and ideology in explaining prejudice. Journal of Research in Personality, 43(4), 686-690. doi:10.1016/j.jrp.2009.02.005 
Hodson, G., Rush, J., \& MacInnis, C. C. (2010). A joke is just a joke (except when it isn't): Cavalier humor beliefs facilitate the expression of group dominance motives. Journal of Personality and Social Psychology,99(4), 660-682. doi:10.1037/a0019627

Jackman, M. R. (1994). The velvet glove: Paternalism and conflict in gender, class, and race relations. Univ of California Press.

Jones, D.N., \& Paulhus, D. L. (2010). Different provocations trigger aggression in narcissists and psychopaths. Social and Personality Psychology Science, 1, 12-18.

Jost, J. T., \& Thompson, E. P. (2000). Group-based dominance and opposition to equality as independent predictors of self-esteem, ethnocentrism, and social policy attitudes among African Americans and European Americans. Journal of Experimental Social Psychology, 36, 209-232. doi:10.1006/jesp.1999.1403

Kahn, K., Ho, A. K., Sidanius, J., \& Pratto, F. (2009). The space between Us and Them: perceptions of status differences. Group Processes and Intergroup Relations, 12, 591604. doi:10.1177/1368430209338716

Katz, I., \& Hass, R. G. (1988). Racial ambivalence and American value conflict: Correlational and priming studies of dual cognitive structures. Journal of Personality and Social Psychology, 55(6), 893-905.

Krosch, A. R., Berntsen, L., Amodio, D. M., Jost, J. T., \& Van Bavel, J. J. (2013). On the ideology of hypodescent: Political conservatism predicts categorization of racially ambiguous faces as Black, Journal of Experimental Social Psychology, 49, 1196-1203.

Kteily, N., Bruneau, E., Waytz, A., \& Cotterill, S. (in press). The 'Ascent of Man': A theoretical and empirical case for blatant dehumanization. Journal of Personality and Social Psychology. 
Kteily, N., Cotterill, S., Sidanius, J., Sheehy-Skeffington, J., \& Bergh, R. (2014). Not one of us: Predictors and consequences of denying ingroup characteristics to ambiguous targets. Personality and Social Psychology Bulletin, 40, 1231-1247.

Kteily, N., Ho, A. K., \& Sidanius, J. (2012). Hierarchy in the mind: The predictive power of social dominance orientation across social contexts and domains. Journal of Experimental Social Psychology, 48, 543-549. doi:10.1016/j.jesp.2011.11.007

Kteily, N., Sidanius, J., \& Levin, S. (2011). Social dominance orientation: Cause or "Mere Effect"? Evidence for SDO as a causal predictor of prejudice and discrimination against ethnic and racial outgroups. Journal of Experimental Social Psychology, 47, 208-214. doi:10.1016/j.jesp.2010.09.009

Kugler, M. B., Cooper, J., \& Nosek, B. A. (2010). Group-based dominance and opposition to equality correspond to different psychological motives. Social Justice Research, 23, 117-155. doi:10.1007/s11211-010-0112-5

Kugler, M., Jost, J. T., \& Noorbaloochi, S. (2014). Another Look at Moral Foundations Theory: Do Authoritarianism and Social Dominance Orientation Explain LiberalConservative Differences in "Moral” Intuitions?. Social Justice Research, 27(4), 413431.

Larsson, M. R., Björklund, F., \& Bäckström, M. (2012). Right-wing authoritarianism is a risk factor of torture-like abuse, but so is social dominance orientation. Personality and Individual Differences, 53(7), 927-929.

Lee, K., \& Ashton, M. C. (2004). Psychometric properties of the HEXACO personality inventory. Multivariate Behavioral Research,39(2), 329-358. doi:10.1207/s15327906mbr3902_8

Lee, K., Ashton, M. C., Ogunfowora, B., Bourdage, J. S., \& Shin, K. (2010). The personality bases of socio-political attitudes: The role of Honesty-Humility and Openness to 
Experience. Journal of Research In Personality, 44(1), 115-119. doi:10.1016/j.jrp.2009.08.007

Lee, I., Pratto, F., \& Johnson, B. T. (2011). Intergroup consensus/disagreement in support of group-based hierarchy: An examination of socio-structural and psycho-cultural factors. Psychological Bulletin, 137(6), 1029-1064. doi:10.1037/a0025410

Levin, S., Sidanius, J., Rabinowitz, J. L., \& Federico, C. (1998). Ethnic identity, legitimizing ideologies, and social status: A matter of ideological asymmetry. Political Psychology, 19(2), 373-404.

Leyens, J., Paladino, P. M., Rodriguez-Torres, R., Vaes, J., Demoulin, S., Rodriguez-Perez, A., \& Gaunt, R. (2000). The emotional side of prejudice: The attribution of secondary emotions to ingroups and outgroups. Personality And Social Psychology Review, 4(2), 186-197. doi:10.1207/S15327957PSPR0402_06

Martinovic, B., \& Verkuyten, M. (2013). 'We were here first, so we determine the rules of the game': Autochthony and prejudice towards out-groups.European Journal of Social Psychology, 43(7), 637-647.

Milojev, P., Osborne, D., Greaves, L. M., Bulbulia, J., Wilson, M. S., Davies, C. L., \& ... Sibley, C. G. (2014). Right-wing authoritarianism and social dominance orientation predict different moral signatures.Social Justice Research, 27(2), 149-174. doi:10.1007/s11211-014-0213-7

Oliver, M. L., \& Shapiro, T. M. (2006). Black wealth, white wealth: A new perspective on racial inequality. New York: Taylor \& Francis.

Paulhus, D. L., \& Williams, K. M. (2002). The Dark Triad of personality: Narcissism, Machiavellianism and psychopathy. Journal of Research in Personality, 36(6), 556-563. doi:10.1016/S0092-6566(02)00505-6 
Perry, R., Sibley, C. G., \& Duckitt, J. (2013). Dangerous and competitive worldviews: A meta-analysis of their associations with social dominance orientation and right-wing authoritarianism.Journal of Research In Personality, 47(1), 116-127. doi:10.1016/j.jrp.2012.10.004

Pinker, S. (2011). The better angels of our nature: Why violence has declined. New York: Viking.

Pratto, F., \& Glasford, D. E. (2008). Ethnocentrism and the value of a human life. Journal of Personality and Social Psychology, 95, 1411-1428. doi:10.1037/a0012636

Pratto, F., Sidanius, J., \& Levin, S. (2006). Social dominance theory and the dynamics of intergroup relations: Taking stock and looking forward. European Review of Social Psychology, 17, 271-320. doi:10.1080/10463280601055772

Pratto, F., Sidanius, J., Stallworth, L. M., \& Malle, B. F. (1994). Social dominance orientation: A personality variable predicting social and political attitudes. Journal of Personality and Social Psychology, 67, 741-763. doi:10.1037/0022-3514.67.4.741

Pratto, F. Stewart, A. L., Foels, R., Henkel, K. E., Bou Zeineddine, F., Laham, S. M., \& Morselli, D. (2015). Beyond Me and Mine: The Socially-Inclusive Psychology of People Low on Social Dominance Orientation. Unpublished manuscript, University of Connecticut.

Pratto, F., Çidam, A., Stewart, A.L., Bou Zeineddine, F., Aranda, M., Aiello, A., Chryssochoou, X., Cichocka, A., Cohrs, C., Durrheim, K., Eicher, V., Foels, R., Górska, P., Lee, I., Licata, L., Li, L., Liu, J., Morselli, D., Meyer, I., Muldoon, O., Muluk, H., Petrovic, N., Prati, F., Papastamou, S., Petrovic, I., Prodromitis, G., Rubini, M., Saab, R., van Stekelenburg, J., Sweetman, J., Zheng, W., Henkel, K.E. (2013). Social Dominance in Context and in Individuals: Contextual Moderation of Robust Effects of 
Social Dominance Orientation in 15 languages and 20 countries. Social Psychological and Personality Science. DOI: 10.1177/1948550612473663

Reynolds, K. J., Turner, J. C., Haslam, S. A., Ryan, M. K., Bizumic, B., \& Subasic, E. (2007). Does personality explain in-group identification and discrimination? Evidence from the minimal group paradigm. British Journal of Social Psychology, 46, 517-539. doi:10.1348/014466606X153080

Roets, A., \& Van Hiel, A. (2011). Allport's prejudiced personality today: Need for closure as the motivated cognitive basis of prejudice.Current Directions In Psychological Science, 20(6), 349-354. doi:10.1177/0963721411424894

Sears, D. O., Haley, H., \& Henry, P. J. (2008). Cultural diversity and sociopolitical attitudes at college entry. In J. Sidanius, S. Levin, C. van Laar, \& D. O. Sears (Eds.), The diversity challenge: Social identity and intergroup relations on the college campus (pp. 65-99). New York, NY: Russell Sage.

Sibley, C. G., \& Duckitt, J. (2008). Personality and prejudice: a meta-analysis and theoreticalreview. Personality and Social Psychology Review, 12, 248-279. doi: $10.1177 / 1088868308319226$

Sibley, C. G., Harding, J. F., Perry, R., Asbrock, F., \& Duckitt, J. (2010). Personality and prejudice: Extension to the HEXACO personality model. European Journal of Personality, 24(6), 515-534. doi:10.1002/per.750

Sidanius, J. (1993). The psychology of group conflict and the dynamics of oppression: A social dominance perspective. Explorations in Political Psychology (pp. 183-219). Durham N.C.: Duke University Press.

Sidanius, J., Cotterill, S., Sheehy-Skeffington, J., Kteily, N., \& Carvacho, H. (2015). Social dominance theory: Explorations in the psychology of oppression. Cambridge Handbook of the Psychology of Prejudice. Manuscript submitted for publication. 
Sidanius, J., Kteily, N., Sheehy-Skeffington, J., Ho, A. K., Sibley, C., \& Duriez, B. (2013). You're inferior and not worth our concern: The interface between empathy and social dominance orientation. Journal of Personality, 81(3), 313-323. doi:10.1111/jopy.12008

Sidanius, J., \& Pratto, F. (1999). Social dominance: An intergroup theory of social hierarchy and oppression. Cambridge: Cambridge University Press.

Sidanius, J., Pratto, F., \& Mitchell, M. (1994). In-group identification, social dominance orientation, and differential intergroup social allocation. The Journal of Social Psychology, 134(2), 151-167. doi:10.1080/00224545.1994.9711378

Sidanius, J., Pratto, F., Sinclair, S., \& Van Laar, C. (1996). Mother Teresa meets Genghis Khan: The dialectics of hierarchy-enhancing and hierarchy-attenuating career choices. Social Justice Research, 9(2), 145-170.

Sidanius, J., Levin, S., Federico, C. M., \& Pratto, F. (2001). Legitimizing ideologies: The social dominance approach. The Psychology of Legitimacy: Emerging Perspectives on Ideology Justice and Intergroup Relations (pp. 307-331). doi:10.1111/j.14679221.2004.00402.x

Sidanius, J., Levin, S., Van Laar, C., \& Sears, D. O. (2008). The diversity challenge: Social identity and intergroup relations on the college campus. Russell Sage Foundation.

Sidanius, J., Mitchell, M., Haley, H., \& Navarrete, C. D. (2006). Support for harsh criminal sanctions and criminal justice beliefs: A social dominance perspective. Social Justice Research, 19, 433-449. doi:10.1007/s11211-006-0026-4

Steiger, J. H. (1980). On the empirical equivalence of regression components and common factors. British Journal of Mathematical and Statistical Psychology, 33, 200-204. doi:10.1111/j.2044-8317.1980.tb00608.x 
Swami, V., Neofytou, R., Jablonska, J., Thirlwell, H., Taylor, D., \& McCreary, D. R. (2013). Social dominance orientation predicts drive for muscularity among British men. Body Image, 10(4), 653-656. doi:10.1016/j.bodyim.2013.07.007

Thomsen, L. (2009). Seeing Social Relations. Doctoral Dissertation, Harvard University

Thomsen, L., Green, E., \& Sidanius, J. (2008). We will hunt them down: How social dominance orientation and right-wing authoritarianism fuel ethnic persecution of immigrants in fundamentally different ways. Journal of Experimental Social Psychology, 44, 1455-1464. doi:10.1016/j.jesp.2008.06.011

Thomsen, L., Green, E. G. T., Ho, A. K., Levin, S., Van Laar, C., Sinclair, S., \& Sidanius, J. (2010). Wolves in sheep's clothing: SDO asymmetrically predicts perceived ethnic victimization among white and Latino students across three years. Personality and Social Psychology Bulletin, 36, 225-238. 10.1177/0146167209348617

Thomsen, L., Kunst, J. R., Sheehy-Skeffington, J., Fiske, A. P., \& Sidanius, J. (2015). Universal, elementary relational motives applied between groups underpin intergroup relations: The Between-group Relational Orientation Scale (BRO). Manuscript in preparation.

Van Hiel, A., Pandelaere, M., \& Duriez, B. (2004). The impact of need for closure on conservative beliefs and racism: Differential mediation by authoritarian submission and authoritarian dominance. Personality and Social Psychology Bulletin, 30(7), 824-837. doi:10.1177/0146167204264333

van Laar, C. V., Levin, S., Sinclair, S., \& Sidanius, J. (2005). The effect of university roommate contact on ethnic attitudes and behavior. Journal of Experimental Social Psychology, 41(4), 329-345.

Webster, D. M., \& Kruglanski, A. W. (1994). Individual differences in need for cognitive closure. Journal of Personality and Social Psychology, 67(6), 1049. 
${ }^{1}$ Although not a primary goal of the current work, we also test the "invariance hypothesis" that men will have higher levels of SDO than women, because of evolutionary pressures on human males to compete for resources on a coalitional, group basis. This has been thoroughly documented with $\mathrm{SDO}_{6}$ (Lee et al., 2011; Sidanius and Pratto, 1999), and thus we assess whether if it holds with $\mathrm{SDO}_{7}$.

${ }^{2}$ Another sample of both White and Black respondents were collected for us by SocialSci. However, we observed some unusual race and sex based patterns in this data and therefore chose to not include it in the present set of studies. A representative from SocialSci informed us that their protocol for vetting participant responses to demographic questions was not in place at the time the data from the omitted sample were collected, though they were at the time Sample 2 was collected. Specifically, in contrast to previous research showing that African Americans have lower levels of SDO and racism than Whites (e.g., Sidanius and Pratto, 1999; van Laar, Levin, Sinclair, \& Sidanius, 2005), the sample of African Americans in the omitted study had marginally significantly higher $\mathrm{SDO}_{6}$ scores and significantly higher scores on anti-Black and Latino racism, than the sample of Whites. In addition, whereas a sex difference in SDO, with men having higher levels of SDO on average than women, was found in every other sample, it was not observed in the omitted sample. Nevertheless, the results from the omitted study were largely consistent with findings in the other six samples in terms of predictive validity reported here. Importantly, the factor structure of SDO in this sample was completely consistent with the rest of the samples, and the set of items chosen for the short scale were first selected based on results from the omitted sample and later validated in the other samples, reported here.

${ }^{3}$ This dataset was analyzed in Ho et al. (2012; Sample 7), where the same factor analytic procedure is described. However, in Ho et al. (2012), we used the item "Having some groups on top really benefits everybody," which we've replaced with "Sometimes other groups must be kept in their place" in the current analyses (Sample 1). These two items both loaded similarly highly on the same dimension in the analysis described in-text.

${ }^{4}$ For African American respondents (Sample 4 and 5b), we adapted criterion variables as needed (e.g., creating a measure of anti-Latino prejudice because existing ethnic prejudice measures typically reference African Americans).

${ }^{5}$ Whereas a partial correlation examines the correlation between an independent variable (IV) and dependent variable (DV) after controlling for the effects of a third variable on both the IV and DV, a semipartial or part correlation examines the correlation between an IV and DV controlling for the effects of a third variable on the IV only. We focused our analyses on semipartial correlations, which in principle are the same as multiple regression coefficients, because we wanted to assess the relative strength of SDO-D and SDO-E in relation to all of the variance in the criterion variables, and not just the residual variance after partialing out the shared variance with one of the SDO subdimensions.

${ }^{6}$ The statistical weight incorporated the following demographic variables:

- Age

○ White/Non-Hispanic: (18-44, 45-59, and 60+)

○ Black/Non-Hispanic: (18-29, 30-44, 45-59, and 60+)

- Gender (Male/Female)

- Education (Less than High School/High School, Some College, Bachelors and higher)

- Household income

○ White/Non-Hispanic: (under $\$ 50 \mathrm{~K}, \$ 50 \mathrm{~K}$ to $<\$ 75 \mathrm{~K}, \$ 75 \mathrm{~K}+$ )

- Black/Non-Hispanic: (under $\$ 25 \mathrm{~K}, \$ 25 \mathrm{~K}$ to $<\$ 50 \mathrm{~K}, \$ 50 \mathrm{~K}$ to $<\$ 75 \mathrm{~K}, \$ 75 \mathrm{~K}+$ )

- Internet Access (Yes, No)

- Census Region (Northeast, Midwest, South, West) 
- Metropolitan Area (Yes, No)

${ }^{7}$ For Samples 5a and 5b, participants either received the SDO measure first, or following survey questions concerning racial categorization. To check for order effects, we tested whether order moderated the effects of SDO-D and SDO-E, and found that it did not in any case, except for old-fashioned racism and opposition to racial policy in Sample 5b.

Specifically, with old-fashioned racism as the criterion, the B-coefficient for SDO-E was .49

lower among respondents who received the SDO scale first than those who received it second (order x SDO-E interaction $t=2.38, p=.02$ ). With opposition to racial policy, the B-

coefficient with SDO-E was .34 higher among respondents who received SDO first than those who received it second (interaction $t=2.08, p=.04$ ). In both cases, the change would be consistent with our hypotheses.

${ }^{8}$ This procedure was developed for this project in consultation with Kathy Welch of the Center for Statistical Consultation and Research at the University of Michigan.

${ }^{9}$ The correlation of ethnic identity with the SDO7 and SDO6 anti-egalitarianism subscales were $-.27(p<.001)$ and $-.31(p<.001)$, respectively. In Sample 5B, the correlation of ethnic identity with SDO-E was $-.33(p<.001)$.

${ }^{10}$ It is also worth noting that the magnitude of the negative relationship may have been tempered by the generality of SDO (Kteily et al., 2012). That is, it's possible that some highly identified Blacks may support other forms of hierarchy, such as gender or religionbased hierarchies.

${ }^{11}$ Since a few items in the $\mathrm{SDO}_{6}$-D subscale may reflect a preference for ingroup dominance - in particular, "In getting what your group wants, it is sometimes necessary to use force against other groups" and "To get ahead in life, it is sometimes necessary to step on other groups"-we would expect that sometimes, there may be a positive correlation between $\mathrm{SDO}_{6}$-D and ingroup identity among members of low status groups. However, since other items in the $\mathrm{SDO}_{6}$-D scale do not reference ingroup advancement per se, we would not expect this result to be obtained consistently. That may explain why we do not find a positive relationship between $\mathrm{SDO}_{6}$-D and ingroup identity among African Americans in Sample 4, whereas Jost and Thompson (2000) did. 
Appendix 1

$\mathrm{SDO}_{7}$ Scale

Instructions: Show how much you favor or oppose each idea below by selecting a number from 1 to 7 on the scale below. You can work quickly; your first feeling is generally best.

$\begin{array}{ccccccc}1 & 2 & 3 & 4 & 5 & 6 & 7 \\ \text { Strongly } & \text { Somewhat } & \text { Slightly } & \text { Neutral } & \text { Slightly } & \text { Somewhat } & \text { Strongly } \\ \text { Oppose } & \text { Oppose } & \text { Oppose } & & \text { Favor } & \text { Favor } & \text { Favor }\end{array}$

Pro-trait dominance:

1. Some groups of people must be kept in their place.

2. It's probably a good thing that certain groups are at the top and other groups are at the bottom

3. An ideal society requires some groups to be on top and others to be on the bottom.

4. Some groups of people are simply inferior to other groups.

Con-trait dominance:

5. Groups at the bottom are just as deserving as groups at the top.

6. No one group should dominate in society.

7. Groups at the bottom should not have to stay in their place.

8. Group dominance is a poor principle.

Pro-trait anti-egalitarianism:

9. We should not push for group equality.

10. We shouldn't try to guarantee that every group has the same quality of life.

11. It is unjust to try to make groups equal.

12. Group equality should not be our primary goal.

Con-trait anti-egalitarianism:

13. We should work to give all groups an equal chance to succeed.

14. We should do what we can to equalize conditions for different groups.

15. No matter how much effort it takes, we ought to strive to ensure that all groups have the same chance in life.

16. Group equality should be our ideal. 
Appendix 2

$\mathrm{SDO}_{7(\mathrm{~s})}$ Scale

Instructions: Show how much you favor or oppose each idea below by selecting a number from 1 to 7 on the scale below. You can work quickly; your first feeling is generally best.

$\begin{array}{ccccccc}1 & 2 & 3 & 4 & 5 & 6 & 7 \\ \text { Strongly } & \text { Somewhat } & \text { Slightly } & \text { Neutral } & \text { Slightly } & \text { Somewhat } & \text { Strongly } \\ \text { Oppose } & \text { Oppose } & \text { Oppose } & & \text { Favor } & \text { Favor } & \text { Favor }\end{array}$

Protrait dominance:

1. An ideal society requires some groups to be on top and others to be on the bottom.

2. Some groups of people are simply inferior to other groups.

Contrait dominance:

3. No one group should dominate in society.

4. Groups at the bottom are just as deserving as groups at the top.

Protrait anti-egalitarianism:

5. Group equality should not be our primary goal.

6. It is unjust to try to make groups equal.

Contrait anti-egalitarianism:

7. We should do what we can to equalize conditions for different groups.

8. We should work to give all groups an equal chance to succeed. 
Table 1. Previous Studies Showing a Relationship between SDO and Personality and Individual Differences.

\begin{tabular}{|l|l|}
\hline $\begin{array}{l}\text { Personality and Individual } \\
\text { Differences }\end{array}$ & Previous studies \\
\hline $\begin{array}{l}\text { Big 5 (specifically, agreeableness } \\
\text { and openness to experience) }\end{array}$ & $\begin{array}{l}\text { Hodson, Hogg, \& MacInnis, 2009; Sibley \& Duckitt, 2008 } \\
\text { (meta-analysis) }\end{array}$ \\
\hline $\begin{array}{l}\text { HEXACO (specifically, honesty- } \\
\text { humility, emotionality, } \\
\text { agreeableness, and openness to } \\
\text { experience) }\end{array}$ & $\begin{array}{l}\text { Lee, Ashton, Ogunfowora, Bourdage, \& Shin, 2010; Sibley, } \\
\text { Harding, Perry, Asbrock, \& Duckitt, 2010 }\end{array}$ \\
\hline $\begin{array}{l}\text { Dark Triad (Machiavellianism*, } \\
\text { narcissism*, and psychopathy*) }\end{array}$ & Hodson et al., 2009 \\
\hline $\begin{array}{l}\text { Empathic Concern (part of the } \\
\text { Interpersonal Reactivity Index; } \\
\text { Davis, 1983) }\end{array}$ & $\begin{array}{l}\text { Sidanius, Kteily, Sheehy-Skeffington, Ho, Sibley, \& Duriez, } \\
\text { 2013 }\end{array}$ \\
\hline $\begin{array}{l}\text { Dual-Process Model (specifically, } \\
\text { tough-mindedness*, competitive } \\
\text { worldview*) }\end{array}$ & $\begin{array}{l}\text { Duckitt, Wagner, du Plessis, \& Birum, 2002; Perry, Sibley, \& } \\
\text { Duckitt, 2013 }\end{array}$ \\
\hline $\begin{array}{l}\text { Need for Closure (specifically, } \\
\text { closed-mindedness*) }\end{array}$ & Roets \& Van Hiel, 2011; Van Hiel, Pandelaere, \& Duriez, 2004 \\
\hline $\begin{array}{l}\text { Moral Foundations (specifically, } \\
\text { harm and fairness) }\end{array}$ & $\begin{array}{l}\text { Federico, Weber, Ergun, \& Hunt, 2013; Graham, } \\
\text { Nosek, Haidt, Iyer, Koleva, \& Ditto, 2011; Kugler, Jost, \& } \\
\text { Noorbaloochi, 2014; Milojev et al., 2014 }\end{array}$ \\
\hline
\end{tabular}

Note. Except where noted with a *, all traits mentioned have a negative correlation with SDO. 
Table 2A. SDO-D criterion variables included in Samples 1-5b.

\begin{tabular}{|c|c|c|c|c|c|c|}
\hline Variables & Sample 1 & Sample 2 & Sample 3 & Sample 4 & Sample 5a & Sample 5b \\
\hline $\begin{array}{l}\text { Old-fashioned racism } \\
\text { (adapted from Sidanius, } \\
\text { Levin, van Laar, Sears, } \\
\text { 2008) }\end{array}$ & $\begin{array}{l}\alpha=.95 \\
m=1.84 \\
S D=1.31\end{array}$ & $\begin{array}{l}\alpha=.95 \\
m=1.59 \\
S D=1.14\end{array}$ & $\begin{array}{l}\alpha=.95 \\
m=1.54 \\
S D=1.07\end{array}$ & $\begin{array}{l}\alpha=.93 \\
m=2.26 \\
S D=1.69\end{array}$ & $\begin{array}{l}\alpha=.93 \\
m=2.15 \\
S D=1.47\end{array}$ & $\begin{array}{l}\alpha=.87 \\
m=2.15 \\
S D=1.36\end{array}$ \\
\hline $\begin{array}{l}\text { Zero-sum competition } \\
\text { (Bobo \& Hutchings, } \\
\text { 1996) }\end{array}$ & $\begin{array}{l}\alpha=.89 \\
m=2.86 \\
S D=1.59\end{array}$ & $\begin{array}{l}\alpha=.88 \\
m=2.65 \\
S D=1.49\end{array}$ & $\begin{array}{l}\alpha=.94 \\
m=2.57 \\
S D=1.60\end{array}$ & $\begin{array}{l}\alpha=.92 \\
m=3.43 \\
S D=1.85\end{array}$ & $\begin{array}{l}\alpha=.89 \\
m=2.79 \\
S D=1.47\end{array}$ & $\begin{array}{l}\alpha=.91 \\
m=3.22 \\
S D=1.63\end{array}$ \\
\hline $\begin{array}{l}\text { Nationalism } \\
\text { (Kosterman \& Feshbach, } \\
\text { 1989) }\end{array}$ & $\begin{array}{l}\alpha=.89 \\
m=3.14 \\
S D=1.40\end{array}$ & $\begin{array}{l}\alpha=.88 \\
m=2.43 \\
S D=1.33\end{array}$ & -- & $\begin{array}{l}\alpha=.83 \\
m=3.59 \\
S D=1.57\end{array}$ & -- & -- \\
\hline $\begin{array}{l}\text { Support for immigrant } \\
\text { persecution (Thomsen, } \\
\text { Green, \& Sidanius, 2008) }\end{array}$ & \begin{tabular}{|l|}
$\alpha=.93$ \\
$m=2.06$ \\
$S D=1.41$ \\
\end{tabular} & $\begin{array}{l}\alpha=.94 \\
m=1.81 \\
S D=1.34 \\
\end{array}$ & $\begin{array}{l}\alpha=.90 \\
m=1.91 \\
S D=1.36 \\
\end{array}$ & \begin{tabular}{|l|}
$\alpha=.93$ \\
$m=2.82$ \\
$S D=1.78$ \\
\end{tabular} & -- & -- \\
\hline $\begin{array}{l}\text { War support (Ho et al., } \\
\text { 2012) }\end{array}$ & $\begin{array}{l}\alpha=.89 \\
m=3.02 \\
S D=1.40\end{array}$ & $\begin{array}{l}\alpha=.78 \\
m=2.34 \\
S D=1.20\end{array}$ & -- & -- & -- & -- \\
\hline $\begin{array}{l}\text { War legitimacy beliefs } \\
\text { (Ho et al., 2012) }\end{array}$ & $\begin{array}{l}\alpha=.78 \\
m=3.18 \\
S D=1.22\end{array}$ & -- & -- & -- & -- & -- \\
\hline $\begin{array}{l}\text { Death penalty support } \\
\text { (Sidanius, Mitchell, } \\
\text { Haley, \& Navarrete, } \\
\text { 2006) }\end{array}$ & $\begin{array}{l}\alpha=.97 \\
m=4.27 \\
S D=1.99\end{array}$ & $\begin{array}{l}\alpha=.90 \\
m=3.67 \\
S D=1.90\end{array}$ & $\begin{array}{l}\alpha=.81 \\
m=4.49 \\
S D=1.92\end{array}$ & $\begin{array}{l}\alpha=.81 \\
m=4.36 \\
S D=1.71\end{array}$ & -- & -- \\
\hline $\begin{array}{l}\text { Punitiveness (Sidanius, } \\
\text { Mitchell, Haley, \& } \\
\text { Navarrete, 2006) }\end{array}$ & $\begin{array}{l}\alpha=.85 \\
m=3.15 \\
S D=1.58 \\
\end{array}$ & $\begin{array}{l}\alpha=.88 \\
m=2.36 \\
S D=1.54 \\
\end{array}$ & $\begin{array}{l}\alpha=.88 \\
m=3.13 \\
S D=1.69 \\
\end{array}$ & -- & \begin{tabular}{|l|}
$\alpha=.74$ \\
$m=3.46$ \\
$S D=1.42$ \\
\end{tabular} & $\begin{array}{l}\alpha=.61 \\
m=3.18 \\
S D=1.33 \\
\end{array}$ \\
\hline $\begin{array}{l}\text { Hierarchy-enhancing } \\
\text { jobs* (Sidanius, Pratto, } \\
\text { Sinclair, van Laar, 1996) }\end{array}$ & -- & $\begin{array}{l}\alpha=.76 \\
m=3.02 \\
S D=1.23\end{array}$ & $\begin{array}{l}\alpha=.81 \\
m=3.24 \\
S D=1.35\end{array}$ & -- & -- & -- \\
\hline $\begin{array}{l}\text { Militarism* (adapted } \\
\text { from Hurwitz \& Peffley, } \\
\text { 1987) }\end{array}$ & -- & $\begin{array}{l}\alpha=.82 \\
m=2.45 \\
S D=.82\end{array}$ & $\begin{array}{l}\alpha=.82 \\
m=3.15 \\
S D=1.28 \\
\end{array}$ & -- & -- & -- \\
\hline Fight Iran & -- & -- & $\begin{array}{l}\alpha=.89 \\
m=4.12 \\
S D=1.53\end{array}$ & -- & -- & -- \\
\hline Syria intervention & -- & -- & $\begin{array}{l}\alpha=\mathrm{n} / \mathrm{a} \\
m=3.00 \\
S D=1.56\end{array}$ & -- & -- & -- \\
\hline Torture & -- & -- & -- & -- & $\begin{array}{l}\alpha=.67 \\
m=3.05 \\
S D=1.49\end{array}$ & $\begin{array}{l}\alpha=.55 \\
m=3.05 \\
S D=1.49\end{array}$ \\
\hline
\end{tabular}


Table 2B. SDO-E criterion variables included in Samples 1-5b.

\begin{tabular}{|c|c|c|c|c|c|c|}
\hline Variables & Sample 1 & Sample 2 & Sample 3 & Sample 4 & Sample 5a & Sample 5b \\
\hline $\begin{array}{l}\text { Political conservatism* } \\
\text { (Sidanius et al., 2008) }\end{array}$ & $\begin{array}{l}\alpha=.87 \\
m=3.61 \\
S D=1.62\end{array}$ & $\begin{array}{l}\alpha=.67 \\
m=2.77 \\
S D=1.37\end{array}$ & $\begin{array}{l}\alpha=.88 \\
m=3.37 \\
S D=1.63\end{array}$ & $\begin{array}{l}\alpha=.72 \\
m=3.34 \\
S D=1.39\end{array}$ & $\begin{array}{l}\alpha=.88 \\
m=4.46 \\
S D=1.70\end{array}$ & $\begin{array}{l}\alpha=.52 \\
m=3.38 \\
S D=1.17\end{array}$ \\
\hline $\begin{array}{l}\text { System justification (Kay } \\
\text { \& Jost, 2003) }\end{array}$ & $\begin{array}{l}\alpha=.81 \\
m=3.68 \\
S D=1.10\end{array}$ & $\begin{array}{l}\alpha=.82 \\
m=2.92 \\
S D=1.09\end{array}$ & $\begin{array}{l}\alpha=.83 \\
m=3.54 \\
S D=1.15\end{array}$ & $\begin{array}{l}\alpha=.84 \\
m=3.78 \\
S D=1.53\end{array}$ & $\begin{array}{l}\alpha=.76 \\
m=3.48 \\
S D=1.15\end{array}$ & $\begin{array}{l}\alpha=.75 \\
m=3.25 \\
S D=1.15\end{array}$ \\
\hline $\begin{array}{l}\text { Opposition to affirmative } \\
\text { action* (Haley \& } \\
\text { Sidanius, 2006) }\end{array}$ & $\begin{array}{l}\alpha=.83 \\
m=4.82 \\
S D=1.31\end{array}$ & $\begin{array}{l}\alpha=.85 \\
m=3.29 \\
S D=1.29\end{array}$ & -- & -- & -- & -- \\
\hline $\begin{array}{l}\text { Opposition to racial } \\
\text { policy (adapted from Ho } \\
\text { et al., 2012) }\end{array}$ & $\begin{array}{l}\alpha=.83 \\
m=3.38 \\
S D=1.36 \\
\end{array}$ & -- & -- & $\begin{array}{l}\alpha=.71 \\
m=2.36 \\
S D=1.28 \\
\end{array}$ & $\begin{array}{l}\alpha=.84 \\
m=3.48 \\
S D=1.53 \\
\end{array}$ & $\begin{array}{l}\alpha=.75 \\
m=2.49 \\
S D=1.25\end{array}$ \\
\hline $\begin{array}{l}\text { Opposition to welfare } \\
\text { (Ho et al., 2012) }\end{array}$ & $\begin{array}{l}\alpha=.79 \\
m=2.91 \\
S D=1.44\end{array}$ & $\begin{array}{l}\alpha=.80 \\
m=2.66 \\
S D=1.40\end{array}$ & $\begin{array}{l}\alpha=.79 \\
m=3.03 \\
S D=1.40\end{array}$ & -- & -- & -- \\
\hline $\begin{array}{l}\text { Symbolic racism* } \\
\text { (Henry \& Sears, 2002) }\end{array}$ & $\begin{array}{l}\alpha=.84 \\
m=2.31 \\
S D=.58\end{array}$ & $\begin{array}{l}\alpha=.86 \\
m=2.12 \\
S D=.65\end{array}$ & $\begin{array}{l}\alpha=.89 \\
m=3.17 \\
S D=1.10\end{array}$ & $\begin{array}{l}\alpha=.41 \\
m=2.22 \\
S D=.57\end{array}$ & -- & -- \\
\hline $\begin{array}{l}\text { Unequal distribution of } \\
\text { university resources (Ho } \\
\text { et al., 2012) }\end{array}$ & $\begin{array}{l}\alpha=.77 \\
m=3.69 \\
S D=1.31\end{array}$ & $\begin{array}{l}\alpha=.78 \\
m=3.57 \\
S D=1.26\end{array}$ & $\begin{array}{l}\alpha=.87 \\
m=3.53 \\
S D=1.49\end{array}$ & $\begin{array}{l}\alpha=.38 \\
m=3.48 \\
S D=1.08\end{array}$ & -- & -- \\
\hline $\begin{array}{l}\text { Hierarchy-attenuating } \\
\text { jobs* (Sidanius et al., } \\
\text { 1996) }\end{array}$ & $\begin{array}{l}\alpha=.87 \\
m=3.81 \\
S D=1.53\end{array}$ & $\begin{array}{l}\alpha=.87 \\
m=3.68 \\
S D=1.54\end{array}$ & $\begin{array}{l}\alpha=.85 \\
m=3.88 \\
S D=1.40\end{array}$ & -- & -- & -- \\
\hline $\begin{array}{l}\text { Affirmative action-race* } \\
\text { (adapted from Haley \& } \\
\text { Sidanius, 2006) }\end{array}$ & -- & -- & $\begin{array}{l}\alpha=.81 \\
m=5.35 \\
S D=1.28\end{array}$ & -- & -- & -- \\
\hline $\begin{array}{l}\text { Affirmative action- } \\
\text { gender* (adapted from } \\
\text { Haley \& Sidanius, 2006) }\end{array}$ & -- & -- & \begin{tabular}{|l|}
$\alpha=.82$ \\
$m=5.25$ \\
$S D=1.37$ \\
\end{tabular} & -- & -- & -- \\
\hline $\begin{array}{l}\text { Anti-discrimination } \\
\text { measures }\end{array}$ & -- & -- & \begin{tabular}{|l|}
$\alpha=.77$ \\
$m=2.72$ \\
$S D=1.24$ \\
\end{tabular} & -- & -- & -- \\
\hline Redistribution of wealth & -- & -- & \begin{tabular}{|l|}
$\alpha=.91$ \\
$m=3.47$ \\
$S D=1.78$ \\
\end{tabular} & -- & -- & -- \\
\hline $\begin{array}{l}\text { Anti-black affect* } \\
\text { (adapted from Ho et al., } \\
\text { 2012) }\end{array}$ & -- & -- & -- & -- & $\begin{array}{l}\alpha=\mathrm{n} / \mathrm{a} \\
m=4.94 \\
S D=1.30\end{array}$ & -- \\
\hline
\end{tabular}

Notes. In Sample 3, race- and gender-based affirmative action were measured separately, as reflected in the Supplemental Appendix. Cells with "--" (two dashes) indicate that a variable was not included for the sample. Otherwise, the cells include values for Cronbach's $\alpha$ (when applicable), mean, and SD. Variables with an asterisk did not use a 1 (strongly disagree/disapprove) to 7 (strongly agree/approve) scale. Scales for these variables can be found in the Supplemental Appendix containing the full text of all items. 
Table 3. Model Fit for Four-Factor, Two Substantive Factor, Two Method Factor, and One-Factor Models of $16 \mathrm{Item}_{\mathrm{SDO}} \mathrm{Scale}$

\begin{tabular}{|c|c|c|c|c|c|c|c|}
\hline Sample & Model & RMSEA & $\chi^{2} / \mathrm{df}$ & CFI & \multicolumn{3}{|c|}{$\chi_{\text {difference }}^{2}$ test } \\
\hline & & & & & $\chi_{\text {difference }}^{2}$ & $d f$ & $p<$ \\
\hline \multirow[t]{4}{*}{ Sample 1} & One-factor & .11 & 6.46 & .97 & 446.36 & 18 & .001 \\
\hline & Two substantive & .08 & 4.08 & .98 & 223.40 & 17 & .001 \\
\hline & Two method & .10 & 5.32 & .90 & 339.12 & 17 & .001 \\
\hline & Four-factor & .06 & 2.43 & .97 & -- & -- & -- \\
\hline \multirow[t]{4}{*}{ Sample 2} & One-factor & .15 & 11.29 & .77 & 880.00 & 18 & .001 \\
\hline & Two substantive & .12 & 7.22 & .88 & 470.37 & 17 & .001 \\
\hline & Two method & .13 & 8.86 & .85 & 620.47 & 17 & .001 \\
\hline & Four-factor & .07 & 3.85 & .96 & -- & 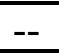 & -- \\
\hline \multirow[t]{4}{*}{ Sample 3} & One-factor & .15 & 10.93 & .81 & 841.48 & 18 & .001 \\
\hline & Two substantive & .12 & 7.43 & .88 & 475.96 & 17 & .001 \\
\hline & Two method & .13 & 8.89 & .85 & 620.47 & 17 & .001 \\
\hline & Four-factor & .07 & 3.43 & .96 & -- & -- & -- \\
\hline \multirow[t]{4}{*}{ Sample 4} & One-factor & .19 & 27.57 & .55 & 2661.93 & 18 & .001 \\
\hline & Two substantive & .16 & 20.81 & .67 & 1938.47 & 17 & .001 \\
\hline & Two method & .10 & 8.78 & .87 & 698.92 & 17 & .001 \\
\hline & Four-factor & .04 & 2.39 & .98 & -- & -- & -- \\
\hline \multirow[t]{4}{*}{ Sample 5a } & One-factor & .18 & 7.30 & .63 & 558.18 & 18 & .001 \\
\hline & Two substantive & .14 & 4.87 & .78 & 301.01 & 17 & .001 \\
\hline & Two method & .15 & 5.39 & .75 & 353.73 & 17 & .001 \\
\hline & Four-factor & .08 & 2.34 & .94 & -- & -- & -- \\
\hline \multirow[t]{4}{*}{ Sample 5b } & One-factor & .18 & 7.54 & .61 & 597.25 & 18 & .001 \\
\hline & Two substantive & .15 & 5.60 & .73 & 389.84 & 17 & .001 \\
\hline & Two method & .13 & 4.13 & .81 & 238.32 & 17 & .001 \\
\hline & Four-factor & .08 & 2.18 & .94 & -- & -- & -- \\
\hline \multirow[t]{4}{*}{ Sample 6} & One-factor & .16 & 11.57 & .77 & 1005.56 & 18 & .001 \\
\hline & Two substantive & .10 & 5.71 & .90 & 390.09 & 17 & .001 \\
\hline & Two method & .14 & 9.57 & .82 & 787.60 & 17 & .001 \\
\hline & Four-factor & .06 & 2.30 & .98 & -- & -- & -- \\
\hline
\end{tabular}


Table 4. Correlations between SDO-D, SDO-E, SDO7, SDO6, and criterion variables hypothesized to primarily relate to SDO-D.

\begin{tabular}{|c|c|c|c|c|c|c|}
\hline$\underline{\text { Sample } 1}$ & SDO-D & SDO-E & \multicolumn{2}{|c|}{ Part r Difference } & Correlations & Correlations \\
\hline SDO-D Criteria & & & $t$ & $p$ & $\begin{array}{l}\mathrm{R}_{\text {sdo6-sdo7 }}= \\
.95^{* * * *}\end{array}$ & \\
\hline Old-fashioned racism & $.38 * * *$ & -.04 & 6.02 & .00 & $.48^{* * *}$ & $.53 * * *$ \\
\hline Zero-sum competition & $.21 * * *$ & $.11 * *$ & 1.31 & .10 & $.46 * * *$ & $.49 * * *$ \\
\hline Nationalism & $.28 * * *$ & .04 & 3.29 & .00 & $.45 * * *$ & $.46^{* * *}$ \\
\hline $\begin{array}{l}\text { Support for immigrant } \\
\text { persecution }\end{array}$ & $.28 * * *$ & .05 & 3.25 & .00 & $.47 * * *$ & $.51 * * *$ \\
\hline War support & $.15 * * *$ & $.12 *$ & .49 & .32 & $.37 * * *$ & $.38 * * *$ \\
\hline War legitimacy beliefs & $.28 * * *$ & -.00 & 3.78 & .00 & $.39 * * *$ & $.41 * * *$ \\
\hline Death penalty support & $.18^{* * *}$ & .04 & 1.78 & .04 & $.31 * * *$ & $.30 * * *$ \\
\hline Punitiveness & $.23 * * *$ & .06 & 2.17 & .02 & $.41 * * *$ & $.39 * * *$ \\
\hline $\begin{array}{l}\text { Hierarchy-enhancing } \\
\text { jobs }\end{array}$ & $.20 * * *$ & $-.11 * *$ & 3.90 & .00 & $.12 * * *$ & $.12 * * *$ \\
\hline Sample 2 & $\begin{array}{l}\text { SDO-D } \\
\text { Part r } \\
\end{array}$ & $\begin{array}{l}\text { SDO-E } \\
\text { Part r } \\
\end{array}$ & \multicolumn{2}{|c|}{ Part r Difference } & $\begin{array}{l}\text { Correlations } \\
\text { with SDO7 } \\
\end{array}$ & $\begin{array}{l}\text { Correlations } \\
\text { with SDO6 }\end{array}$ \\
\hline SDO-D Criteria & & & $t$ & $p$ & $\begin{array}{l}\mathrm{R}_{\text {sdo6-sdo7 }}= \\
.92 * * *\end{array}$ & \\
\hline Old-fashioned racism & $.28 * * *$ & $.12 *$ & 2.17 & .02 & $.53 * * *$ & $.57 * * *$ \\
\hline Zero-sum competition & $.29 * * *$ & $.12 * *$ & 2.36 & .01 & $.54 * * *$ & $.56^{* * *}$ \\
\hline Nationalism & $.28 * * *$ & $.08+$ & 2.67 & .01 & $.48 * * *$ & $.50 * * *$ \\
\hline $\begin{array}{l}\text { Support for immigrant } \\
\text { persecution }\end{array}$ & $.26 * * *$ & $.11^{*}$ & 2.03 & .02 & $.51 * * *$ & $.52 * * *$ \\
\hline War support & $.22 * * *$ & .07 & 1.89 & .03 & $.38 * * *$ & $.40 * * *$ \\
\hline Militarism & $.17 * * *$ & $.20 * * *$ & -.44 & .67 & $.50 * * *$ & $.51 * * *$ \\
\hline Death penalty support & $.24 * * *$ & .07 & 2.22 & .02 & $.42 * * *$ & $.42 * * *$ \\
\hline Punitiveness & $.22 * * *$ & $.12 *$ & 1.24 & .11 & $.45 * * *$ & $.45 * * *$ \\
\hline $\begin{array}{l}\text { Hierarchy-enhancing } \\
\text { jobs }\end{array}$ & $.16^{* *}$ & .05 & 1.33 & .09 & $.29 * * *$ & $.30 * * *$ \\
\hline Sample 3 & $\begin{array}{l}\text { SDO-D } \\
\text { Part r }\end{array}$ & $\begin{array}{l}\text { SDO-E } \\
\text { Part r }\end{array}$ & \multicolumn{2}{|c|}{ Part r Difference } & $\begin{array}{l}\text { Correlations } \\
\text { with SDO7 }\end{array}$ & $\begin{array}{l}\text { Correlations } \\
\text { with SDO6 }\end{array}$ \\
\hline SDO-D Criteria & & & $t$ & $p$ & $\begin{array}{l}\mathrm{R}_{\text {sdo6-sdo7 }}= \\
.94\end{array}$ & \\
\hline Old-fashioned racism & $.31 * * *$ & .03 & 3.22 & .00 & $.53 * * *$ & $.59 * * *$ \\
\hline Zero-sum competition & $.24 * * *$ & .01 & 2.50 & .01 & $.39 * * *$ & $.46^{* * *}$ \\
\hline $\begin{array}{l}\text { Support for immigrant } \\
\text { persecution }\end{array}$ & $.30 * * *$ & .00 & 3.88 & .00 & $.44 * * *$ & $.48^{* * *}$ \\
\hline Militarism & $.28 * * *$ & .05 & 2.60 & .01 & $.52 * * *$ & $.53 * * *$ \\
\hline Death penalty support & $.14^{* *}$ & $.09+$ & .56 & .29 & $.36^{* * *}$ & $.37 * * *$ \\
\hline Punitiveness & $.23 * * *$ & .02 & 2.25 & .02 & $.39 * * *$ & $.41 * * *$ \\
\hline $\begin{array}{l}\text { Hierarchy-enhancing } \\
\text { jobs }\end{array}$ & $.16^{* *}$ & -.00 & 1.67 & .05 & $.25 * * *$ & $.28 * * *$ \\
\hline Fight Iran & $.21 * * *$ & -.02 & 2.38 & .01 & $.30 * * *$ & $.29 * * *$ \\
\hline Syria intervention & $.22 * * *$ & $-.11 *$ & 3.39 & .00 & $.17 * *$ & $.19 * * *$ \\
\hline Sample 4 & $\begin{array}{l}\text { SDO-D } \\
\text { Part r }\end{array}$ & $\begin{array}{l}\text { SDO-E } \\
\text { Part r } \\
\end{array}$ & \multicolumn{2}{|c|}{ Part r Difference } & $\begin{array}{l}\text { Correlations } \\
\text { with SDO7 } \\
\end{array}$ & $\begin{array}{l}\text { Correlations } \\
\text { with SDO6 }\end{array}$ \\
\hline SDO-D Criteria & & & $t$ & $p$ & $\mathrm{R}_{\text {sdo6-sdo7 }}=$ & \\
\hline
\end{tabular}




\begin{tabular}{|c|c|c|c|c|c|c|}
\hline & & & & & $.88 * * *$ & \\
\hline Old-fashioned racism & $.21 * * *$ & $.28 * * *$ & -1.22 & .89 & $.58 * * *$ & $.63 * * *$ \\
\hline Zero-sum competition & $.16^{* * *}$ & $.21 * * *$ & -.80 & .79 & $.45 * * *$ & $.46^{* * *}$ \\
\hline Nationalism & $.19 * * *$ & $.18^{* * *}$ & .04 & .49 & $.45 * * *$ & $.46^{* * *}$ \\
\hline $\begin{array}{l}\text { Support for immigrant } \\
\text { persecution }\end{array}$ & $.19 * * *$ & $.27 * * *$ & -1.32 & .91 & $.55 * * *$ & $.59 * * *$ \\
\hline Death penalty support & $.06+$ & .02 & .66 & .26 & $.09 *$ & $.07+$ \\
\hline Sample 5a & $\begin{array}{l}\text { SDO-D } \\
B \\
\end{array}$ & SDO-E $B$ & \multicolumn{2}{|c|}{ Part r Difference } & $\begin{array}{l}\text { Correlations } \\
\text { with SDO7 }\end{array}$ & $\begin{array}{l}\text { Correlations } \\
\text { with SDO6 }\end{array}$ \\
\hline SDO-D Criteria & & & $F$ & $p$ & & \\
\hline Old-fashioned racism & $.66^{* * *}$ & -.00 & 13.93 & .00 & $.48 * * *$ & -- \\
\hline Zero-sum competition & $.62 * * *$ & .09 & 10.07 & .00 & $.53 * * *$ & -- \\
\hline Punitiveness & $.32 * *$ & $.20^{*}$ & .31 & .29 & $.41 * * *$ & -- \\
\hline Torture & $.41 * * *$ & $.26 * *$ & .41 & .26 & $.51 * * *$ & -- \\
\hline Sample 5b & $\begin{array}{l}\text { SDO-D } \\
B\end{array}$ & SDO-E $B$ & \multicolumn{2}{|c|}{ Part r Difference } & $\begin{array}{l}\text { Correlations } \\
\text { with SDO7 }\end{array}$ & $\begin{array}{l}\text { Correlations } \\
\text { with SDO6 }\end{array}$ \\
\hline SDO-D Criteria & & & $F$ & $p$ & & \\
\hline Old-fashioned racism & $.36 * *$ & $.21+$ & .51 & .24 & $.43 * * *$ & -- \\
\hline Zero-sum competition & $.38 * *$ & -.00 & 2.11 & .07 & $.24 * *$ & -- \\
\hline Punitiveness & $.48 * * *$ & -.12 & 10.72 & .00 & $.28 * *$ & -- \\
\hline Torture & $.40 * * *$ & .06 & 2.87 & .05 & $.36 * * *$ & -- \\
\hline
\end{tabular}

Note. ${ }^{* * *} p<.001,{ }^{* *} p<.01, * p<.05,+p<.10$. The $\mathrm{p}$-values for the part-r difference t-test are onetailed, because of the apriori directional hypothesis concerning the relative predictive strength of SDO-D and - E. Complex samples procedures were used for Samples $5 \mathrm{a}$ and $5 \mathrm{~b}$ due to the effects of statistical weighting and stratified sampling by race (Black/White) on variance estimates. $B$-coefficients rather than part $r$ are used for these two samples because the part $r$ is not available in the SPSS Complex Samples GLM procedure; the two are interchangeable in principle. In addition, a Wald F test is used to compute the part correlation difference in the complex samples general linear model framework. 
Table 5. Correlations between SDO-D, SDO-E, SDO7, SDO6, and criterion variables hypothesized to primarily relate to SDO-E.

\begin{tabular}{|c|c|c|c|c|c|c|}
\hline Sample 1 & SDO-D & SDO-E & \multicolumn{2}{|c|}{ Part r Difference } & \multirow{2}{*}{$\begin{array}{l}\text { Correlations } \\
\text { with SDO7 } \\
\end{array}$} & \multirow{2}{*}{$\begin{array}{l}\text { Correlations } \\
\text { with SDO6 }\end{array}$} \\
\hline SDO-E Criteria & & & $t$ & $p$ & & \\
\hline Political conservatism & .01 & $.25 * * *$ & -3.10 & .00 & $.37 * * *$ & $.33 * * *$ \\
\hline System justification & $.14 * *$ & .03 & 1.36 & .92 & $.23 * * *$ & $.23 * * *$ \\
\hline $\begin{array}{l}\text { Opposition to } \\
\text { affirmative action }\end{array}$ & -.03 & $.21 * * *$ & -2.96 & .00 & $.26 * * *$ & $.23 * * *$ \\
\hline $\begin{array}{l}\text { Opposition to racial } \\
\text { policy }\end{array}$ & .05 & $.40 * * *$ & -5.64 & .00 & $.63 * * *$ & $.61 * * *$ \\
\hline Opposition to welfare & $.14 * * *$ & $.28 * * *$ & -2.31 & .01 & $.60 * * *$ & $.60 * * *$ \\
\hline Symbolic racism & $.18 * * *$ & $.18 * * *$ & -.08 & .47 & $.51 * * *$ & $.51 * * *$ \\
\hline $\begin{array}{l}\text { Unequal distribution } \\
\text { of university } \\
\text { resources }\end{array}$ & $.12 * * *$ & $.19 * * *$ & -.93 & .18 & $.43 * * *$ & $.43 * * *$ \\
\hline $\begin{array}{l}\text { Hierarchy-attenuating } \\
\text { jobs }\end{array}$ & $.07+$ & $.24 * * *$ & -2.30 & .01 & $.43 * * *$ & $.42 * * *$ \\
\hline Sample 2 & $\begin{array}{l}\text { SDO-D } \\
\text { Part r } \\
\end{array}$ & $\begin{array}{l}\text { SDO-E } \\
\text { Part r } \\
\end{array}$ & \multicolumn{2}{|c|}{ Part r Difference } & $\begin{array}{l}\text { Correlations } \\
\text { with SDO7 } \\
\end{array}$ & $\begin{array}{l}\text { Correlations } \\
\text { with SDO6 }\end{array}$ \\
\hline SDO-E Criteria & & & $T$ & $p$ & & \\
\hline Political conservatism & $.07+$ & $.23 * * *$ & -1.98 & .01 & $.40 * * *$ & $.39 * * *$ \\
\hline System justification & .07 & $.20 * * *$ & -1.59 & .06 & $.37 * * *$ & $.39 * * *$ \\
\hline $\begin{array}{l}\text { Opposition to } \\
\text { affirmative action }\end{array}$ & .01 & $.21 * * *$ & -2.69 & .01 & $.28 * * *$ & $.23 * * *$ \\
\hline Opposition to welfare & $.13^{* *}$ & $.30 * * *$ & -2.53 & .01 & $.59 * * *$ & $.57 * * *$ \\
\hline Symbolic racism & $.23 * * *$ & $.24 * * *$ & -.15 & .33 & $.63 * * *$ & $.62 * * *$ \\
\hline $\begin{array}{l}\text { Unequal distribution } \\
\text { of university } \\
\text { resources }\end{array}$ & $.05^{*}$ & $.28 * * *$ & -3.17 & .00 & $.45 * * *$ & $.44 * * *$ \\
\hline $\begin{array}{l}\text { Hierarchy-attenuating } \\
\text { jobs }\end{array}$ & $.08^{*}$ & $.17 * *$ & -1.10 & .14 & $.34 * * *$ & $.33 * * *$ \\
\hline Sample 3 & $\begin{array}{l}\text { SDO-D } \\
\text { Part r } \\
\end{array}$ & $\begin{array}{l}\text { SDO-E } \\
\text { Part r } \\
\end{array}$ & \multicolumn{2}{|c|}{ Part r Difference } & $\begin{array}{l}\text { Correlations } \\
\text { with SDO7 }\end{array}$ & $\begin{array}{l}\text { Correlations } \\
\text { with SDO6 }\end{array}$ \\
\hline SDO-E Criteria & & & $t$ & $p$ & & \\
\hline Political conservatism & $.06+$ & $.30 * * *$ & -3.29 & .00 & $.55 * * *$ & $.51 * * *$ \\
\hline System justification & $.10^{*}$ & $.13 * *$ & -.33 & .37 & $.34 * * *$ & $.30 * * *$ \\
\hline $\begin{array}{l}\text { Affirmative action- } \\
\text { race }\end{array}$ & .06 & $.14^{* *}$ & -.89 & .19 & $.31 * * *$ & $.30 * * *$ \\
\hline $\begin{array}{l}\text { Affirmative action- } \\
\text { gender }\end{array}$ & .00 & $.19 * * *$ & -2.01 & .02 & $.31 * * *$ & $.27 * * *$ \\
\hline Opposition to welfare & $.11 * *$ & $.35 * * *$ & -3.75 & .00 & $.69 * * *$ & $.64 * * *$ \\
\hline Symbolic racism & $.21 * * *$ & $.18 * * *$ & .45 & .67 & $.62 * * *$ & $.61 * * *$ \\
\hline $\begin{array}{l}\text { Unequal distribution } \\
\text { of university } \\
\text { resources }\end{array}$ & .03 & $.25 * * *$ & -2.50 & .01 & $.44 * * *$ & $.40 * * *$ \\
\hline $\begin{array}{l}\text { Hierarchy-attenuating } \\
\text { jobs }\end{array}$ & $.13^{*}$ & $.12^{*}$ & .10 & .54 & $.38 * * *$ & $.37 * * *$ \\
\hline
\end{tabular}




\begin{tabular}{|c|c|c|c|c|c|c|}
\hline $\begin{array}{l}\text { Anti-discrimination } \\
\text { measures }\end{array}$ & .06 & $.39 * * *$ & -4.82 & .00 & $.71 * * *$ & $.67 * * *$ \\
\hline $\begin{array}{l}\text { Redistribution of } \\
\text { wealth }\end{array}$ & .04 & $.41 * * *$ & -5.73 & .00 & $.67 * * *$ & $.61 * * *$ \\
\hline Sample 4 & $\begin{array}{l}\text { SDO-D } \\
\text { Part r }\end{array}$ & $\begin{array}{l}\text { SDO-E } \\
\text { Part } r\end{array}$ & \multicolumn{2}{|c|}{ Part r Difference } & $\begin{array}{l}\text { Correlations } \\
\text { with SDO7 }\end{array}$ & $\begin{array}{l}\text { Correlations } \\
\text { with SDO6 }\end{array}$ \\
\hline SDO-E Criteria & & & $t$ & $p$ & & \\
\hline Political conservatism & .05 & $.21 * * *$ & -2.69 & .00 & $.31 * * *$ & $.31 * * *$ \\
\hline System justification & $.09 *$ & $.20 * * *$ & -1.80 & .04 & $.33 * * *$ & $.35 * * *$ \\
\hline Symbolic racism & $.13 * * *$ & $.21 * * *$ & -1.42 & .08 & $.40 * * *$ & $.37 * * *$ \\
\hline $\begin{array}{l}\text { Opposition to racial } \\
\text { policy }\end{array}$ & $.08^{* *}$ & $.46^{* * *}$ & -7.64 & .00 & $.64 * * *$ & $.67 * * *$ \\
\hline $\begin{array}{l}\text { Unequal distribution } \\
\text { of university } \\
\text { resources }\end{array}$ & $.10 * *$ & $.19 * * *$ & -1.56 & .06 & $.35 * * *$ & $.33 * * *$ \\
\hline Sample 5a & $\begin{array}{l}\text { SDO-D } \\
\text { Part r }\end{array}$ & $\begin{array}{l}\text { SDO-E } \\
\text { Part } r\end{array}$ & \multicolumn{2}{|c|}{ Part r Difference } & $\begin{array}{l}\text { Correlations } \\
\text { with SDO7 }\end{array}$ & $\begin{array}{l}\text { Correlations } \\
\text { with SDO6 }\end{array}$ \\
\hline SDO-E Criteria & & & $F$ & $p$ & & \\
\hline Political conservatism & .01 & $.52 * * *$ & 7.72 & .00 & $.37 * * *$ & -- \\
\hline System justification & .13 & $.24 * *$ & .79 & .19 & $.37 * * *$ & -- \\
\hline $\begin{array}{l}\text { Opposition to racial } \\
\text { policy }\end{array}$ & $.26^{* *}$ & $.66^{* * *}$ & 11.87 & .00 & $.71 * * *$ & -- \\
\hline Anti-black affect & $.20 *$ & $.16+$ & 1.19 & .86 & $.31 * * *$ & -- \\
\hline Sample 5b & $\begin{array}{l}\text { SDO-D } \\
\text { Part r }\end{array}$ & $\begin{array}{l}\text { SDO-E } \\
\text { Part } r\end{array}$ & \multicolumn{2}{|c|}{ Part r Difference } & $\begin{array}{l}\text { Correlations } \\
\text { with SDO7 } \\
\end{array}$ & $\begin{array}{l}\text { Correlations } \\
\text { with SDO6 }\end{array}$ \\
\hline SDO-E Criteria & & & $F$ & $p$ & & \\
\hline Political conservatism & $.23 *$ & .08 & .01 & .53 & $.26^{* * *}$ & -- \\
\hline System justification & .07 & .06 & .09 & .61 & .12 & -- \\
\hline $\begin{array}{l}\text { Opposition to racial } \\
\text { policy }\end{array}$ & $.28 * *$ & $.52 * * *$ & 2.18 & .07 & $.66^{* * *}$ & -- \\
\hline
\end{tabular}

Note. ${ }^{* * *} p<.001,{ }^{* *} p<.01,{ }^{*} p<.05,+p<.10$. The $\mathrm{p}$-values for the part-R difference t-test are onetailed, because of the apriori directional hypothesis concerning the relative predictive strength of SDO-D and -E. Complex samples procedures were used for Samples $5 \mathrm{a}$ and $5 \mathrm{~b}$ due to the effects of statistical weighting and stratified sampling by race (Black/White) on variance estimates. $B$-coefficients rather than part $r$ are used for these two samples because the part $r$ is not available in the SPSS Complex Samples GLM procedure - the two are interchangeable in principle. In addition, a Wald F test is used to compute the part correlation difference in the complex samples general linear model framework. 


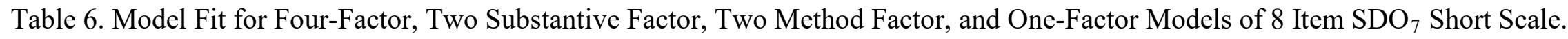

\begin{tabular}{|c|c|c|c|c|c|c|c|}
\hline \multirow[t]{2}{*}{ Sample } & \multirow[t]{2}{*}{ Model } & \multirow{2}{*}{ RMSEA } & \multirow{2}{*}{$\chi^{2} / \mathbf{d f}$} & \multirow[t]{2}{*}{ CFI } & \multicolumn{3}{|c|}{$\chi_{\text {difference }}^{2}$ test } \\
\hline & & & & & $\chi_{\text {difference }}^{2}$ & $d f$ & $p<$ \\
\hline \multirow[t]{4}{*}{ Sample 1} & One-factor & .11 & 6.32 & .93 & 112.05 & 10 & .001 \\
\hline & Two substantive factors ${ }^{1}$ & .07 & 3.60 & .97 & 54.11 & 9 & .001 \\
\hline & Two method factors ${ }^{2}$ & .10 & 5.96 & .94 & 98.96 & 9 & .001 \\
\hline & Four-factor ${ }^{3}$ & .03 & 1.43 & 1.00 & -- & -- & -- \\
\hline \multirow[t]{4}{*}{ Sample 2} & One-factor & .16 & 11.62 & .87 & 220.37 & 10 & .001 \\
\hline & Two substantive factors & .15 & 11.34 & .88 & 203.35 & 9 & .001 \\
\hline & Two method factors & .13 & 7.90 & .91 & 138.01 & 9 & .001 \\
\hline & Four-factor & .02 & 1.21 & 1.00 & -- & -- & -- \\
\hline \multirow[t]{4}{*}{ Sample 3} & One-factor & .14 & 9.81 & .91 & 189.82 & 10 & .001 \\
\hline & Two substantive factors & .13 & 8.69 & .93 & 158.87 & 9 & .001 \\
\hline & Two method factors & .12 & 7.50 & .94 & 136.28 & 9 & .001 \\
\hline & Four-factor & .00 & .00 & 1.00 & -- & -- & -- \\
\hline \multirow[t]{4}{*}{ Sample 4} & One-factor & .24 & 41.50 & .61 & 818.50 & 10 & .001 \\
\hline & Two substantive factors & .24 & 41.36 & .63 & 774.20 & 9 & .001 \\
\hline & Two method factors & .11 & 9.85 & .92 & 175.64 & 9 & .001 \\
\hline & Four-factor & .02 & 1.16 & 1.00 & -- & -- & -- \\
\hline \multirow[t]{4}{*}{ Sample 5a } & One-factor & .19 & 8.21 & .77 & 148.35 & 10 & .001 \\
\hline & Two substantive factors & .18 & 7.14 & .82 & 119.77 & 9 & .001 \\
\hline & Two method factors & .17 & 6.77 & .83 & 112.90 & 9 & .001 \\
\hline & Four-factor & .05 & 1.58 & .99 & -- & -- & -- \\
\hline \multirow[t]{4}{*}{ Sample 5b } & One-factor & .24 & 12.43 & .64 & 238.65 & 10 & .001 \\
\hline & Two substantive factors & .22 & 10.56 & .71 & 190.69 & 9 & .001 \\
\hline & Two method factors & .17 & 6.77 & .83 & 118.55 & 9 & .001 \\
\hline & Four-factor & .00 & 1.03 & 1.00 & -- & -- & -- \\
\hline \multirow[t]{4}{*}{ Sample 6} & One-factor & .16 & 12.05 & .87 & 230.06 & 10 & .001 \\
\hline & Two substantive factors & .11 & 6.39 & .94 & 110.43 & 9 & .001 \\
\hline & Two method factors & .16 & 11.64 & .88 & 210.24 & 9 & .001 \\
\hline & Four-factor & .02 & 1.10 & 1.00 & -- & -- & -- \\
\hline
\end{tabular}


Table 7. Correlations between short forms of SDO-D, SDO-E, SDO7 and criterion variables hypothesized to primarily relate to SDO-D.

\begin{tabular}{|c|c|c|c|c|c|}
\hline Sample 1 & \begin{tabular}{|l|} 
SDO-D \\
Part r \\
\end{tabular} & $\begin{array}{l}\text { SDO-E } \\
\text { Part r } \\
\end{array}$ & \multicolumn{2}{|c|}{ Part r Difference } & $\begin{array}{l}\text { Correlations } \\
\text { with SDO7 }_{(\mathrm{s})}\end{array}$ \\
\hline SDO-D Criteria & & & $t$ & $\bar{p}$ & $\begin{array}{l}\mathrm{R}_{\mathrm{SDO6}-\mathrm{SDO} 7(\mathrm{~s})} \\
=.92 * * *\end{array}$ \\
\hline Old-fashioned racism & $.38 * * *$ & -.02 & 5.62 & .00 & $.53 * * *$ \\
\hline Zero-sum competition & $.19 * * *$ & $.15 * * *$ & .57 & .29 & $.43 * * *$ \\
\hline Nationalism & $.30 * * *$ & .04 & 3.52 & .00 & \\
\hline Support for immigrant persecution & $.27 * * *$ & $.08 *$ & 2.63 & .01 & $.43 * * *$ \\
\hline War support & $.16^{* * *}$ & $.13 * *$ & .34 & .37 & $.37 * * *$ \\
\hline War legitimacy beliefs & $.30 * * *$ & .02 & 3.92 & .00 & $.39 * * *$ \\
\hline Death penalty support & $.18 * * *$ & .06 & 1.67 & .05 & $.30 * * *$ \\
\hline Punitiveness & $.23 * * *$ & $.09 *$ & 1.77 & .04 & $.39 * * *$ \\
\hline Hierarchy-enhancing jobs & $.17 * * *$ & $-.08+$ & 3.20 & .00 & $.11 *$ \\
\hline Sample 2 & \begin{tabular}{|l} 
SDO-D \\
Part $r$
\end{tabular} & $\begin{array}{l}\text { SDO-E } \\
\text { Part } r\end{array}$ & \multicolumn{2}{|c|}{ Part r Difference } & $\begin{array}{l}\text { Correlations } \\
\text { with SDO7 }_{(\mathrm{s})}\end{array}$ \\
\hline SDO-D Criteria & & & $t$ & $p$ & $\begin{array}{l}\mathrm{R}_{\mathrm{SDO6-SDO} 7(\mathrm{~s})} \\
=.90 * * *\end{array}$ \\
\hline Old-fashioned racism & $.27 * * *$ & $.11 * *$ & 2.20 & .01 & $.52 * * *$ \\
\hline Zero-sum competition & $.26 * * *$ & $.13 * *$ & 1.84 & .04 & $.53 * * *$ \\
\hline Nationalism & $.28 * * *$ & $.08+$ & 2.68 & .00 & $.47 * * *$ \\
\hline Support for immigrant persecution & $.22 * * *$ & $.15 * * *$ & .93 & .18 & $.50 * * *$ \\
\hline War support & $.19 * * *$ & $.09 *$ & 1.22 & .11 & $.38 * * *$ \\
\hline Militarism & $.17 * * *$ & $.19 * * *$ & -.26 & .60 & $.49 * * *$ \\
\hline Death penalty support & $.20 * * *$ & $.10 *$ & 1.26 & .10 & $.39 * * *$ \\
\hline Punitiveness & $.17 * * *$ & $.17 * * *$ & .00 & .50 & $.44 * * *$ \\
\hline Hierarchy-enhancing jobs & $.15^{* *}$ & .07 & .91 & .18 & $.29 * * *$ \\
\hline$\underline{\text { Sample } 3}$ & \begin{tabular}{|l} 
SDO-D \\
Part r \\
\end{tabular} & $\begin{array}{l}\text { SDO-E } \\
\text { Part } r \\
\end{array}$ & \multicolumn{2}{|c|}{ Part r Difference } & $\begin{array}{l}\text { Correlations } \\
\text { with SDO7 } \\
\text { (s) }\end{array}$ \\
\hline SDO-D Criteria & & & $t$ & $p$ & $\begin{array}{l}\mathrm{R}_{\mathrm{SDO} 6-\mathrm{SDO} 7(\mathrm{~s})} \\
=.92 * * *\end{array}$ \\
\hline Old-fashioned racism & $.32 * * *$ & .01 & 3.68 & .00 & $.50 * * *$ \\
\hline Zero-sum competition & $.26 * * *$ & -.02 & 3.03 & .00 & $.37 * * *$ \\
\hline Support for immigrant persecution & $.29 * * *$ & .00 & 3.71 & .00 & $.43 * * *$ \\
\hline Militarism & $.28 * * *$ & .06 & 2.62 & .01 & $.51 * * *$ \\
\hline Death penalty support & $.11^{*}$ & $.12 *$ & -.12 & .54 & $.36 * * *$ \\
\hline Punitiveness & $.22 * * *$ & .03 & 2.12 & .02 & $.38 * * *$ \\
\hline Hierarchy-enhancing jobs & $.14 * *$ & .01 & 1.28 & .10 & $.23 * * *$ \\
\hline Fight Iran & $.19 * * *$ & -.00 & 1.96 & .03 & $.27 * * *$ \\
\hline Syria intervention & $.20 * * *$ & $-.11 *$ & 3.06 & .00 & $.14 * *$ \\
\hline Sample 4 & \begin{tabular}{|l|} 
SDO-D \\
Part $r$ \\
\end{tabular} & $\begin{array}{l}\text { SDO-E } \\
\text { Part } r\end{array}$ & \multicolumn{2}{|c|}{ Part r Difference } & $\begin{array}{l}\text { Correlations } \\
\text { with SDO7 }_{(\mathrm{s})}\end{array}$ \\
\hline SDO-D Criteria & & & $t$ & $P$ & $\begin{array}{l}\mathrm{R}_{\text {sdo6-sdo7 }}= \\
.87 * * *\end{array}$ \\
\hline Old-fashioned racism & $.22 * * *$ & $.29 * * *$ & -1.16 & .87 & $.57 * * *$ \\
\hline Zero-sum competition & $.16^{* * *}$ & $.22 * * *$ & -1.05 & .85 & $.43 * * *$ \\
\hline Nationalism & $.20 * * *$ & $.20 * * *$ & .00 & .50 & $.44 * * *$ \\
\hline Support for immigrant persecution & $.20 * * *$ & $.28 * * *$ & -1.48 & .93 & $.54 * * *$ \\
\hline
\end{tabular}




\begin{tabular}{|c|c|c|c|c|c|}
\hline Death penalty support & $.07 *$ & .01 & 1.05 & .15 & $.09 * *$ \\
\hline Sample 5a & SDO-D $B$ & SDO-E $B$ & \multicolumn{2}{|c|}{ Part r Difference } & $\begin{array}{l}\text { Correlations } \\
\text { with SDO7 } \\
(\mathrm{s})\end{array}$ \\
\hline \multicolumn{6}{|l|}{ SDO-D Criteria } \\
\hline Old-fashioned racism & $.63 * * *$ & -.07 & 4.76 & .00 & $.46^{* * *}$ \\
\hline Zero-sum competition & $.60 * * *$ & .02 & 3.97 & .00 & $.51 * * *$ \\
\hline Punitiveness & $.24^{*}$ & $.23 *$ & .02 & .99 & $.40 * * *$ \\
\hline Torture & $.42 * * *$ & $.19+$ & 1.60 & .06 & $.49 * * *$ \\
\hline Sample 5b & SDO-D $B$ & SDO-E $B$ & \multicolumn{2}{|c|}{ Part r Difference } & $\begin{array}{l}\text { Correlations } \\
\text { with SDO7 }_{(\mathrm{s})}\end{array}$ \\
\hline \multicolumn{6}{|l|}{ SDO-D Criteria } \\
\hline Old-fashioned racism & $.37 * * *$ & .17 & 1.36 & .09 & $.42 * * *$ \\
\hline Zero-sum competition & $.24+$ & .03 & 1.09 & .14 & $.18^{*}$ \\
\hline Punitiveness & $.37 * *$ & -.03 & 2.74 & .00 & $.26^{* *}$ \\
\hline Torture & $.33^{* *}$ & .14 & 1.33 & .09 & $.38 * * *$ \\
\hline
\end{tabular}

Note. ${ }^{* * *} p<.001,{ }^{* *} p<.01,{ }^{*} p<.05,+p<.10$. The $\mathrm{p}$-values for the part-R difference t-test are onetailed, because of the apriori directional hypothesis concerning the relative predictive strength of SDO-D and -E. Complex samples procedures were used for Samples $5 \mathrm{a}$ and $5 \mathrm{~b}$ due to the effects of statistical weighting and stratified sampling by race (Black/White) on variance estimates. $B$-coefficients rather than part $r$ are used for these two samples because the part $r$ is not available in the SPSS Complex Samples GLM procedure - the two are interchangeable in principle. 
Table 8. Correlations between short forms of SDO-D, SDO-E, SDO7 and criterion variables hypothesized to primarily relate to SDO-E.

\begin{tabular}{|c|c|c|c|c|c|}
\hline Sample 1 & $\begin{array}{l}\text { SDO-D } \\
\text { Part r }\end{array}$ & $\begin{array}{l}\text { SDO-E } \\
\text { Part r }\end{array}$ & \multicolumn{2}{|c|}{ Part r Difference } & $\begin{array}{l}\text { Correlations } \\
\text { with } \mathrm{SDO}_{7(\mathrm{~S})}\end{array}$ \\
\hline SDO-E Criteria & & & $t$ & $p$ & \\
\hline Political conservatism & .07 & $.21 * * *$ & -1.92 & .03 & $.35 * * *$ \\
\hline System justification & $.18^{* * *}$ & $.00+$ & 2.31 & .99 & $.23 * * *$ \\
\hline Opposition to affirmative action & -.01 & $.21 * * *$ & -2.74 & .01 & $.25 * * *$ \\
\hline Opposition to racial policy & $.14 * * *$ & $.36^{* * *}$ & -3.61 & .00 & $.61 * * *$ \\
\hline Opposition to welfare & $.21 * * *$ & $.26 * * *$ & -.77 & .22 & $.59 * * *$ \\
\hline Symbolic racism & $.22 * * *$ & $.18^{* * *}$ & .59 & .72 & $.49 * * *$ \\
\hline $\begin{array}{l}\text { Unequal distribution of university } \\
\text { resources }\end{array}$ & $.15^{* * *}$ & $.19^{* * *}$ & -.41 & .34 & $.42 * * *$ \\
\hline Hierarchy-attenuating jobs & $.12 * *$ & $.23 * * *$ & -1.73 & .04 & $.43 * * *$ \\
\hline Sample 2 & $\begin{array}{l}\text { SDO-D } \\
\text { Part r }\end{array}$ & $\begin{array}{l}\text { SDO-E } \\
\text { Part r }\end{array}$ & \multicolumn{2}{|c|}{ Part r Difference } & $\begin{array}{l}\text { Correlations } \\
\text { with } \mathrm{SDO}_{7(\mathrm{~S})}\end{array}$ \\
\hline SDO-E Criteria & & & $t$ & $p$ & \\
\hline Political conservatism & $.06+$ & $.23 * * *$ & -2.22 & .02 & $.40 * * *$ \\
\hline System justification & $.08+$ & $.19 * * *$ & -1.46 & .07 & $.36 * * *$ \\
\hline Opposition to affirmative action & .01 & $.19 * * *$ & -2.14 & .02 & $.27 * * *$ \\
\hline Opposition to welfare & $.16^{* * *}$ & $.27 * * *$ & -1.52 & .07 & $.57 * * *$ \\
\hline Symbolic racism & $.21 * * *$ & $.25 * * *$ & -.62 & .27 & $.62 * * *$ \\
\hline $\begin{array}{l}\text { Unequal distribution of university } \\
\text { resources }\end{array}$ & $.05+$ & $.28 * * *$ & -3.02 & .00 & $.43 * * *$ \\
\hline Hierarchy-attenuating jobs & $.12 * *$ & $.13^{* *}$ & -.18 & .43 & $.33 * * *$ \\
\hline Sample 3 & $\begin{array}{l}\text { SDO-D } \\
\text { Part r }\end{array}$ & $\begin{array}{l}\text { SDO-E } \\
\text { Part r }\end{array}$ & \multicolumn{2}{|c|}{ Part r Difference } & $\begin{array}{l}\text { Correlations } \\
\text { with } \mathrm{SDO}_{7(\mathrm{~S})}\end{array}$ \\
\hline SDO-E Criteria & & & $t$ & $p$ & \\
\hline Political conservatism & $.07+$ & $.29 * * *$ & -2.99 & .00 & $.54 * * *$ \\
\hline System justification & $.11^{*}$ & $.12 * *$ & -.13 & .45 & $.34 * * *$ \\
\hline Affirmative action- race & .07 & $.14 * * *$ & -.78 & .22 & $.32 * * *$ \\
\hline Affirmative action- gender & .03 & $.18^{* * *}$ & -1.62 & .05 & $.32 * * *$ \\
\hline Opposition to welfare & $.12 * * *$ & $.35 * * *$ & -3.56 & .00 & $.69 * * *$ \\
\hline Symbolic racism & $.20 * * *$ & $.19 * * *$ & .11 & .54 & $.60 * * *$ \\
\hline $\begin{array}{l}\text { Unequal distribution of university } \\
\text { resources }\end{array}$ & .05 & $.25 * * *$ & -2.26 & .01 & $.45 * * *$ \\
\hline Hierarchy-attenuating jobs & $.14^{* *}$ & $.11^{*}$ & .30 & .62 & $.37 * * *$ \\
\hline Anti-discrimination measures & $.10 * *$ & $.36^{* * *}$ & -3.65 & .00 & $.70 * * *$ \\
\hline Redistribution of wealth & $.07 *$ & $.39 * * *$ & -5.01 & .00 & $.67 * * *$ \\
\hline Sample 4 & $\begin{array}{l}\text { SDO-D } \\
\text { Part r }\end{array}$ & $\begin{array}{l}\text { SDO-E } \\
\text { Part r } \\
\end{array}$ & \multicolumn{2}{|c|}{ Part r Difference } & $\begin{array}{l}\text { Correlations } \\
\text { with } \mathrm{SDO}_{7(\mathrm{~S})}\end{array}$ \\
\hline SDO-E Criteria & & & $t$ & $p$ & \\
\hline Political conservatism & $.08^{*}$ & $.21 * * *$ & -2.05 & .02 & $.32 * * *$ \\
\hline System justification & $.12 * * *$ & $.20 * * *$ & -1.34 & .09 & $.35 * * *$ \\
\hline Symbolic racism & $.16^{* * *}$ & $.20 * * *$ & -.56 & .29 & $.40 * * *$ \\
\hline Opposition to racial policy & $.15^{* * *}$ & $.42 * * *$ & -5.52 & .00 & $.64 * * *$ \\
\hline
\end{tabular}




\begin{tabular}{|c|c|c|c|c|c|}
\hline $\begin{array}{l}\text { Unequal distribution of university } \\
\text { resources }\end{array}$ & $.11 * *$ & $.20 * * *$ & -1.43 & .08 & $.35 * * *$ \\
\hline Sample 5a & SDO-D $B$ & $\begin{array}{l}\text { SDO-E } B \\
\mathrm{r}\end{array}$ & \multicolumn{2}{|c|}{ Part $r$ Difference } & $\begin{array}{l}\text { Correlations } \\
\text { with } \mathrm{SDO}_{7(\mathrm{~S})}\end{array}$ \\
\hline \multicolumn{6}{|l|}{ SDO-E Criteria } \\
\hline Political conservatism & -.08 & $.59 * * *$ & -3.64 & .00 & $.37 * * *$ \\
\hline System justification & $.17 *$ & $.17^{*}$ & -.02 & .49 & $.36 * * *$ \\
\hline Opposition to racial policy & $.22 *$ & $.67 * * *$ & -3.82 & .00 & $.72 * * *$ \\
\hline Anti-black affect & $.27 * *$ & .08 & 1.33 & .91 & $.33 * * *$ \\
\hline$\underline{\text { Sample 5b }}$ & SDO-D $B$ & SDO-E $B$ & \multicolumn{2}{|c|}{ Part r Difference } & $\begin{array}{l}\text { Correlations } \\
\text { with } \mathrm{SDO}_{7(\mathrm{~S})}\end{array}$ \\
\hline \multicolumn{6}{|l|}{ SDO-E Criteria } \\
\hline Political conservatism & .12 & .14 & -.12 & .45 & $.23 * *$ \\
\hline System justification & .10 & .06 & .33 & .63 & $.15+$ \\
\hline Opposition to racial policy & $.25 * *$ & $.51 * * *$ & -2.43 & .02 & $.64 * * *$ \\
\hline
\end{tabular}

Note. ${ }^{* *} p<.001,{ }^{* *} p<.01,{ }^{*} p<.05,+p<.10$. The $\mathrm{p}$-values for the part-R difference t-test are onetailed, because of the apriori directional hypothesis concerning the relative predictive strength of SDO-D and-E. Complex samples procedures were used for Samples $5 \mathrm{a}$ and $5 \mathrm{~b}$ due to the effects of statistical weighting and stratified sampling by race (Black/White) on variance estimates. $B$-coefficients rather than part $r$ are used for these two samples because the part $r$ is not available in the SPSS Complex Samples GLM procedure - the two are interchangeable in principle. 
Table 9. Correlations between SDO and Personality and Individual Differences

\begin{tabular}{|c|c|c|c|c|c|c|c|c|}
\hline$\underline{\text { Sample } 5}$ & $\mathrm{R}_{\mathrm{SDO7-Criterion}}$ & SDO-D Part r & SDO-E Part r & \multicolumn{2}{|c|}{ Part r Difference } & $\alpha$ & Mean & $S D$ \\
\hline \multicolumn{9}{|l|}{ Sample 5a: Whites } \\
\hline Machiavellianism & $.34 * * *$ & $.51 * * *$ & -.13 & 5.05 & .00 & .66 & 2.84 & 1.13 \\
\hline Moral Foundations: Purity & $.18^{*}$ & $.22 *$ & -.00 & 1.44 & .15 & .83 & 3.90 & 1.20 \\
\hline \multicolumn{9}{|l|}{ Sample 5b: Blacks } \\
\hline Machiavellianism & $.40 * * *$ & .13 & $.40^{* *}$ & -1.72 & .09 & .75 & 2.96 & 1.40 \\
\hline$\underline{\text { Sample } 6}$ & $\mathrm{R}_{\mathrm{SDO7-Criterion}}$ & SDO-D Part $r$ & SDO-E Part r & \multicolumn{2}{|c|}{ Part r Difference } & $\alpha$ & Mean & $S D$ \\
\hline \multicolumn{9}{|l|}{ Big 5} \\
\hline Neuroticism & .02 & $.10^{*}$ & $\begin{array}{l}-.08+ \\
\end{array}$ & 1.99 & .05 & .93 & 2.71 & .79 \\
\hline Agreeableness & $-.38^{* * * *}$ & $-.14 * *$ & $-.14 * *$ & -.06 & .95 & .89 & 3.91 & .58 \\
\hline Conscientiousness & $-.10^{*}$ & -.06 & -.02 & -.37 & .71 & .87 & 3.69 & .50 \\
\hline Extraversion & .01 & .00 & .01 & -.11 & .91 & .89 & 4.21 & 1.09 \\
\hline Agreeableness & $-.11 *$ & .04 & $-.12 *$ & 1.77 & .08 & .87 & 4.07 & .98 \\
\hline Conscientiousness & $-.09 *$ & -.06 & -.01 & $\begin{array}{l}-60 \\
\end{array}$ & .55 & .85 & 5.01 & .89 \\
\hline Openness to Experience & $-.29^{* * *}$ & $-.14 * *$ & $\begin{array}{l}-.07 \\
\end{array}$ & -.89 & .37 & .88 & 4.91 & 1.10 \\
\hline Altruism & $-.38^{* * *}$ & $-.16^{* * *}$ & $-.13^{* *}$ & -.43 & .67 & .72 & 5.47 & 1.16 \\
\hline \multicolumn{9}{|l|}{ Dark Triad } \\
\hline Machiavellianism & $.30^{* * *}$ & $.18 * * *$ & .04 & 1.73 & .08 & .85 & 3.78 & 1.14 \\
\hline Narcissism & $.27 * * *$ & $.14^{* *}$ & .07 & .80 & .43 & .78 & 3.26 & 1.07 \\
\hline Psychopathy & $.27 * * *$ & $.23 * * *$ & -.02 & 2.95 & .00 & .81 & 2.50 & 1.09 \\
\hline Empathic Concern & $-.35^{* * *}$ & $-.12 * *$ & $-.14 * *$ & .27 & .80 & .90 & 3.94 & .86 \\
\hline \multicolumn{9}{|l|}{ Dual-Process Model } \\
\hline Social conformity & $.17 * * *$ & -.02 & $.14^{* *}$ & -1.91 & .06 & .89 & 4.30 & 1.08 \\
\hline Tough-mindedness & $.31 * * *$ & $.11^{*}$ & $.14^{* *}$ & -.48 & .63 & .95 & 2.49 & 1.09 \\
\hline
\end{tabular}




\begin{tabular}{|c|c|c|c|c|c|c|c|c|}
\hline Dangerous world view & $.26 * * *$ & $.15^{* *}$ & .04 & -1.32 & .19 & .89 & 3.83 & 1.25 \\
\hline Competitive jungle world view & $.48 * * *$ & $.26 * * *$ & $.10^{*}$ & 2.05 & .04 & .93 & 2.51 & 1.01 \\
\hline Need for Closure & $.12 *$ & .02 & .07 & -.49 & .63 & .89 & 4.42 & .68 \\
\hline Order & .08 & .07 & -.01 & .94 & .35 & .87 & 4.80 & 1.13 \\
\hline Predictability & .07 & .01 & .05 & -.48 & .63 & .85 & 4.62 & 1.16 \\
\hline Decisiveness & -.04 & $-.10^{*}$ & .07 & -1.88 & .06 & .83 & 4.48 & 1.20 \\
\hline Ambiguity & .06 & .03 & .02 & .08 & .93 & .79 & 4.64 & .97 \\
\hline Close-mindedness & $.23 * * *$ & .06 & $.12^{*}$ & -.73 & .47 & .69 & 3.46 & .87 \\
\hline \multicolumn{9}{|l|}{ Moral Foundations } \\
\hline Harm & $-.43 * * *$ & -.03 & $-.29 * * *$ & 3.38 & .00 & .69 & 5.67 & 1.18 \\
\hline Fairness & $-.52 * * *$ & -.05 & $-.34 * * *$ & 3.86 & .00 & .66 & 5.48 & 1.07 \\
\hline Ingroup & $.17 * * *$ & $.09 *$ & .03 & .75 & .45 & .73 & 4.28 & 1.26 \\
\hline Authority & $.21 * * *$ & $.11^{*}$ & .05 & .75 & .45 & .74 & 4.48 & 1.29 \\
\hline Purity & $.26 * * *$ & .07 & $.13 * *$ & -.76 & .44 & .85 & 4.00 & 1.71 \\
\hline
\end{tabular}

Note. ${ }^{* * *} p<.001,{ }^{* *} p<.01,{ }^{*} p<.05,+p<.10$. 
Table 10a. SDO Descriptive Statistics, Reliability, and Gender Difference

\begin{tabular}{|c|c|c|c|c|c|c|c|c|c|}
\hline Sample 1 & $\mathbf{M}$ & SD & $\alpha$ & $\mathbf{M}_{\text {Male }}$ & $S D_{\text {Male }}$ & $\mathbf{M}_{\text {Female }}$ & $S D_{\text {Female }}$ & \multicolumn{2}{|c|}{ Sex Difference $(t$ and $p)$} \\
\hline Full $\mathrm{SDO}_{7}$ & 2.88 & 1.19 & .93 & 3.19 & 1.23 & 2.67 & 1.11 & 4.97 & .00 \\
\hline SDO-D & 2.83 & 1.24 & .88 & 3.17 & 1.29 & 2.60 & 1.15 & 5.17 & .00 \\
\hline SDO-E & 2.94 & 1.30 & .90 & 3.21 & 1.34 & 2.75 & 1.24 & 4.00 & .00 \\
\hline $\mathrm{SDO}_{7-\text { Short }}$ & 2.90 & 1.22 & .87 & 3.22 & 1.27 & 2.69 & 1.13 & 4.99 & .00 \\
\hline SDO-D Short & 2.83 & 1.36 & .80 & 3.20 & 1.46 & 2.58 & 1.23 & 5.00 & .00 \\
\hline SDO- $E_{\text {Short }}$ & 2.98 & 1.30 & .80 & 3.25 & 1.36 & 2.79 & 1.23 & 3.97 & .00 \\
\hline Sample 2 & $\mathbf{M}$ & SD & $\alpha$ & $\mathbf{M}_{\text {Male }}$ & $S D_{\text {Male }}$ & $\mathbf{M}_{\text {Female }}$ & $S D_{\text {Female }}$ & \multicolumn{2}{|c|}{ Sex Difference ( $t$ and $p$ ) } \\
\hline 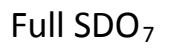 & 2.55 & 1.19 & .94 & 2.73 & 1.21 & 2.39 & 1.15 & 3.10 & .00 \\
\hline SDO-D & 2.48 & 1.24 & .89 & 2.65 & 1.26 & 2.32 & 1.20 & 2.93 & .00 \\
\hline SDO-E & 2.63 & 1.32 & .91 & 2.80 & 1.33 & 2.46 & 1.29 & 2.83 & .00 \\
\hline $\mathrm{SDO}_{7 \text {-Short }}$ & 2.60 & 1.23 & .88 & 2.78 & $\mid 1.27$ & 2.43 & 1.17 & 3.15 & .00 \\
\hline SDO- $D_{\text {Short }}$ & 2.53 & 1.35 & .79 & 2.74 & 1.40 & 2.34 & 1.27 & 3.29 & .00 \\
\hline SDO- $E_{\text {Short }}$ & 2.66 & 1.31 & .80 & 2.81 & 1.32 & 2.51 & 1.27 & 2.53 & .01 \\
\hline Sample 3 & $\mathbf{M}$ & SD & $\alpha$ & $\mathbf{M}_{\text {Male }}$ & $S D_{\text {Male }}$ & $\mathbf{M}_{\text {Female }}$ & $S D_{\text {Female }}$ & \multicolumn{2}{|c|}{ Sex Difference ( $t$ and $p$ ) } \\
\hline Full SDO $_{7}$ & 2.56 & 1.28 & .95 & 2.75 & 1.32 & 2.43 & 1.24 & 2.61 & .00 \\
\hline SDO-D & 2.49 & 1.30 & .90 & 2.68 & 1.32 & 2.36 & 1.26 & 2.53 & .01 \\
\hline SDO-E & 2.63 & 1.43 & .93 & 2.82 & 1.45 & 2.49 & 1.41 & 2.37 & .01 \\
\hline
\end{tabular}




\begin{tabular}{|c|c|c|c|c|c|c|c|c|c|}
\hline $\mathrm{SDO}_{7-\text { Short }}$ & 2.59 & 1.32 & .90 & 2.78 & 1.36 & 2.45 & 1.29 & 2.59 & .01 \\
\hline SDO-D Short $_{1}$ & 2.54 & 1.36 & .80 & 2.74 & 1.36 & 2.41 & 1.34 & 2.59 & .01 \\
\hline SDO-E $\mathrm{E}_{\text {Short }}$ & 2.63 & 1.46 & .86 & 2.81 & 1.49 & 2.50 & 1.43 & 2.24 & .01 \\
\hline Sample 4 & M & SD & $\alpha$ & $\mathbf{M}_{\text {Male }}$ & $S D_{\text {Male }}$ & $M_{\text {Female }}$ & $S D_{\text {Female }}$ & \multicolumn{2}{|c|}{ Sex Difference ( $t$ and $p)$} \\
\hline Full $\mathrm{SDO}_{7}$ & 2.46 & 1.09 & .89 & 2.56 & 1.10 & 2.32 & 1.06 & 3.09 & .00 \\
\hline SDO-D & 2.52 & 1.18 & .83 & 2.63 & 1.18 & 2.38 & 1.18 & 3.05 & .00 \\
\hline SDO-E & 2.38 & 1.21 & .82 & 2.47 & 1.25 & 2.25 & 1.15 & 2.64 & .00 \\
\hline $\mathrm{SDO}_{7-\text { Short }}$ & 2.40 & 1.12 & .78 & 2.50 & 1.15 & 2.26 & 1.08 & 3.05 & .00 \\
\hline SDO- $D_{\text {Short }}$ & 2.42 & 1.24 & .59 & 2.54 & 1.24 & 2.26 & 1.22 & 3.12 & .00 \\
\hline SDO-E $E_{\text {Short }}$ & 2.37 & 1.27 & .68 & 2.46 & 1.31 & 2.24 & 1.21 & 2.40 & .01 \\
\hline Sample 5 & $M$ & SD & $\alpha$ & $\mathbf{M}_{\text {Male }}$ & $S D_{\text {Male }}$ & $M_{\text {Female }}$ & $S D_{\text {Female }}$ & \multicolumn{2}{|c|}{ Sex Difference ( $t$ and $p)$} \\
\hline Full $\mathrm{SDO}_{7}$ & 2.95 & 1.17 & .89 & 3.17 & 1.17 & 2.74 & 1.14 & 2.59 & .01 \\
\hline SDO-D & 2.74 & 1.23 & .82 & 2.96 & 1.22 & 2.53 & 1.22 & 2.04 & .04 \\
\hline SDO-E & 3.16 & 1.35 & .86 & 3.38 & 1.37 & 2.95 & 1.30 & 2.56 & .01 \\
\hline $\mathrm{SDO}_{7 \text {-Short }}$ & 2.91 & 1.23 & .81 & 3.12 & 1.24 & 2.72 & 1.21 & 2.60 & .01 \\
\hline SDO-D $D_{\text {Short }}$ & 2.67 & 1.31 & .72 & 2.90 & 1.30 & 2.45 & 1.29 & 2.52 & .01 \\
\hline SDO-E Short & 3.15 & 1.40 & .75 & 3.33 & 1.43 & 3.00 & 1.36 & 2.13 & .03 \\
\hline Sample 6 & $\mathbf{M}$ & SD & $\alpha$ & $\mathbf{M}_{\text {Male }}$ & $S D_{\text {Male }}$ & $M_{\text {Female }}$ & $S D_{\text {Female }}$ & \multicolumn{2}{|c|}{ Sex Difference ( $t$ and $p)$} \\
\hline Full SDO $_{7}$ & 2.51 & 1.24 & .94 & 2.79 & 1.30 & 2.34 & 1.17 & 3.63 & .00 \\
\hline
\end{tabular}




\begin{tabular}{|l|l|l|l|l|l|l|l|l|l|}
\hline SDO-D & 2.42 & 1.25 & .88 & 2.66 & 1.29 & 2.29 & 1.20 & 3.08 & .00 \\
\hline SDO-E & 2.59 & 1.42 & .92 & 2.92 & 1.52 & 2.40 & 1.33 & 3.66 & .00 \\
\hline SDO $_{7-\text { Short }}$ & 2.46 & 1.25 & .88 & 2.69 & 1.30 & 2.32 & 1.19 & 2.98 & .00 \\
\hline SDO-D $_{\text {Short }}$ & 2.35 & 1.28 & .76 & 2.54 & 1.33 & 2.24 & 1.24 & 2.38 & .01 \\
\hline SDO-E & 2.56 & 1.45 & .86 & 2.85 & 1.55 & 2.40 & 1.36 & 3.07 & .00 \\
\hline
\end{tabular}

Notes. Test of gender difference is one-tailed due to apriori hypothesis that men have higher levels of SDO than women (i.e., the "invariance hypothesis"; Lee et al., 2011; Sidanius and Pratto, 1999). The descriptive statistics reported for Sample 5 as a whole are from the half of the sample that completed the $\mathrm{SDO}_{7}$ measure before any other measure. This sample consists of both Blacks and Whites, whereas Samples 1-3 and 6 are composed of Whites alone, and Sample 4 has Blacks alone. Table 10b below breaks Sample 5 down by Blacks and Whites to enable comparisons with the other homogenous samples. 
Table 10b. Descriptive Statistics by Race in Sample 5

\begin{tabular}{|c|c|c|c|c|c|c|c|}
\hline & $\mathrm{M}_{\text {White }}$ & $\mathrm{SD}_{\text {White }}$ & $\alpha_{\text {White }}$ & $\mathrm{M}_{\text {Black }}$ & $\mathrm{SD}_{\text {Black }}$ & $\alpha_{\text {Black }}$ & Race Difference \\
\hline Full $\mathrm{SDO}_{7}$ & 2.98 & 1.19 & .91 & 2.74 & 1.00 & .88 & $\begin{array}{l}t=-1.67 \\
p=.05\end{array}$ \\
\hline SDO-D & 2.71 & 1.25 & .86 & 2.89 & 1.10 & .80 & $\begin{array}{l}t=.89 \\
p=.82\end{array}$ \\
\hline SDO-E & 3.25 & 1.35 & .87 & 2.56 & 1.19 & .85 & $\begin{array}{l}t=-3.88 \\
p=.00\end{array}$ \\
\hline $\mathrm{SDO}_{7-\text { Short }}$ & 2.97 & 1.25 & .86 & 2.56 & 1.04 & .79 & $\begin{array}{l}t=-2.39 \\
p=.01\end{array}$ \\
\hline SDO-D $D_{\text {Short }}$ & 2.67 & 1.34 & .82 & 2.64 & 1.11 & .67 & $\begin{array}{l}t=-.19 \\
p=.43\end{array}$ \\
\hline SDO-E $E_{\text {Short }}$ & 3.26 & 1.40 & .76 & 2.45 & 1.24 & .75 & $\begin{array}{l}t=-4.17 \\
p=.00\end{array}$ \\
\hline
\end{tabular}

Note. Test of race difference is one-tailed due to apriori hypothesis that members of higher status groups (Whites here) have higher levels of SDO than members of lower status groups (Blacks here; Sidanius and Pratto, 1999). 
Figure 1. Four-factor Confirmatory Factor Analysis Model with Each Item Loading on One Substantive (SDO-D or SDO-E) and One Method Dimension (Pro-trait or Con-trait)

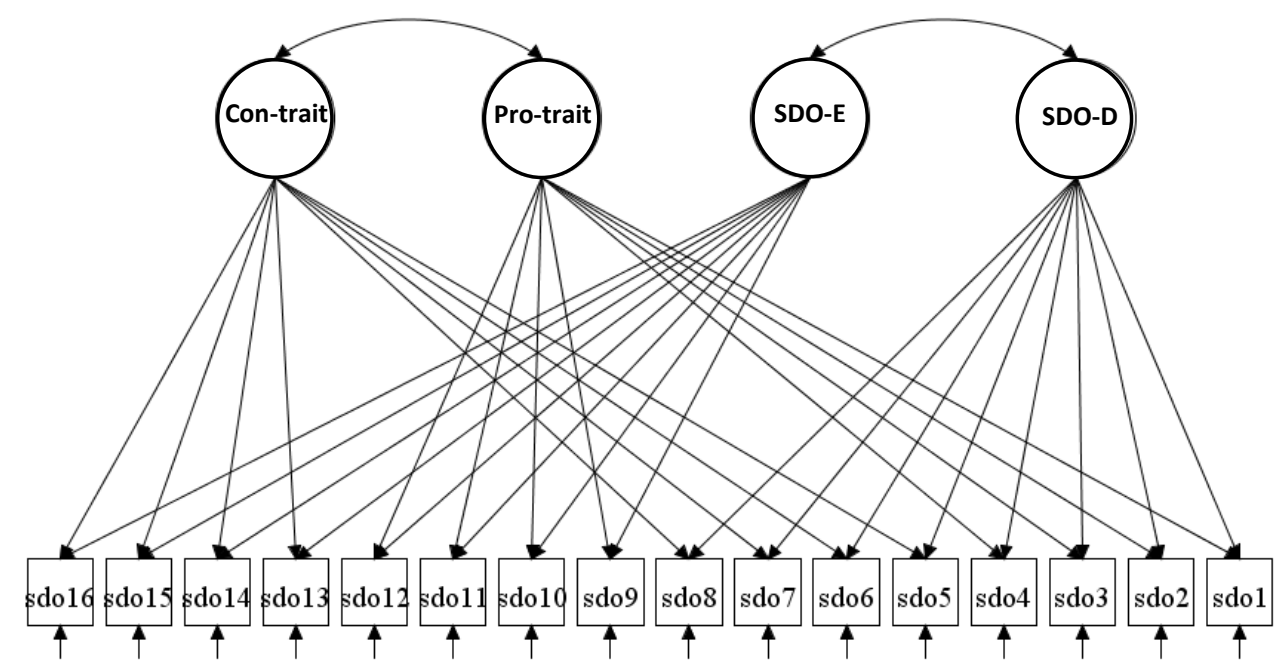


Figure 2. Four-factor Confirmatory Factor Analysis Model with Each Item Loading on One Substantive (SDO-D or SDO-E) and One Method Dimension (Pro-trait or Con-trait)

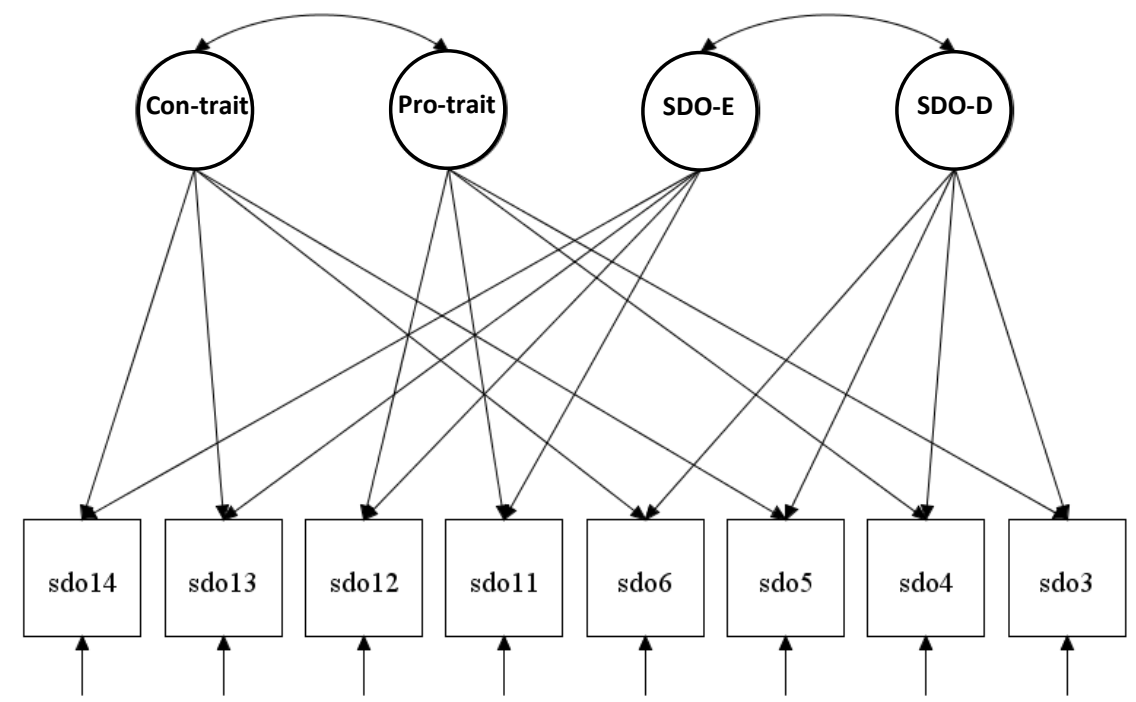

Note. Item numbers are taken from the full $\mathrm{SDO}_{7} \mathrm{scale}$ 


\section{Supplemental Online Material}

As noted in text, seven out of the eight items in the SDO-E scale use a plural personal pronoun, such as "we" or "our". This was unintentional - these items were derived from a factor analysis we performed on Sample 1, described in text. However, one concern is that the plural personal pronoun may activate ingroup collective norms, and thereby strengthen the relationship between SDO-E and collective ideologies, such as the Protestant Work Ethic (Katz \& Hass, 1988). Alternatively, "we" may represent a generic term referring to all people as opposed to a specific group. In addition to the several findings that would support this latter interpretation, described in the discussion section in text, we ran an additional experiment to directly test whether the use of a plural personal pronoun influences the relationship between SDO-E and its criterion variables. We recruited 201 Americans on Amazon MTurk $\left(55.5 \%\right.$ male; $M_{\text {age }}=34.95, \mathrm{SD}_{\text {age }}=$ 11.46; 155 Caucasian/White, 20 Asian/Asian American/Pacific Islander; 10 African

American/Black; 8 Latino/Hispanic, 3 Middle Eastern; 3 Biracial/mixed race, and 2 "other"). In this study, we randomly assigned participants to receive the SDO-E subscale presented in Appendix 1, or a modified scale with "people" replacing "we":

Pro-trait anti-egalitarianism:

1. People should not push for group equality.

2. People shouldn't try to guarantee that every group has the same quality of life.

3. It is unjust to try to make groups equal.

4. Group equality should not be a primary goal.

Con-trait anti-egalitarianism:

5. People should work to give all groups an equal chance to succeed.

6. People should do what they can to equalize conditions for different groups.

7. No matter how much effort it takes, people ought to strive to ensure that all groups have the same chance in life.

8. Group equality should be the ideal.

Participants then received the eight SDO-E criterion measures used most across the six samples examining criterion validity in text: 1) political conservatism, 2) system justification, 3) opposition to affirmative action, 4) opposition to racial policy, 5) opposition to welfare, 6) symbolic racism, 7) unequal distribution of university resources, and 8) hierarchy attenuating jobs (Table 2B; Appendix 2). Additionally, we added a measure of Protestant Work Ethic endorsement, because it appeals directly to American collective norms like individualism and meritocracy (Katz and Hass, 1988).

First, we found that the $\mathrm{SDO}_{7}$-E scale presented in text was significantly related to all nine criterion variables $(r=.21$ to .69$)$. More importantly, the wording did not make a differencei.e., the version of the SDO-E scale did not significantly moderate its relationship with any criterion variables. With affirmative action, the SDO-E x scale version interaction was marginally significant $(\mathrm{p}=.07)$, and all other interaction $\mathrm{p}$-values were .19 or higher. This suggests that the plural personal pronoun does not influence SDO-E's relationship with criterion variables, and that the scale reported in text operates similarly as a version that refers to "people" in general instead of the plural personal pronoun. 
Supplemental Table 1. Correlations between Variables in Sample 1 (Listwise $\mathrm{N}=516$ ).

\begin{tabular}{|c|c|c|c|c|c|c|c|c|c|c|}
\hline Variable & 1 & 2 & 3 & 4 & 5 & 6 & 7 & 8 & 9 & 10 \\
\hline 1. $\mathrm{SDO}_{7}$ & - & & & & & & & & & \\
\hline 2. SDO-D & $.93^{* * *}$ & - & & & & & & & & \\
\hline 3. SDO-E & $.94 * * *$ & $.76^{* * *}$ & - & & & & & & & \\
\hline 4. Old-fashioned racism & $.48 * * *$ & $.52 * * *$ & $.38 * * *$ & - & & & & & & \\
\hline 5. Zero-sum competition & $.45^{* * *}$ & $.44 * * *$ & $.41 * * *$ & $.49 * * *$ & - & & & & & \\
\hline 6. Nationalism & $.45^{* * *}$ & $.46^{* * *}$ & $.38 * * *$ & $.48 * * *$ & $.38 * * *$ & - & & & & \\
\hline $\begin{array}{l}\text { 7. Support for immigrant } \\
\text { persecution }\end{array}$ & $.47 * * *$ & $.48^{* * *}$ & $.40 * * *$ & $.69 * * *$ & $.46^{* * *}$ & $.45^{* * *}$ & - & & & \\
\hline 8. War support & $.38 * * *$ & $.36^{* * *}$ & $.35^{* * *}$ & $.32 * * *$ & $.29 * * *$ & $.70 * * *$ & $.37 * * *$ & - & & \\
\hline 9. War legitimacy beliefs & $.39 * * *$ & $.42 * * *$ & $.32 * * *$ & $.48 * * *$ & $.41^{* * *}$ & $.49 * * *$ & $.44 * * *$ & $.45^{* * *}$ & - & \\
\hline 10. Death penalty support & $.32 * * *$ & $.33 * * *$ & $.28 * * *$ & $.19 * * *$ & $.25 * * *$ & $.37 * * *$ & $.27 * * *$ & $.36^{* * *}$ & $.33^{* * *}$ & 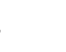 \\
\hline
\end{tabular}




\begin{tabular}{|c|c|c|c|c|c|c|c|c|c|c|}
\hline Variable & 11 & 12 & 13 & 14 & 15 & 16 & 17 & 18 & 19 & 20 \\
\hline 1. $\mathrm{SDO}_{7}$ & $.41 * * *$ & $.12 * *$ & $.37 * * *$ & $.23 * * *$ & $.26 * * *$ & $.63 * * *$ & $.60 * * *$ & $.51 * * *$ & $.43 * * *$ & $.43 * * *$ \\
\hline 2. SDO-D & $.41 * * *$ & $.17 * * *$ & $.30 * * *$ & $.24 * * *$ & $.20 * * *$ & $.53 * * *$ & $.53 * * *$ & $.48 * * *$ & $.39 * * *$ & $.37 * * *$ \\
\hline 3. SDO-E & $.36^{* * *}$ & .06 & $.39 * * *$ & $.20 * * *$ & $.28 * * *$ & $.65 * * *$ & $.58 * * *$ & $.48 * * *$ & $.42 * * *$ & $.44 * * *$ \\
\hline 4. Old-fashioned racism & $.37 * * *$ & $.14^{* *}$ & $.29 * * *$ & $.17 * * *$ & .02 & $.32 * * *$ & $.36 * * *$ & $.44 * * *$ & $.25 * * *$ & $.20 * * *$ \\
\hline 5. Zero-sum competition & $.33 * * *$ & $.14^{* *}$ & $.36^{* * *}$ & $.11 *$ & $.23 * * *$ & $.43 * * *$ & $.33 * * *$ & $.52 * * *$ & $.25 * * *$ & $.25 * * *$ \\
\hline 6. Nationalism & $.55 * * *$ & $.37 * * *$ & $.14 * *$ & $.49 * * *$ & $.10^{*}$ & $.33 * * *$ & $.39 * * *$ & $.47 * * *$ & $.29 * * *$ & $.16^{* * *}$ \\
\hline $\begin{array}{l}\text { 7. Support for immigrant } \\
\text { persecution }\end{array}$ & $.45 * * *$ & $.17 * * *$ & $.20 * * *$ & $.13 * *$ & .03 & $.34 * * *$ & $.42 * * *$ & $.44 * * *$ & $.30 * * *$ & $.25 * * *$ \\
\hline 8. War support & $.48 * * *$ & $.32 * * *$ & $.52 * * *$ & $.44 * * *$ & $.12 * *$ & $.27 * * *$ & $.36 * * *$ & $.38 * * *$ & $.25 * * *$ & $.19 * * *$ \\
\hline 9. War legitimacy beliefs & $.45 * * *$ & $.24 * * *$ & $.36 * * *$ & $.19 * * *$ & $.19 * * *$ & $.35 * * *$ & $.38 * * *$ & $.54 * * *$ & $.27 * * *$ & $.29 * * *$ \\
\hline 10. Death penalty support & $.50 * * *$ & $.27 * * *$ & $.38 * * *$ & $.18 * * *$ & $.27 * * *$ & $.29 * * *$ & $.31 * * *$ & $.45^{* * *}$ & $.23 * * *$ & $.30 * * *$ \\
\hline 11. Punitiveness & - & - & - & - & - & - & - & - & - & - \\
\hline 12. Hierarchy-enhancing jobs & $.32 * * *$ & - & - & - & - & - & - & - & - & - \\
\hline 13. Political conservatism & $.37 * * *$ & $.16^{* * *}$ & - & - & - & - & - & - & - & - \\
\hline 14. System justification & $.35 * * *$ & $.28 * * *$ & $.26 * * *$ & - & - & - & - & - & - & - \\
\hline $\begin{array}{l}15 . \text { Opposition to affirmative } \\
\text { action }\end{array}$ & $.15^{* * *}$ & -.01 & $.35 * * *$ & .02 & - & - & - & - & - & - \\
\hline
\end{tabular}




\begin{tabular}{|c|c|c|c|c|c|c|c|c|c|}
\hline 16. Opposition to racial policy & $.32 * * *$ & .04 & $.37 * * *$ & $.15^{* *}$ & $.47 * * *$ & - & - & - & - \\
\hline 17. Opposition to welfare & $.36^{* * *}$ & $.07^{+}$ & $.38 * * *$ & $.24 * * *$ & $.28 * * *$ & $.65^{* * *}$ & - & - & - \\
\hline 18. Symbolic racism & $.48^{* * *}$ & $.19 * * *$ & $.41 * * *$ & $.21 * * *$ & $.47 * * *$ & $.57 * * *$ & $.50 * * *$ & - & - \\
\hline $\begin{array}{l}\text { 19. Unequal distribution of } \\
\text { university resources }\end{array}$ & $.31 * * *$ & $.11^{*}$ & $.26 * * *$ & $.18^{* * *}$ & $.26 * * *$ & $.43^{* * *}$ & $.44 * * *$ & $.42 * * *$ & - \\
\hline 20. Hierarchy-attenuating jobs & $.31 * * *$ & $-.29 * * *$ & $.33 * * *$ & $.07^{+}$ & $.36^{* * *}$ & $.42 * * *$ & $.43 * * *$ & $.43 * * *$ & $.27 * * *$ \\
\hline
\end{tabular}

${ }^{* * *} p<.001 ;{ }^{* *} p<.01 ;{ }^{*} p<.05 ;^{+} p<.10$. 
Supplemental Table 2. Correlations between Variables in Sample 2 (Listwise N = 473).

\begin{tabular}{|c|c|c|c|c|c|c|c|c|c|c|c|c|c|c|}
\hline Variable & 1 & 2 & 3 & 4 & 5 & 6 & 7 & 8 & 9 & 10 & 11 & 12 & 13 & 14 \\
\hline 1. $\mathrm{SDO}_{7}$ & - & & & & & & & & & & & & & \\
\hline 3. SDO-E & $.93^{* *}$ & $.73^{* *}$ & - & & & & & & & & & & & \\
\hline 5. Zero-sum competition & $.54^{* *}$ & $.54^{* *}$ & $.47^{* *}$ & $.58^{* *}$ & - & & & & & & & & & \\
\hline 6. Nationalism & $.48^{* *}$ & $.48^{* *}$ & $.40^{* *}$ & $.47^{* *}$ & $.48^{* *}$ & - & & & & & & & & \\
\hline 7. War support & $.38^{* *}$ & $.38^{* *}$ & $.33^{* *}$ & $.38^{* *}$ & $.38^{* *}$ & $.70^{* *}$ & - & & & & & & & \\
\hline 10. Punitiveness & $.45^{* *}$ & $.44^{* *}$ & $.40^{* *}$ & $.45^{* *}$ & $.43^{* *}$ & $.55^{* *}$ & $.53^{* *}$ & $.51^{* *}$ & $.51^{* *}$ & - & & & & \\
\hline 11. Hierarchy-enhancing jobs & $.29^{* *}$ & $.29^{* *}$ & $.24^{* *}$ & $.27^{* *}$ & $.29^{* *}$ & $.41^{* *}$ & $.30^{* *}$ & $.37^{* *}$ & $.21^{* *}$ & $.33^{* *}$ & - & & & \\
\hline 12. Political conservatism & $.40^{* *}$ & $.33^{* *}$ & $.40^{* *}$ & $.27^{* *}$ & $.38^{* *}$ & $.41^{* *}$ & $.43^{* *}$ & $.50^{* *}$ & $.40^{* *}$ & $.43^{* *}$ & $.27^{* *}$ & - & & \\
\hline 13. System justification & $.37^{* *}$ & $.31^{* *}$ & $.36^{* *}$ & $.28^{* *}$ & $.28^{* *}$ & $.48^{* *}$ & $.43^{* *}$ & $.43^{* *}$ & $.20^{* *}$ & $.42^{* *}$ & $.39^{* *}$ & $.38^{* *}$ & - & \\
\hline 14. Opposition to affirmative action & $-.28^{* *}$ & $-.21^{* *}$ & $-.30^{* *}$ & -.03 & $-.18^{* *}$ & .04 & .01 & $-.10^{*}$ & $-.32^{* *}$ & $-.15^{* *}$ & -.05 & $-.23^{* *}$ & $-.10^{*}$ & - \\
\hline
\end{tabular}




\begin{tabular}{lcccc}
\hline Variable & 15 & 16 & 17 & 18 \\
\hline 1. $\mathrm{SDO}_{7}$ & & & & \\
2. SDO-D & & & & \\
3. SDO-E & & & & \\
4. Old-fashioned racism & & & \\
5. Zero-sum competition & & & \\
6. Nationalism & & & \\
7. War support & & & \\
8. Militarism & & & \\
9. Death penalty support & & & \\
10. Punitiveness & & & & \\
11. Hierarchy-enhancing jobs & & & \\
12. Political conservatism & & & \\
13. System justification & - & & \\
14. Opposition to affirmative action & & & \\
15. Opposition to welfare & $.56^{* *}$ & - & & \\
16. Symbolic racism & $.45^{* *}$ & $.41^{* *}$ & - & \\
17. New hierarchy & $.38^{* *}$ & $.37^{* *}$ & $.29^{* *}$ & - \\
18. Hierarchy-attenuating jobs & & & \\
& & &
\end{tabular}


Supplemental Table 3. Correlations between Variables in Sample $3(\mathrm{~N}=458$, Listwise $\mathrm{N}=351)$.

\begin{tabular}{|c|c|c|c|c|c|c|c|c|c|c|}
\hline Variable & 1 & 2 & 3 & 4 & 5 & 6 & 7 & 8 & 9 & 10 \\
\hline 1. $\mathrm{SDO}_{7}$ & - & - & - & - & - & - & - & - & - & - \\
\hline 2. SDO-D & $.93 * * *$ & - & - & - & - & - & - & - & - & - \\
\hline 3. SDO-E & $.95 * * *$ & $.77 * * *$ & - & - & - & - & - & - & - & - \\
\hline 4. Old-fashioned racism* & $.53 * * *$ & $.55 * * *$ & $.45^{* * *}$ & - & - & - & - & - & - & - \\
\hline 5. Zero-sum competition* & $.39 * * *$ & $.41 * * *$ & $.33 * * *$ & $.57 * * *$ & - & - & - & - & - & - \\
\hline $\begin{array}{l}\text { 6. Support for immigrant } \\
\text { persecution }\end{array}$ & $.44 * * *$ & $.47 * * *$ & $.37 * * *$ & $.50 * * *$ & $.48 * * *$ & - & - & - & - & - \\
\hline 7. Militarism* & $.52 * * *$ & $.53 * * *$ & $.46^{* * *}$ & $.36 * * *$ & $.33 * * *$ & $.44 * * *$ & - & - & - & - \\
\hline 8. Death penalty support* & $.36 * * *$ & $.35 * * *$ & $.33 * * *$ & $.23 * * *$ & $.26 * * *$ & $.35 * * *$ & $.48 * * *$ & - & - & - \\
\hline 9. Punitiveness* & $.39 * * *$ & $.41 * * *$ & $.34 * * *$ & $.34 * * *$ & $.36 * * *$ & $.47 * * *$ & $.57 * * *$ & $.56^{* * *}$ & - & - \\
\hline 10. Hierarchy-enhancing jobs* & $.25 * * *$ & $.26 * * *$ & $.21 * * *$ & $.19 * * *$ & $.19 * * *$ & $.30 * * *$ & $.49 * * *$ & $.32 * * *$ & $.47 * * *$ & - \\
\hline
\end{tabular}




\begin{tabular}{|c|c|c|c|c|c|c|c|c|c|c|c|c|}
\hline Variable & 11 & 12 & 13 & 14 & 15 & 16 & 17 & 18 & 19 & 20 & 21 & 22 \\
\hline 1. $\mathrm{SDO}_{7}$ & $.30 * * *$ & $.17^{* *}$ & $.55 * * *$ & $.34 * * *$ & $.31 * * *$ & $.31 * * *$ & $.69 * * *$ & $.62 * * *$ & $.44 * * *$ & $.38 * * *$ & .71 & $.67 * * *$ \\
\hline 2. SDO-D & $.32 * * *$ & $.22 * * *$ & $.47 * * *$ & $.31 * * *$ & $.28 * * *$ & $.26 * * *$ & $.60 * * *$ & $.59 * * *$ & $.38 * * *$ & $.36 * * *$ & $.61 * * *$ & $.56 * * *$ \\
\hline 3. SDO-E & $.24 * * *$ & $.11 *$ & $.55 * * *$ & $.32 * * *$ & $.31 * * *$ & $.32 * * *$ & $.69 * * *$ & $.58 * * *$ & $.46^{* * *}$ & $.36 * * *$ & $.72 * * *$ & $.69 * * *$ \\
\hline 4. Old-fashioned racism & $.19 * * *$ & $.18 * *$ &. $.28 * * *$ & $.10+$ & $.13 *$ & .06 & $.34 * * *$ & $.54 * * *$ & $.20 * * *$ & $.23 * * *$ & $.44 * * *$ & $.27 * * *$ \\
\hline 5. Zero-sum competition & $.15^{* *}$ & $.14 * *$ & $.29 * * *$ & .02 & $.09+$ & .01 & $.35 * * *$ & $.49 * * *$ & $.21 * * *$ & $.19 * * *$ & $.43 * * *$ & $.29 * * *$ \\
\hline $\begin{array}{l}\text { 6. Support for immigrant } \\
\text { persecution }\end{array}$ & $.26 * * *$ & $.22 * * *$ & $.32 * * *$ & $.15^{* *}$ & $.10+$ & .03 & $.36^{* * *}$ & $.50 * * *$ & $.15 * * *$ & $.16^{* *}$ & $.35 * * *$ & $.23 * * *$ \\
\hline 7. Militarism & $.68 * * *$ & $.46^{* * *}$ & $.59 * * *$ & $.36 * * *$ & $.25 * * *$ & $.20 * * *$ & $.44 * * *$ & $.59 * * *$ & $.31 * * *$ & $.26 * * *$ & $.36 * * *$ & $.46^{* * *}$ \\
\hline 8. Death penalty support & $.40 * * *$ & $.17 * *$ & $.42 * * *$ & $.13 *$ & $.36 * * *$ & $.28 * * *$ & $.32 * * *$ & $.51 * * *$ & $.17 * * *$ & $.27 * * *$ & $.34 * * *$ & $.31 * * *$ \\
\hline 9. Punitiveness & $.41 * * *$ & $.26 * * *$ & $.48 * * *$ & $.27 * * *$ & $.28 * * *$ & $.20 * * *$ & $.39 * * *$ & $.54 * * *$ & $.20 * * *$ & $.16^{* *}$ & $.31 * * *$ & $.34 * * *$ \\
\hline 10. Hierarchy-enhancing jobs & $.41 * * *$ & $.19 * * *$ & $.31 * * *$ & $.34 * * *$ & $.15^{* *}$ & $.11 *$ & $.24 * * *$ & $.31 * * *$ & $.15^{* *}$ & $-.15 * *$ & $.17 * * *$ & $.24 * * *$ \\
\hline 11. Fight Iran* & - & - & - & - & - & - & - & - & - & - & - & - \\
\hline 12. Syria intervention* & $.43 * * *$ & - & - & - & - & - & - & - & - & - & - & - \\
\hline 13. Political conservatism & $.43 * * *$ & $.19 * * *$ & - & - & - & - & - & - & - & - & - & - \\
\hline 14. System justification & $.32 * * *$ & $.19 * * *$ & $.30 * * *$ & - & - & - & - & - & - & - & - & - \\
\hline 15. Affirmative action-race* & $.19 * * *$ & -.08 & $.37 * * *$ & .01 & - & - & - & - & - & - & - & - \\
\hline
\end{tabular}


16. Affirmative action-gender*

$\begin{array}{lllll}.16^{* * *} & -.10+ & .37 * * * & .04 & .91 * * *\end{array}$

17. Opposition to welfare

18. Symbolic racism*

$\begin{array}{llllll}.24 * * * & .02 & .60^{* * *} & .33^{* * *} & .38^{* * *} & .39 * * *\end{array}$

19. New hierarchy*

$$
\begin{array}{lllllll}
.41^{* * *} & .17^{* *} & .59^{* * *} & .26^{* * *} & .51^{* * *} & .45^{* * *} & .56^{* * *}
\end{array}
$$

20. Hierarchy-attenuating jobs*

$.14^{* *}$

$.04 \quad .37^{* * *} \quad .23 * * * \quad .24 * * *$

21. Anti-discrimination measures*

22. Redistribution of wealth

$$
\begin{array}{lllllllllllll}
.14 * * & .06 & .53^{* * *} & .18^{* * *} & .37 * * * & .35^{* * *} & .60^{* * *} & .54^{* * *} & .38^{* * *} & .34 * * * & - & - \\
.28 * * * & .01 & .64^{* * *} & .32^{* * *} & .41^{* * *} & .42^{* * *} & .79 * * * & .55^{* * *} & .51^{* * *} & .38^{* * *} & .59 * * * & -
\end{array}
$$

Note. ${ }^{* * *} p<.001 ;{ }^{* *} p<.01 ; * p<.05 ;{ }^{+} p<.10$. We used pairwise deletion to compute correlations in this sample, due to the discrepancy in $\mathrm{N}$ between variables. As noted elsewhere, due to the length of the survey, it was split into two parts. There was some attrition between parts 1 and 2, and thus the listwise $\mathrm{N}$ was 351 whereas the total $\mathrm{N}$ was 458 . The variables with the smaller sample size are marked with an asterisk. 
Supplemental Table 4. Correlations between Variables in Sample 4 (Listwise $\mathrm{N}=714$ ).

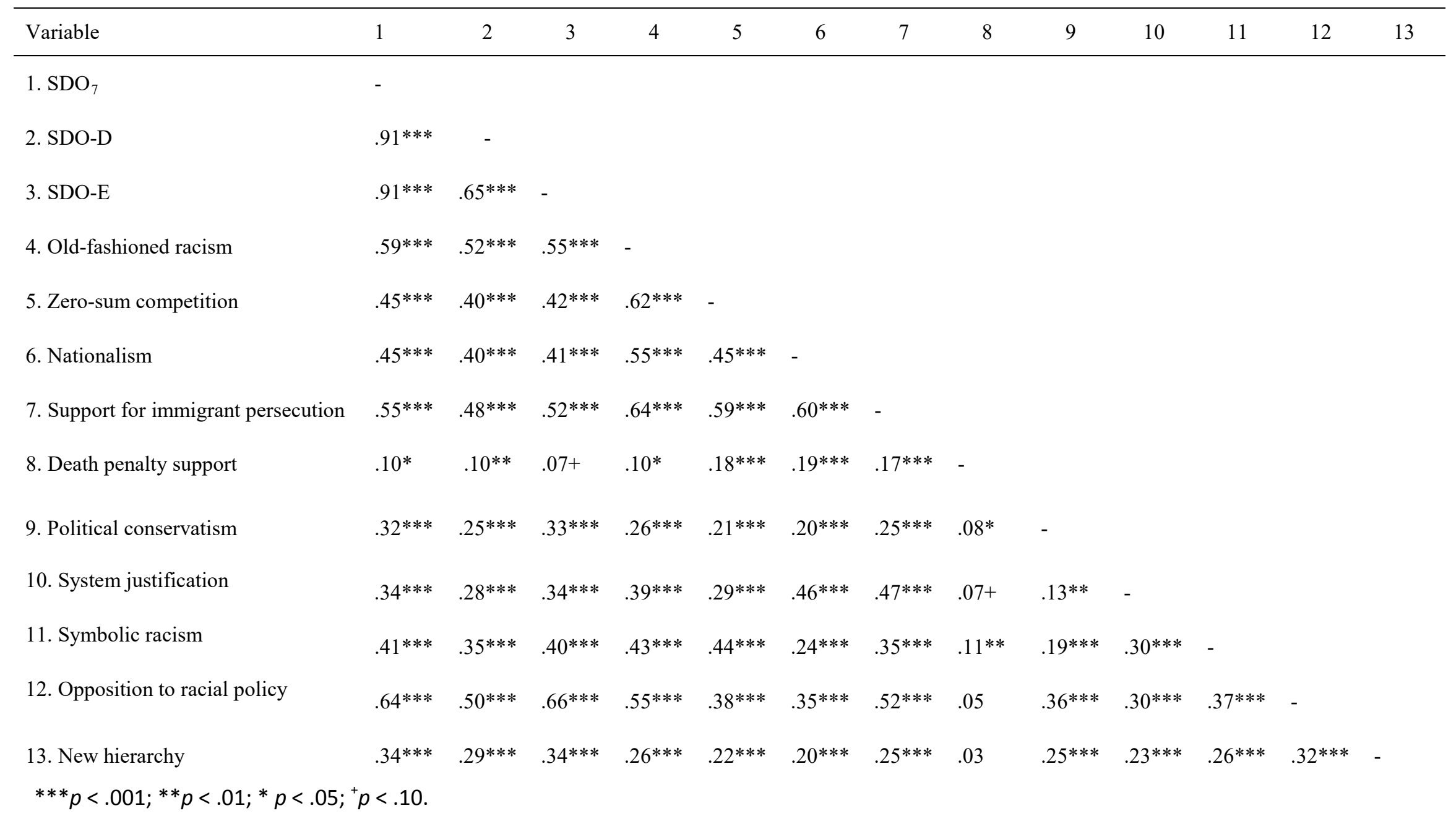


Supplemental Table 5a. Correlations between Variables in Sample 5a (Listwise $\mathrm{N}=208$ ).

\begin{tabular}{|c|c|c|c|c|c|c|c|c|c|c|c|}
\hline Variable & 1 & 2 & 3 & 4 & 5 & 6 & 7 & 8 & 9 & 10 & 11 \\
\hline 1. $\mathrm{SDO}_{7}$ & - & & & & & & & & & & \\
\hline 2. SDO-D & $.87 * * *$ & - & & & & & & & & & \\
\hline 3. SDO-E & $.90 * * *$ & $.56^{* * *}$ & - & & & & & & & & \\
\hline 4. Old-fashioned racism & $.47 * * *$ & $.51 * * *$ & $.32 * * *$ & - & & & & & & & \\
\hline 5. Zero-sum competition & $.51 * * *$ & $.55 * * *$ & $.37 * * *$ & $.57 * * *$ & - & & & & & & \\
\hline 6. Punitiveness & $.37 * * *$ & $.34 * * *$ & $.32 * * *$ & $.28 * * *$ & $.27 * * *$ & - & & & & & \\
\hline 7. Torture & $.47 * * *$ & $.42 * * *$ & $.41 * * *$ & $.29 * * *$ & $.34 * * *$ & $.50 * * *$ & - & & & & \\
\hline 8. Political conservatism & $.34 * * *$ & $.21 * *$ & $.39 * * *$ & $.23 * *$ & $.22 * * *$ & $.31 * * *$ & $.35 * * *$ & - & & & \\
\hline 9. System justification & $.34 * * *$ & $.27 * * *$ & $.32 * * *$ & $.15^{*}$ & $.22 * *$ & $.36 * * *$ & $.37 * * *$ & $.38 * * *$ & - & & \\
\hline 10. Opposition to racial policy & $.67 * * *$ & $.51 * * *$ & $.67 * * *$ & $.34 * * *$ & $.45 * * *$ & $.41 * * *$ & $.51 * * *$ & $.48 * * *$ & $.41 * * *$ & - & \\
\hline 11. Anti-black affect & $.29 * * *$ & $.26 * * *$ & $.25 * * *$ & $.28 * * *$ & $.36 * * *$ & .03 & $.16^{*}$ & $.17^{*}$ & -.01 & $.33 * * *$ & - \\
\hline
\end{tabular}

${ }^{* * *} p<.001 ; * *<.01 ; * p<.05$. Note that these correlations are computed using sample data without complex samples because the SPSS complex samples module does not have a facility for computing zero-order correlations. 
Supplemental Table 5b. Correlations between Variables in Sample 5b (Listwise N = 195).

\begin{tabular}{|c|c|c|c|c|c|c|c|c|c|c|}
\hline Variable & 1 & 2 & 3 & 4 & 5 & 6 & 7 & 8 & 9 & 10 \\
\hline 1. $\mathrm{SDO}_{7}$ & - & & & & & & & & & \\
\hline 2. SDO-D & $.88^{* * *}$ & - & & & & & & & & \\
\hline 3. SDO-E & $.89 * * *$ & $.57 * * *$ & - & & & & & & & \\
\hline 4. Old-fashioned racism & $.46^{* * *}$ & $.43^{* * *}$ & $37 * * *$ & - & & & & & & \\
\hline 5. Zero-sum competition & $.23 * *$ & $.24 * *$ & $.17^{*}$ & $.46^{* * *}$ & - & & & & & \\
\hline 6. Punitiveness & $.29 * * *$ & $.39 * * *$ & $.15^{*}$ & $.36 * * *$ & $.25^{* * *}$ & - & & & & \\
\hline 7. Torture & $.40 * * *$ & $.40 * * *$ & $.32 * * *$ & $.30 * * *$ & $.17^{*}$ & $.30 * * *$ & - & & & \\
\hline 8. Political conservatism & $.25^{* * *}$ & $.21 * *$ & $.23 * *$ & .09 & .08 & $.15^{*}$ & $.15^{*}$ & - & & \\
\hline 9. System justification & $.19 * *$ & $.17^{*}$ & $.16^{*}$ & $.14+$ & -.04 & $.21^{* *}$ & $.24 * *$ & .08 & - & \\
\hline 10. Opposition to racial policy & $.64 * * *$ & $.52 * * *$ & $.62 * * *$ & $.36^{* * *}$ & $.14^{*}$ & $.29 * * *$ & $.41 * * *$ & $.36^{* * *}$ & $.19^{*}$ & - \\
\hline
\end{tabular}

${ }^{* * *} p<.001 ; * * p<.01 ; * p .05 ;^{+} p<.10$. Note that these correlations are computed using sample data without complex samples because the SPSS complex samples module does not have a facility for computing zero-order correlations. 
Supplemental Table 6. Correlations between Variables in Sample 6 (Listwise N = 452).

\begin{tabular}{|c|c|c|c|c|c|c|c|c|c|c|c|c|c|c|}
\hline Variable & 1 & 2 & 3 & 4 & 5 & 6 & 7 & 8 & 9 & 10 & 11 & 12 & 13 & 14 \\
\hline 1. SDO7 & - & - & - & - & - & - & - & - & - & - & - & - & - & - \\
\hline 2. SDO-D & $.92 * *$ & - & - & - & - & - & - & - & - & - & - & - & - & - \\
\hline 3. SDO-E & $.94 * *$ & $.72 * *$ & - & - & - & - & - & - & - & - & - & - & - & - \\
\hline 4. Neuroticism & .02 & .06 & -.02 & - & - & - & - & - & - & - & - & - & - & - \\
\hline 5. Agreeableness & $-.38 * *$ & $-.35 * *$ & $-.35 * *$ & $-.19 * *$ & - & - & - & - & - & - & - & - & - & - \\
\hline 6. Conscientiousness & $-.10 *$ & $-.10 *$ & -.09 & $-.17 * *$ & $.61 * *$ & - & - & - & - & - & - & - & - & - \\
\hline 7. Extraversion & -.03 & -.02 & -.05 & $-.45 * *$ & $.20 * *$ & .04 & - & - & - & - & - & - & - & - \\
\hline 8. Openness/Intellect & $-.31 * *$ & $-.30 * *$ & $-.27 * *$ & $-.27 * *$ & $.47 * *$ & $.17 * *$ & $.43 * *$ & - & - & - & - & - & - & - \\
\hline 9. Honesty/Humility & $-.31 * *$ & $-.34 * *$ & $-.23 * *$ & $-.25 * *$ & $.53 * *$ & $.34 * *$ & -.03 & $.22 * *$ & - & - & - & - & - & - \\
\hline 10. Emotionality & $-.18 * *$ & $-.14 * *$ & $-.20 * *$ & $.48 * *$ & $.41 * *$ & $.25^{* *}$ & -.07 & .07 & .08 & - & - & - & - & - \\
\hline 11. Extraversion & .01 & .01 & .01 & $-.62 * *$ & $.19 * *$ & .05 & $.82 * *$ & $.32 * *$ & .07 & $-.17 * *$ & - & - & - & - \\
\hline 12. Agreeableness & $-.11 *$ & -.07 & $-.13 * *$ & $-.57 * *$ & $.38 * *$ & $.20 * *$ & $.22 * *$ & $.15^{* *}$ & $.36^{* *}$ & $-.14 * *$ & $.37 * *$ & - & - & - \\
\hline 13. Conscientiousness & $-.09 *$ & $-.10^{*}$ & -.08 & $-.36 * *$ & $.40 * *$ & $.66^{* *}$ & $.28 * *$ & $.43^{* *}$ & $.31 * *$ & .04 & $.30 * *$ & $.16^{* *}$ & - & - \\
\hline 14. Openness to Experience & $-.28 * *$ & $-.28 * *$ & $-.25 * *$ & $-.19 * *$ & $.30 * *$ & -.01 & $.32 * *$ & $.78 * *$ & $.21 * *$ & .00 & $.26 * *$ & $.13 * *$ & $.24 * *$ & - \\
\hline 15. Altruism & $-.38 * *$ & $-.36 * *$ & $-.35 * *$ & $-.13 * *$ & $.73 * *$ & $.35 * *$ & $.23 * *$ & $.39 * *$ & $.51 * *$ & $.34 * *$ & $.24 * *$ & $.30 * *$ & $.32 * *$ & $.36^{* *}$ \\
\hline 16. Machiavellianism & $.30 * *$ & $.31 * *$ & $.25 * *$ & $.20 * *$ & $-.44 * *$ & $-.23 * *$ & -.01 & $-.12 * *$ & $-.63 * *$ & $-.13 * *$ & $-.14 * *$ & $-.34 * *$ & $-.14 * *$ & $-.11 *$ \\
\hline 17. Narcissism & $.27 * *$ & $.27 * *$ & $.24 * *$ & $-.18 * *$ & $-.36 * *$ & $-.33 * *$ & $.53 * *$ & .07 & $-.48 * *$ & $-.26 * *$ & $.49 * *$ & -.07 & -.06 & .09 \\
\hline 18. Psychopathy & $.27 * *$ & $.30 * *$ & $.20 * *$ & $.25 * *$ & $-.63 * *$ & $-.51 * *$ & -.01 & $-.22 * *$ & $-.61 * *$ & $-.23 * *$ & $-.10 *$ & $-.34 * *$ & $-.38 * *$ & $-.18 * *$ \\
\hline 19. Empathic Concern & $-.35 * *$ & $-.32 * *$ & $-.33 * *$ & -.05 & $.75 * *$ & $.35 * *$ & $.25 * *$ & $.41 * *$ & $.45 * *$ & $.47 * *$ & $.20 * *$ & $.28 * *$ & $.28 * *$ & $.32 * *$ \\
\hline 20. Social Conformity & $.17 * *$ & $.12 *$ & $.19 * *$ & -.04 & $.19 * *$ & $.52 * *$ & $-.13 * *$ & $-.21 * *$ & $.16 * *$ & $.18 * *$ & -.03 & $.10 *$ & $.31 * *$ & $-.34 * *$ \\
\hline 21. Tough-mindedness & $.31 * *$ & $.28 * *$ & $.29 * *$ & $.16^{* *}$ & $-.79 * *$ & $-.46 * *$ & $-.19 * *$ & $-.34 * *$ & $-.50 * *$ & $-.39 * *$ & $-.22 * *$ & $-.40 * *$ & $-.31 * *$ & $-.22 * *$ \\
\hline 22. Dangerous world view & $.26 * *$ & $.22 * *$ & $.26 * *$ & $.12 *$ & -.05 & $.15 * *$ & -.05 & $-.23 * *$ & -.08 & .02 & $-.11 *$ & $-.13 * *$ & .04 & $-.28 * *$ \\
\hline 23. Competitive world view & $.48 * *$ & $.48 * *$ & $.42 * *$ & $.15^{* *}$ & $-.66 * *$ & $-.35 * *$ & -.03 & $-.34 * *$ & $-.68 * *$ & $-.25 * *$ & $-.11 *$ & $-.30 * *$ & $-.29 * *$ & $-.33 * *$ \\
\hline 24. Need for Closure & $.12 *$ & $.10^{*}$ & $.12 *$ & .08 & .03 & $.53 * *$ & -.09 & $-.14 * *$ & -.07 & $.15 * *$ & $-.11 *$ & $-.20 * *$ & $.38 * *$ & $-.28 * *$ \\
\hline 25. Order & .07 & .09 & .05 & .01 & $.12 * *$ & $.65 * *$ & -.01 & -.06 & .03 & $.18 * *$ & -.01 & -.07 & $.54 * *$ & $-.16 * *$ \\
\hline 26. Predictability & .07 & .06 & .08 & $.18 * *$ & .06 & $.46^{* *}$ & $-.25 * *$ & $-.17 * *$ & .00 & $.27 * *$ & $-.26 * *$ & $-.19 * *$ & $.24 * *$ & $-.27 * *$ \\
\hline 27. Decisiveness & -.04 & -.07 & -.01 & $-.53 * *$ & $.13^{* *}$ & $.20 * *$ & $.36 * *$ & $.28 * *$ & $.15 * *$ & $-.34 * *$ & $.43 * *$ & $.21 * *$ & $.45 * *$ & $.16^{* *}$ \\
\hline 28. Ambiguity & .06 & .06 & .06 & $.35 * *$ & .03 & $.28 * *$ & $-.14 * *$ & -.06 & $-.16 * *$ & $.29 * *$ & $-.24 * *$ & $-.28 * *$ & $.10^{*}$ & $-.14 * *$ \\
\hline 29. Close-mindedness & $.23 * *$ & $.20 * *$ & $.23 * *$ & $.29 * *$ & $-.35 * *$ & -.04 & $-.30 * *$ & $-.53 * *$ & $-.32 * *$ & .02 & $-.31 * *$ & $-.37 * *$ & $-.32 * *$ & $-.54 * *$ \\
\hline 30. Harm & $-.44 * *$ & $-.35 * *$ & $-.45 * *$ & .04 & $.54 * *$ & $.27 * *$ & .08 & $.26 * *$ & $.29 * *$ & $.35 * *$ & .02 & $.16^{* *}$ & $.17 * *$ & $.23 * *$ \\
\hline 31. Fairness & $-.52 * *$ & $-.42 * *$ & $-.53 * *$ & .01 & $.34 * *$ & $.13 * *$ & .08 & $.27 * *$ & $.20 * *$ & $.20 * *$ & .03 & .08 & $.17 * *$ & $.27 * *$ \\
\hline 32. Ingroup & $.17 * *$ & $.17 * *$ & $.14 * *$ & $-.12 *$ & $.14 * *$ & $.26^{* *}$ & $.20 * *$ & -.05 & -.04 & .03 & $.19 * *$ & $.17 * *$ & $.18 * *$ & $-.16 * *$ \\
\hline 33. Authority & $.21 * *$ & $.21 * *$ & $.18 * *$ & -.05 & $.15^{* *}$ & $.39 * *$ & $.10^{*}$ & $-.14 * *$ & .01 & .09 & .09 & $.09 *$ & $.23 * *$ & $-.22 * *$ \\
\hline 34. Purity & $.26^{* *}$ & $.23 * *$ & $.26^{* *}$ & $-.09 *$ & $.15^{* *}$ & $.32 * *$ & $.10 *$ & $-.12 *$ & .01 & .09 & $.13 * *$ & $.12 *$ & $.21 * *$ & $-.23 * *$ \\
\hline
\end{tabular}




\begin{tabular}{|c|c|c|c|c|c|c|c|c|c|c|c|c|c|c|}
\hline Variable & 15 & 16 & 17 & 18 & 19 & 20 & 21 & 22 & 23 & 24 & 25 & 26 & 27 & 28 \\
\hline 1. SDO7 & - & - & - & - & - & - & - & - & - & - & - & - & - & - \\
\hline 2. SDO-D & - & - & - & - & - & - & - & - & - & - & - & - & - & - \\
\hline 3. SDO-E & - & - & - & - & - & - & - & - & - & - & - & - & - & - \\
\hline 4. Neuroticism & - & - & - & - & - & - & - & - & - & - & - & - & - & - \\
\hline 5. Agreeableness & - & - & - & - & - & - & - & - & - & - & - & - & - & - \\
\hline 6. Conscientiousness & - & - & - & - & - & - & - & - & - & - & - & - & - & - \\
\hline 7. Extraversion & - & - & - & - & - & - & - & - & - & - & - & - & - & - \\
\hline 8. Openness/Intellect & - & - & - & - & - & - & - & - & - & - & - & - & - & - \\
\hline 9. Honesty/Humility & - & - & - & - & - & - & - & - & - & - & - & - & - & - \\
\hline 10. Emotionality & - & - & - & - & - & - & - & - & - & - & - & - & - & - \\
\hline 11. Extraversion & - & - & - & - & - & - & - & - & - & - & - & - & - & - \\
\hline 12. Agreeableness & - & - & - & - & - & - & - & - & - & - & - & - & - & - \\
\hline 13. Conscientiousness & - & - & - & - & - & - & - & - & - & - & - & - & - & - \\
\hline 14. Openness to Experience & - & - & - & - & - & - & - & - & - & - & - & - & - & - \\
\hline 15. Altruism & - & - & - & - & - & - & - & - & - & - & - & - & - & - \\
\hline 16. Machiavellianism & $-.41 * *$ & - & - & - & - & - & - & - & - & - & - & - & - & - \\
\hline 17. Narcissism & $-.22 * *$ & $.36^{* *}$ & - & - & - & - & - & - & - & - & - & - & - & - \\
\hline 18. Psychopathy & $-.60 * *$ & $.54 * *$ & $.43 * *$ & - & - & - & - & - & - & - & - & - & - & - \\
\hline 19. Empathic Concern & $.73 * *$ & $-.39 * *$ & $-.23 * *$ & $-.48 * *$ & - & - & - & - & - & - & - & - & - & - \\
\hline 20. Social Conformity & $.12 *$ & $-.12 *$ & $-.24 * *$ & $-.35 * *$ & .08 & - & - & - & - & - & - & - & - & - \\
\hline 21. Tough-mindedness & $-.72 * *$ & $.47 * *$ & $.29 * *$ & $.62 * *$ & $-.76 * *$ & $-.27 * *$ & - & - & - & - & - & - & - & - \\
\hline 22. Dangerous world view & $-.14 * *$ & $.14 * *$ & .04 & $.16^{* *}$ & -.06 & $.13^{* *}$ & .07 & - & - & - & - & - & - & - \\
\hline 23. Competitive world view & $-.68 * *$ & $.59 * *$ & $.41 * *$ & $.68 * *$ & $-.59 * *$ & $-.13 * *$ & $.68 * *$ & $.18^{* *}$ & - & - & - & - & - & - \\
\hline 24. Need for Closure & -.04 & $.19 * *$ & $-.13 * *$ & $-.10 *$ & -.06 & $.49 * *$ & -.02 & $.20 * *$ & .03 & - & - & - & - & - \\
\hline 25. Order & .08 & .09 & $-.14 * *$ & $-.17 * *$ & .07 & $.53 * *$ & $-.12 * *$ & $.13 * *$ & -.07 & $.83 * *$ & - & - & - & - \\
\hline 26. Predictability & -.02 & $.14 * *$ & $-.25 * *$ & $-.17 * *$ & -.01 & $.49 * *$ & -.05 & $.13 * *$ & -.01 & $.85 * *$ & $.65 * *$ & - & - & - \\
\hline 27. Decisiveness & $.11^{*}$ & $-.11 *$ & $.13 * *$ & $-.17 * *$ & .01 & .04 & -.08 & .00 & $-.13 * *$ & $.25 * *$ & $.14 * *$ & -.05 & - & - \\
\hline 28. Ambiguity & -.01 & $.32 * *$ & $-.10 *$ & .05 & .02 & $.28 * *$ & -.02 & $.18 * *$ & .07 & $.74 * *$ & $.51 * *$ & $.67 * *$ & $-.15 * *$ & - \\
\hline 29. Close-mindedness & $-.39 * *$ & $.18^{* *}$ & -.01 & $.24 * *$ & $-.38 * *$ & $.12 * *$ & $.30 * *$ & $.19 * *$ & $.33 * *$ & $.42 * *$ & $.10 *$ & $.32 * *$ & $-.15 * *$ & $.26 * *$ \\
\hline 30. Harm & $.53 * *$ & $-.26 * *$ & $-.29 * *$ & $-.41 * *$ & $.57 * *$ & .05 & $-.53 * *$ & $-.10 *$ & $-.55 * *$ & .03 & $.11 *$ & .08 & -.06 & $.09 *$ \\
\hline 31. Fairness & $.35 * *$ & $-.12 *$ & $-.18 * *$ & $-.25 * *$ & $.36^{* *}$ & -.04 & $-.33 * *$ & $-.12 * *$ & $-.48 * *$ & .03 & $.10^{*}$ & .06 & .00 & .09 \\
\hline 32. Ingroup & .07 & .06 & .07 & -.04 & $.11 *$ & $.40 * *$ & $-.16 * *$ & $.25 * *$ & .04 & $.21 * *$ & $.25 * *$ & $.11 *$ & $.10^{*}$ & $.16^{* *}$ \\
\hline 33. Authority & $.10^{*}$ & .07 & -.02 & $-.10 *$ & .07 & $.57 * *$ & $-.18 * *$ & $.33 * *$ & .01 & $.40 * *$ & $.42 * *$ & $.30 * *$ & $.09^{*}$ & $.33 * *$ \\
\hline 34. Purity & $.10^{*}$ & .02 & .04 & $-.12 * *$ & $.10^{*}$ & $.52 * *$ & $-.18 * *$ & $.47 * *$ & .01 & $.32 * *$ & $.32 * *$ & $.24 * *$ & .09 & $.22 * *$ \\
\hline
\end{tabular}




\begin{tabular}{|c|c|c|c|c|c|}
\hline Variable & 29 & 30 & 31 & 32 & 33 \\
\hline 1. SDO7 & - & - & - & - & - \\
\hline 2. SDO-D & - & - & - & - & - \\
\hline 3. SDO-E & - & - & - & - & - \\
\hline 4. Neuroticism & - & - & - & - & - \\
\hline 5. Agreeableness & - & - & - & - & - \\
\hline 6. Conscientiousness & - & - & - & - & - \\
\hline 7. Extraversion & - & - & - & - & - \\
\hline 8. Openness/Intellect & - & - & - & - & - \\
\hline 9. Honesty/Humility & - & - & - & - & - \\
\hline 10. Emotionality & - & - & - & - & - \\
\hline 11. Extraversion & - & - & - & - & - \\
\hline 12. Agreeableness & - & - & - & - & - \\
\hline 13. Conscientiousness & - & - & - & - & - \\
\hline 14. Openness to Experience & - & - & - & - & - \\
\hline 15. Altruism & - & - & - & - & - \\
\hline 16. Machiavellianism & - & - & - & - & - \\
\hline 17. Narcissism & - & - & - & - & - \\
\hline 18. Psychopathy & - & - & - & - & - \\
\hline 19. Empathic Concern & - & - & - & - & - \\
\hline 20. Social Conformity & - & - & - & - & - \\
\hline 21. Tough-mindedness & - & - & - & - & - \\
\hline 22. Dangerous world view & - & - & - & - & - \\
\hline 23. Competitive world view & - & - & - & - & - \\
\hline 24. Need for Closure & - & - & - & - & - \\
\hline 25. Order & - & - & - & - & - \\
\hline 26. Predictability & - & - & - & - & - \\
\hline 27. Decisiveness & - & - & - & - & - \\
\hline 28. Ambiguity & - & - & - & - & - \\
\hline 29. Close-mindedness & - & - & - & - & - \\
\hline 30. Harm & $-.21 * *$ & - & - & - & - \\
\hline 31. Fairness & $-.24 * *$ & $.64 * *$ & - & - & - \\
\hline 32. Ingroup & -.03 & $.16^{* *}$ & .06 & - & - \\
\hline 33. Authority & .06 & $.15^{* *}$ & .04 & $.71 * *$ & - \\
\hline 34. Purity & .08 & $.11 *$ & -.06 & $.62 * *$ & $.67 * *$ \\
\hline
\end{tabular}

${ }^{* *} p<.01 ;{ }^{*} p<.05$ 
Supplemental Table 7. Skewness of $\mathrm{SDO}_{7}$ and $\mathrm{SDO}_{6}$

\begin{tabular}{|c|l|l|l|}
\hline & Skewness & SE $_{\text {skewness }}$ & $Z_{\text {skewness }}$ \\
\hline Sample 1 & & & \\
\hline $\mathrm{SDO}_{7}$ & .19 & .11 & 1.78 \\
\hline $\mathrm{SDO}_{6}$ & .37 & .11 & $3.46^{* * *}$ \\
\hline Sample 2 & & & \\
\hline $\mathrm{SDO}_{7}$ & .65 & .11 & $5.77^{* * *}$ \\
\hline $\mathrm{SDO}_{6}$ & .76 & .11 & $6.87^{* * *}$ \\
\hline Sample 3 $^{*}$ & & & \\
\hline $\mathrm{SDO}_{7}$ & .85 & .12 & $6.99^{* * *}$ \\
\hline $\mathrm{SDO}_{6}$ & 1.06 & .12 & $8.74^{* * *}$ \\
\hline Sample 4 & & & \\
\hline $\mathrm{SDO}_{7}$ & .43 & .09 & $4.94^{* * *}$ \\
\hline $\mathrm{SDO}_{6}$ & .56 & .09 & $6.50^{* * *}$ \\
\hline Sample 5A & & & .76 \\
\hline $\mathrm{SDO}_{7}$ & .18 & .24 & \\
\hline Sample 5B & & & .03 \\
\hline $\mathrm{SDO}_{7}$ & .01 & .24 & $4.82^{* * *}$ \\
\hline Sample 6 & & & \\
\hline $\mathrm{SDO}_{7}$ & .55 & .12 & \\
\hline
\end{tabular}

Note. $* * * p<.001$ 
Supplemental Appendix

All measures used a 1 (strongly disagree/disapprove) to 7 (strongly agree/approve) scale unless otherwise indicated. Reverse-coded items are marked with an asterisk. Citations for scales are included in Tables 2a and $2 b$, except for citations for personality and individual difference scales, given in Samples 5 and 6 below.

SDO-D Criterion Variables:

\section{Sample 1}

Old-fashioned racism $(\alpha=.95 ; m=1.84 ; S D=1.31)$

1. Blacks are inherently inferior.

2. Chicanos/Latinos are inherently inferior.

3. African Americans are less intellectually able than other groups.

4. African Americans are lazier than other groups.

5. Latinos are less intellectually able than other groups.

6. Latinos are lazier than other groups.

Zero-sum competition $(\alpha=.89 ; m=2.86 ; S D=1.59)$

1. More good jobs for Blacks means fewer good jobs for members of other groups.

2. The more influence Blacks have in local politics the less influence members of other groups will have in local politics.

3. The more good housing and neighborhoods go to Blacks, the fewer good houses and neighborhoods there will be for members of other groups.

4. Many Blacks have been trying to get ahead economically at the expense of members of other groups.

Nationalism $(\alpha=.89 ; m=3.14 ; S D=1.40)$

1. In view of America's moral and material superiority, it is only right that we should have the biggest say in deciding United Nations policy.

2. This country must continue to lead the "Free World."

3. We should do anything necessary to increase the power of our country, even if it means war.

4. Sometimes it is necessary for our country to make war on other countries for their own good.

5. The important thing for the U.S. foreign aid program is to see to it that the U.S. gains a political advantage.

6. Generally, the more influence America has on other nations, the better off they are.

Support for immigrant persecution $(\alpha=.93 ; m=2.06 ; S D=1.41)$

Now, suppose that the American government some time in the future passed a law outlawing immigrant organizations in the US. Government officials then stated that the law would only be effective if it were vigorously enforced at the local level and appealed to every American to aid in the fight against these organizations. Please indicate how much you agree or disagree with the following statements:

1. I would tell my friends and neighbors that it was a good law.

2. I would tell the police about any immigrant organizations that I knew.

3. If asked by the police, I would help hunt down and arrest members of immigrant organizations.

4. I would participate in attacks on the immigrant headquarters organized by the proper authorities.

5. I would support physical force to make members of immigrant organizations reveal the identity of other members.

6. I would support the execution of leaders of immigrant organizations if the government insisted it was necessary to protect the U.S.

War support $(\alpha=.89 ; m=3.02 ; S D=1.40)$

1. The war against Iraq was absolutely justified. 
2. War against Iran would be completely justifiable.

3. The USA should maintain a strong military presence in the Middle East.

4. The USA must leave countries in the Middle East alone to decide their own futures.*

5. The USA should overthrow the regime in Iran.

6. President Bush was justified in attacking Iraq to ensure our continued supply of oil.

7. The USA should only go to war if directly attacked by a foreign power.*

War legitimacy beliefs $(\alpha=.78 ; m=3.18 ; S D=1.22)$

1. Most of the terrorists in the world today are Arabs.

2. Historically, Arabs have made important contributions to world culture.*

3. Iraqis have little appreciation for democratic values.

4. People of the Muslim religion tend to be fanatical.

5. Muslims value peace and love.*

Death penalty support $(\alpha=.97 ; m=4.27 ; S D=1.99)$

1. I support the use of capital punishment.

2. I favor the death penalty.

3. I favor a law which permits the execution of convicted murderers.

4. We must have capital punishment for some crimes.

5. Capital punishment should be used more often than it is.

6. No offense is so serious that it deserves to be punished by death.*

7. I do not believe in capital punishment in any circumstances.*

8. Capital punishment is never justified.*

Punitiveness $(\alpha=.85 ; m=3.15 ; S D=1.58)$

1. I support harsher police measures.

2. If we let the police get tough, the crime problem in this country will be solved.

3. Harsher treatment of criminals is not the solution to the crime problem.*

Hierarchy-enhancing jobs $(\alpha=.90 ; m=3.63 ; S D=1.68)$

Please indicate how attractive you find the following careers:

1. Criminal prosecutor

2. Police officer

3. FBI agent

4. Working to enforce the law \& prevent crime

$1=$ Strongly unattractive to $7=$ Strongly attractive

\section{SDO-E Criterion Variables:}

Political conservatism $(\alpha=.87 ; m=3.61 ; S D=1.62)$

1. How would you describe your political party preference?

$1=$ Strong Democrat to $7=$ Strong Republican

2. In terms of economic issues, how would you describe your political attitudes and beliefs? $1=$ very liberal to $7=$ very conservative

3. In terms of social issues, how would you describe your political attitudes and beliefs? $1=$ very liberal to $7=$ very conservative

System justification $(\alpha=.81 ; m=3.68 ; S D=1.10)$

1. In general, you find society to be fair.

2. In general, the American political system operates as it should.

3. American society needs to be radically restructured.* 
4. The U.S. is the best country in the world to live in.

5. Most policies serve the greater good.

6. Everyone has a fair shot at wealth and happiness.

7. Our society is getting worse every year.*

8. Society is set up so that people usually get what they deserve.

Opposition to affirmative action $(\alpha=.83 ; m=4.82 ; S D=1.31)$

How do you personally feel about different kinds of affirmative action? For each of the following policies, please indicate the extent to which you support or oppose the policy using the scale below.

1. Quotas, that is, setting aside places for certain groups.

2. Using group membership as one of several considerations.

3. Using membership in certain groups as a tie-breaker when applicants are equally qualified.

4. Giving training to certain groups so they can compete equally.

5. Making a special effort to find qualified people from certain groups.

6. Giving preference to members of certain groups who are less qualified than someone else. $l=$ strongly support the policy to $7=$ strongly oppose the policy

Opposition to racial policy $(\alpha=.83 ; m=3.38 ; S D=1.36)$

1. Government should see to it that minorities get fair treatment in jobs.*

2. Government should not pass laws concerning the hiring of ethnic minorities.

3. Government should ensure that Whites and minorities go to the same school.*

4. Government has no business trying to ensure racial integration in schools.

5. Government should do what it can to improve the economic condition of poor ethnic minorities.*

6. Government has no business trying to improve the economic condition of poor ethnic minorities.

Opposition to welfare $(\alpha=.79 ; m=2.91 ; S D=1.44)$

1. Greater assistance to the poor*

2. Reduced public support for the homeless

3. Reduced benefits for the unemployed

Symbolic racism $(\alpha=.84 ; m=2.31 ; S D=.58)$

1. It's really a matter of some people not trying hard enough; if blacks would only try harder they could be just as well off as whites.

2. Irish, Italian, Jewish and many other minorities overcame prejudice and worked their way up. Blacks should do the same.

3. Some say that black leaders have been trying to push too fast. Others feel that they haven't pushed fast enough. What do you think?*

$l=$ trying to push very much too fast, $2=$ going too slowly, $3=$ moving at about the right speed

4. How much of the racial tension that exists in the U.S. today do you think blacks are responsible for creating?*

$1=$ all of it, $2=$ most, $3=$ some, $4=$ not much at all

5. How much discrimination against blacks do you feel there is in the U.S. today, limiting their chances to get ahead?

$1=$ a lot, $2=$ some, $3=$ just a little, $4=$ none at all

6. Generations of slavery and discrimination have created conditions that make it difficult for blacks to work their way out of the lower class.*

7. Over the past few years, blacks have gotten less than they deserve.*

8. Over the past few years, blacks have gotten more economically than they deserve.

Except where specified otherwise, the following scale was used:

$1=$ strongly disagree, $2=$ somewhat disagree, $3=$ somewhat agree, $4=$ strongly agree

Unequal distribution of university resources $(\alpha=.77 ; m=3.69 ; S D=1.31)$ 
Imaging the University of Massachusetts is building a new campus. It has to decide how to fund its various schools (e.g., the law school, the medical school, the engineering school etc.). Specifically, one option would be to adopt a model in which each school would be responsible for its own fundraising and expenses. While such a model may give schools more freedom, it is likely that the schools would be unevenly funded, resulting in some schools with large operating budgets and many resources, and other schools with minimal budgets and limited resources. Another model would entail fundraising at the level of the university, and distributing resources equally between schools. Please indicate which of these two models you would prefer by using the scale below for each of the following statements.

1. I would prefer schools to be responsible for their own funding.

2. I would prefer the university to distribute resources equally rather than have each school fund itself.*

3. It would be unfair if schools had unequal budgets.*

4. It would be fair for each school to get the budget it earns.

Hierarchy-attenuating jobs $(\alpha=.87 ; m=3.81 ; S D=1.53)$

Please indicate how attractive you find the following careers:

1. Public defender

2. Civil rights lawyer

3. Human rights advocate

4. Working to improve the welfare of the poor, ill and elderly

5. Social worker

$1=$ Strongly unattractive to $7=$ Strongly attractive

\section{Sample 2}

\section{SDO-D Criterion Variables:}

Old-fashioned racism $(\alpha=.95, m=1.59, S D=1.14)$

See Sample 1 above

Zero-sum competition $(\alpha=.88, m=2.65, S D=1.49)$

See Sample 1 above

Nationalism $(\alpha=.88, m=2.43, S D=1.33)$

1. In view of America's moral and material superiority, it is only right that we should have the biggest say in deciding United Nations policy.

2. This country must continue to lead the "Free World."

3. We should do anything necessary to increase the power of our country, even if it means war.

4. Sometimes it is necessary for our country to make war on other countries for their own good.

5. Generally, the more influence America has on other nations, the better off they are.

Support for immigrant persecution $(\alpha=.94, m=1.81, S D=1.34)$

1. I would tell my friends and neighbors that it was a good law.

2. If asked by the police, I would help hunt down and arrest members of immigrant organizations.

3. I would support physical force to make members of immigrant organizations reveal the identity of other members.

4. I would support the execution of leaders of immigrant organizations if the government insisted it was necessary to protect the U.S.

War support $(\alpha=.78, m=2.34, S D=1.20)$

1. The war against Iraq was absolutely justified.

2. The USA should maintain a strong military presence in the Middle East.

3. The USA must leave countries in the Middle East alone to decide their own futures.* 
4. President Bush was justified in attacking Iraq to ensure our continued supply of oil.

Militarism $(\alpha=.82, m=2.45, S D=.82)$

1. Some people feel that in dealing with other nations our government should be strong and tough.

Others feel that our government should be understanding and flexible. Which comes closer to the way you feel - that our government should be strong and tough or understanding and flexible?

$1=$ Understanding and flexible to $5=$ Strong and tough

2. Which do you think is the better way for us to keep the peace - by having a very strong military so other countries won't attack us, or by working out our disagreements at the bargaining table?

$1=$ Bargaining to $5=$ Strong military

3. The U.S. should maintain its position as the world's most powerful nation, even if it means going to the brink of war.

$1=$ Strongly disagree to $5=$ Strongly agree

4. The only way to settle disputes with other countries is to negotiate with them, not by using military force.*

$1=$ Strongly disagree to $5=$ Strongly agree

5. How important is it for the U.S. to have a strong military force in order to get our way with our adversaries?

$1=$ Not at all important to $5=$ Extremely important

Death penalty support $(\alpha=.90, m=3.67, S D=1.90)$

1. I favor the death penalty.

2. Capital punishment should be used more often than it is.

3. No offense is so serious that it deserves to be punished by death.*

4. I do not believe in capital punishment in any circumstances.*

Punitiveness $(\alpha=.88, m=2.36, S D=1.54)$

See Sample 1 above

Hierarchy-enhancing jobs $(\alpha=.76, m=3.02, S D=1.23)$

1. Criminal prosecutor

2. Police officer

3. FBI agent

4. Financial analyst

5. Corporate lawyer

$1=$ Strongly unattractive to $7=$ Strongly attractive

\section{SDO-E Criterion Variables:}

Political conservatism $(\alpha=.67, m=2.77, S D=1.37)$

1. In terms of economic issues, how would you describe your political attitudes and beliefs?

2. In terms of social issues, how would you describe your political attitudes and beliefs?

$I=$ very liberal to $7=$ very conservative

System justification $(\alpha=.82, m=2.92, S D=1.09)$

1. In general, you find society to be fair.

2. In general, the American political system operates as it should.

3. American society needs to be radically restructured.*

4. Most policies serve the greater good.

5. Everyone has a fair shot at wealth and happiness.

6. Society is set up so that people usually get what they deserve. 
Opposition to affirmative action $(\alpha=.85, m=3.29, S D=1.29)$

See Sample 1 above

Opposition to welfare $(\alpha=.80, m=2.66, S D=1.40)$

See Sample 1 above

Symbolic racism $(\alpha=.86, m=2.12, S D=.65)$

See Sample 1 above

Unequal distribution of university resources $(\alpha=.78, m=3.57, S D=1.26)$

See Sample 1 above

Hierarchy-attenuating jobs $(\alpha=.87, m=3.68, S D=1.54)$

1. School teacher

2. Civil rights lawyer

3. Human rights advocate

4. Working to improve the welfare of the poor, ill and elderly.

5. Social worker

$1=$ Strongly unattractive to $7=$ Strongly attractive

\section{Sample 3}

Due to the length of the survey, it was split into two parts. There was some attrition between parts 1 and 2, and thus for some criterion variables, the sample size was 355 instead of 458 . The variables with the smaller sample size are marked with a double asterisk.

\section{SDO-D Criterion Variables:}

Old-fashioned racism $* *(\alpha=.95 ; m=1.54 ; S D=1.07)$

See Sample 1 above

Zero-sum competition $* *(\alpha=.94 ; m=2.57 ; S D=1.60)$

1. More good jobs for Blacks means fewer good jobs for members of other groups.

2. The more influence Blacks have in local politics the less influence members of other groups will have in local politics.

3. The more good housing and neighborhoods go to Blacks, the fewer good houses and neighborhoods there will be for members of other groups.

Support for immigrant persecution $(\alpha=.90 ; m=1.91 ; S D=1.36)$

See Sample 2 above

Militarism $^{* *}(\alpha=.82 ; m=3.15 ; S D=1.28)$

See Sample 2 above

Death penalty support $* *(\alpha=.81 ; m=4.49 ; S D=1.92)$

See Sample 2 above

Punitiveness $^{* *}(\alpha=.88 ; m=3.13 ; S D=1.69)$

See Sample 1 above

Hierarchy-enhancing jobs $* *(\alpha=.81 ; m=3.24 ; S D=1.35)$ 
1. Criminal prosecutor

2. Police officer

3. CIA agent

4. Border patrol agent

5. Soldier

6. Investment banker

7. Advertising executive

$1=$ Strongly unattractive to $7=$ Strongly attractive

Fight Iran $* *(\alpha=.89 ; m=4.12 ; S D=1.53)$

1. Under no circumstances should we allow Iran to acquire nuclear weapon capabilities.

2. We need to strike Iran as soon as possible to end its nuclear energy program.

3. Iran has just as much right to a nuclear program as the United States does.*

4. All countries have an equal right to developing a nuclear energy program.*

Syria intervention $* *(\alpha=\mathrm{n} / \mathrm{a} ; m=3.00 ; S D=1.56)$

1. The United States should use its military to force out the Syrian regime.

\section{SDO-E Criterion Variables:}

Political conservatism $(\alpha=.88 ; m=3.37 ; S D=1.63)$

See Sample 1 above

System justification $(\alpha=.83 ; m=3.54 ; S D=1.15)$

See Sample 1 above

Affirmative action-race ${ }^{* *}(\alpha=.81 ; m=5.35 ; S D=1.28)$

1. Quotas, that is, setting aside positions for minority ethnic groups.

2. Using membership in certain racial groups as a tie-breaker when applicants are equally qualified.

3. Making a special effort to find and train ethnic minorities for good jobs.

4. Giving preference to minorities, even when they are less qualified than other candidates. $1=$ Strongly support the policy to $7=$ Strongly oppose the policy

Affirmative action-gender ${ }^{* *}(\alpha=.82 ; m=5.25 ; S D=1.37)$

1. Quotas, that is, setting aside positions for women.

2. Using gender as a tie-breaker when applicants are equally qualified.

3. Making a special effort to find and women for good jobs.

4. Giving preference to women, even when they are less qualified than other candidates. $I=$ Strongly support the policy to $7=$ Strongly oppose the policy

Opposition to welfare $(\alpha=.79 ; m=3.03 ; S D=1.40)$

See Sample 1 above

Symbolic racism $* *(\alpha=.89 ; m=3.17 ; S D=1.10)$

See Sample 1 above

Unequal distribution of university resources** $(\alpha=.87 ; m=3.53 ; S D=1.49)$

See Sample 1 above

Hierarchy-attenuating jobs $* *(\alpha=.85 ; m=3.88 ; S D=1.40)$

1. Public defender

2. Civil rights lawyer 
3. Human rights advocate

4. Working to improve the welfare of the poor, the ill, the elderly

5. Social worker

6. Public school teacher

$1=$ Strongly unattractive to $7=$ Strongly attractive

Anti-discrimination measures ${ }^{* *}(\alpha=.77 ; m=2.72 ; S D=1.24)$

1. Society should make sure that women and minorities get fair treatment in jobs.

2. People in society should do everything that they can to make sure that Whites and minorities go to the same schools.

3. People have no business trying to ensure racial integration in society.*

4. There should be more research into whether ethnic minorities still face discrimination in the housing market.

Redistribution of wealth $(\alpha=.91 ; m=3.47 ; S D=1.78)$

1. The richest citizens should contribute more to make our society a better place for all.

2. The lowest earners in our society need greater social and financial support from government.

3. Those who are poor or unemployed should not be given as much government assistance as much as they are.*

4. I would be willing to pay a higher rate of tax if it meant that the money would be given to those who earn less in society.

5. Government should redistribute more income from the rich to the poor.

\section{SDO-D Criterion Variables:}

\section{Sample 4:}

Old-fashioned racism $(\alpha=.93 ; m=2.26 ; S D=1.69)$

1. Chicanos/Latinos are inherently inferior.

2. Latinos are less intellectually able than other groups.

3. Latinos are lazier than other groups.

Zero-sum competition $(\alpha=.92 ; m=3.43 ; S D=1.85)$

1. More good jobs for Latinos means fewer good jobs for members of other groups.

2. The more influence Latinos have in local politics the less influence members of other groups will have in local politics.

3. The more good housing and neighborhoods go to Latinos, the fewer good houses and neighborhoods there will be for members of other groups.

4. Many Latinos have been trying to get ahead economically at the expense of members of other groups.

Nationalism $(\alpha=.83 ; m=3.59 ; S D=1.57)$

1. In view of America's moral and material superiority, it is only right that we should have the biggest say in deciding United Nations policy.

2. We should do anything necessary to increase the power of our country, even if it means war.

3. Sometimes it is necessary for our country to make war on other countries for their own good.

4. Generally, the more influence America has on other nations, the better off they are.

Support for immigrant persecution $(\alpha=.93 ; m=2.82 ; S D=1.78)$

See Sample 1 above

Death penalty support $(\alpha=.81 ; m=4.36 ; S D=1.71)$

1. I favor the death penalty.

2. I favor a law which permits the execution of convicted murderers.

3. We must have capital punishment for some crimes. 
4. I do not believe in capital punishment in any circumstances.*

\section{SDO-E Criterion Variables:}

Political conservatism $(\alpha=.72 ; m=3.34 ; S D=1.39)$

See Sample 1 above

System justification $(\alpha=.84 ; m=3.78 ; S D=1.53)$

1. In general, you find society to be fair.

2. Most policies serve the greater good.

3. Everyone has a fair shot at wealth and happiness.

4. Society is set up so that people usually get what they deserve.

Symbolic racism $(\alpha=.41 ; m=2.22 ; S D=.57)$

1. It's really a matter of some people not trying hard enough; if Latinos would only try harder they could be just as well off as whites.

2. Generations of discrimination have created conditions that make it difficult for Latinos to work their way out of the lower class.

3. Over the past few years, Latinos have gotten less than they deserve.

4. Over the past few years, Latinos have gotten more economically than they deserve. $1=$ Strongly disagree to $4=$ Strongly agree

Opposition to racial policy $(\alpha=.71 ; m=2.36 ; S D=1.28)$

1. Government should see to it that minorities get fair treatment in jobs.

2. Government has no business trying to ensure racial integration in schools

3. Government should do what it can to improve the economic condition of poor ethnic minorities.

4. Government has no business trying to improve the economic condition of poor ethnic minorities.

Unequal distribution of university resources $(\alpha=.38 ; m=3.48 ; S D=1.08)$

See Sample 1 above

\section{Sample 5A and 5B:}

\section{SDO-D Criterion Variables:}

Old-fashioned racism (5A: $\alpha=.93, m=2.15, S D=1.47 ; 5 \mathrm{~B}: \alpha=.87, m=2.15, S D=1.36)$

See Sample 1 above (White sample (5a) received items referencing Blacks and Black sample (5b) received items referencing Latinos.)

Zero-sum competition ( $5 \mathrm{~A}: \alpha=.89, m=2.79, S D=1.47 ; 5 \mathrm{~B}: \alpha=.91, m=3.22, S D=1.63$ )

See Sample 1 above (Black sample received items referencing Latinos.)

Punitiveness (5A: $\alpha=.74, m=3.46, S D=1.42 ; 5 \mathrm{~B}: \alpha=.61, m=3.18, S D=1.33$ )

See Sample 1 above

Torture (5A: $\alpha=.67, m=3.05, S D=1.49 ; 5 \mathrm{~B}: \alpha=.55, m=3.05, S D=1.49$ )

1. I support the torture of terrorism suspects during interrogation.

2. Torture of terrorism suspects is morally unacceptable.

3. Police authorities should be allowed to torture criminals.

\section{SDO-E Criterion Variables:}

Political conservatism (5A: $\alpha=.88, m=4.46, S D=1.70 ; 5 \mathrm{~B}: \alpha=.52, m=3.38, S D=1.17$ )

See Sample 1 above. 
System justification (5A: $\alpha=.76, m=3.48, S D=1.15 ; 5 \mathrm{~B}: \alpha=.75, m=3.25, S D=1.15$ )

See Sample 1, items 1, 5, 6, and 8 above.

Opposition to racial policy $(5 \mathrm{~A}: \alpha=.84, m=3.48, S D=1.53 ; 5 \mathrm{~B}: \alpha=.75, m=2.49, S D=1.25)$

See Sample 1, items 1, 4, 5, and 6 above.

Anti-black affect (Sample 5A only: $\alpha=\mathrm{n} / \mathrm{a}, m=4.94, S D=1.30$ )

1. Blacks/African American

$1=$ Very Cold to $7=$ Very Warm

\section{Personality and Individual Differences Variables:}

Machiavellianism (5A: $\alpha=.66, m=2.84, S D=1.13 ; 5 \mathrm{~B}: \alpha=.75, m=2.96, S D=1.40$; four items from Paulhus \& Williams, 2002)

Empathic Concern (5A: $\alpha=.85, m=4.24, S D=1.08 ; 5 \mathrm{~B}: \alpha=.83, m=4.61, S D=1.11$; Davis, 1983)

Moral Foundations: Purity (5A: $\alpha=.83, m=3.90, S D=1.20 ; 5 \mathrm{~B}: \alpha=.74, m=4.09, S D=1.06)$

Items from short version (www.moralfoundations.org)

\section{Sample 6:}

\section{Personality and Individual Differences Variables:}

Big Five (De Young, Quilty, \& Peterson, 2007)

Neuroticism $(\alpha=.93, m=2.71, S D=.79)$

Agreeableness $(\alpha=.89, m=3.91, S D=.58)$

Conscientiousness $(\alpha=.87, m=3.69, S D=.50)$

Extraversion $(\alpha=.91, m=3.31, S D=.67)$

Openness/Intellect $(\alpha=.88, m=3.84, S D=.59)$

HEXACO (Lee \& Ashton, 2004)

Honesty-Humility $(\alpha=.87, m=4.82, S D=1.06)$

Emotionality $(\alpha=.84, m=4.41, S D=.96)$

Extraversion $(\alpha=.89, m=4.21, S D=1.09)$

Agreeableness $(\alpha=.87, m=4.07, S D=.98)$

Conscientiousness $(\alpha=.85, m=5.01, S D=.89)$

Openness to Experience $(\alpha=.88, m=4.91, S D=1.10)$

Altruism $(\alpha=.72, m=5.47, S D=1.16)$

Dark Triad (Paulhus \& Williams, 2002)

Machiavellianism $(\alpha=.85, m=3.78, S D=1.14)$

Narcissism $(\alpha=.78, m=3.26, S D=1.07)$

Psychopathy $(\alpha=.81, m=2.50, S D=1.09)$

Interpersonal Reactivity Index (Davis, 1983)

Empathic Concern $(\alpha=.90, m=3.94, S D=.86)$

Dual-Process Model (Duckitt, Wagner, du Plessis, \& Birum, 2002)

Social conformity $(\alpha=.89, m=4.30, S D=1.08)$

Tough-mindedness $(\alpha=.95, m=2.49, S D=1.09)$ 
Dangerous world view $(\alpha=.89, m=3.83, S D=1.25)$

Competitive jungle world view $(\alpha=.93, m=2.51, S D=1.01)$

Need for Closure $(\alpha=.89, m=4.42, S D=.68 ;$ Webster $\&$ Kruglanski, 1994)

$\operatorname{Order}(\alpha=.87, m=4.80, S D=1.13)$

Predictability $(\alpha=.85, m=4.62, S D=1.16)$

Decisiveness $(\alpha=.83, m=4.48, S D=1.20)$

Ambiguity $(\alpha=.79, m=4.64, S D=.97)$

Close-mindedness $(\alpha=.69, m=3.46, S D=.87)$

Moral Foundations (Graham, Haidt, \& Nosek, 2009)

Harm $(\alpha=.69, m=5.67, S D=1.18)$

Fairness $(\alpha=.66, m=5.48, S D=1.07)$

Ingroup $(\alpha=.73, m=4.28, S D=1.26)$

Authority $(\alpha=.74, m=4.48, S D=1.29)$

Purity $(\alpha=.85, m=4.00, S D=1.71)$ 